NBER WORKING PAPER SERIES

\title{
SAVING FOR MULTIPLE FINANCIAL NEEDS: \\ EVIDENCE FROM LOCKBOXES AND MOBILE MONEY IN MALAWI
}

\author{
Shilpa Aggarwal \\ Valentina Brailovskaya \\ Jonathan Robinson \\ Working Paper 27035 \\ http://www.nber.org/papers/w27035 \\ NATIONAL BUREAU OF ECONOMIC RESEARCH \\ 1050 Massachusetts Avenue \\ Cambridge, MA 02138 \\ April 2020
}

We are extremely grateful to Calvin Mhango and Gabriella Fleischman for overseeing the project and to Marble Karuu and David Park for research assistance. We thank Carly Farver for her continuous support, and IPA Malawi for implementing the research protocol in Malawi. We thank Naresh Kumar and Raychel Schwartz for supporting data collection for the long-term follow-up. We thank the Financial Inclusion Program at IPA, ISB, and UCSC for financial support. We thank Amit Khandelwal, Jessie $\mathrm{Li}$ and two anonymous referees for helpful comments in shaping this paper. We thank seminar participants at the 4th Annual Researcher Gathering on Financial Inclusion and Social Protection, the 2018 Williams CDE conference, UCSC, and IDinsight for valuable feedback. This research protocol was approved by the the National Commission for Science and Technology in Malawi and the IRBs of UCSC and the ISB. This trial is registered in the American Economic Association's registry for randomized controlled trials (AEARCTR-0002449). A pre-analysis plan is available on the AEA registry website. All errors are our own. The views expressed herein are those of the authors and do not necessarily reflect the views of the National Bureau of Economic Research.

NBER working papers are circulated for discussion and comment purposes. They have not been peer-reviewed or been subject to the review by the NBER Board of Directors that accompanies official NBER publications.

(C) 2020 by Shilpa Aggarwal, Valentina Brailovskaya, and Jonathan Robinson. All rights reserved. Short sections of text, not to exceed two paragraphs, may be quoted without explicit permission provided that full credit, including $\odot$ notice, is given to the source. 
Saving for Multiple Financial Needs: Evidence from Lockboxes and Mobile Money in Malawi Shilpa Aggarwal, Valentina Brailovskaya, and Jonathan Robinson

NBER Working Paper No. 27035

April 2020

JEL No. D14,O12,O16

\begin{abstract}
$\underline{\text { ABSTRACT }}$
We test whether the provision of multiple labeled savings accounts affects savings and downstream outcomes in an experiment with 761 microentrepreneurs in urban Malawi. Treatment respondents received one or multiple savings accounts, in the form of lockboxes or mobile money. We find that while providing additional boxes increased savings by $40 \%$, technical issues marred the efficacy of a second mobile money account. Both types of accounts had impacts on downstream outcomes, including farming decisions and credit extended to customers. We do not detect differential downstream effects by the number of accounts.
\end{abstract}

Shilpa Aggarwal

Indian School of Business

Gachibowli, Hyderabad 500032

India

shilpa_aggarwal@isb.edu

Valentina Brailovskaya

IDInsight

valentina.brailovskaya@idinsight.org
Jonathan Robinson

Department of Economics

University of California, Santa Cruz

457 Engineering 2

Santa Cruz, CA 95064

and NBER

jmrtwo@ucsc.edu

A randomized controlled trials registry entry is available at https://www.socialscienceregistry.org/trials/2449 


\title{
Saving for Multiple Financial Needs: Evidence from Lockboxes and Mobile Money in Malawi*
}

\author{
Shilpa Aggarwal ${ }^{\dagger} \quad$ Valentina Brailovskaya $^{\ddagger} \quad$ Jonathan Robinson $^{\S}$
}

April 9, 2020

\begin{abstract}
We test whether the provision of multiple labeled savings accounts affects savings and downstream outcomes in an experiment with 761 microentrepreneurs in urban Malawi. Treatment respondents received one or multiple savings accounts, in the form of lockboxes or mobile money. We find that while providing additional boxes increased savings by $40 \%$, technical issues marred the efficacy of a second mobile money account. Both types of accounts had impacts on downstream outcomes, including farming decisions and credit extended to customers. We do not detect differential downstream effects by the number of accounts.
\end{abstract}

JEL Codes: D14, L26, O12, O16

Keywords: savings, mobile money, lockboxes, liquidity, labeling, mental accounting, goalsetting, microenterprises,

\footnotetext{
${ }^{*}$ We are extremely grateful to Calvin Mhango and Gabriella Fleischman for overseeing the project and to Marble Karuu and David Park for research assistance. We thank Carly Farver for her continuous support, and IPA Malawi for implementing the research protocol in Malawi. We thank Naresh Kumar and Raychel Schwartz for supporting data collection for the long-term follow-up. We thank the Financial Inclusion Program at IPA, ISB, and UCSC for financial support. We thank Amit Khandelwal, Jessie Li and two anonymous referees for helpful comments in shaping this paper. We thank seminar participants at the 4th Annual Researcher Gathering on Financial Inclusion and Social Protection, the 2018 Williams CDE conference, UCSC, and IDinsight for valuable feedback. This research protocol was approved by the the National Commission for Science and Technology in Malawi and the IRBs of UCSC and the ISB. This trial is registered in the American Economic Association's registry for randomized controlled trials (AEARCTR-0002449). A pre-analysis plan is available on the AEA registry website. All errors are our own.

${ }^{\dagger}$ Indian School of Business, email: shilpa_aggarwal@isb.edu

${ }^{\ddagger}$ IDinsight, email: valentina.brailovskaya@idinsight.org

${ }^{\S}$ University of California, Santa Cruz and NBER, email: jmrtwo@ucsc.edu
} 


\section{Introduction}

Most people have multiple concurrent financial goals. For example, it is common for households to be saving up for large indivisible investments such as buying a house or paying for higher education, while also setting aside smaller amounts for day-to-day expenses or for dealing with unforeseen emergencies. How do people save towards multiple goals simultaneously? One potential strategy is to create separate labeled accounts. Research in behavioral economics suggests that once these accounts are created, withdrawals for any purpose other than the labeled one impose a utility cost on the account-holder (Ainslie 2001; Benabou and Tirole 2004; Koch and Nafziger 2016; Thaler 1990; 1999). Previous studies have shown that creating a single labeled account increases the probability of reaching the labeled goal by making money less fungible across uses (i.e. Brune et al., 2014; Dupas and Robinson 2013a; Karlan and Linden, 2014), and this finding likely generalizes to having more than one labeled account.

As a practical matter, however, it is not clear how one can accomplish the cognitively challenging task of keeping track of distinct sums of money that have been mentally allocated towards different purposes $]^{1}$ We conjecture that the effectiveness of mental accounts will likely be enhanced when accounts are accompanied by the physical separation of money. The practice of physically separating pots of money meant for distinct uses has precedent ${ }^{2}$ although it is not known if this method actually leads to an increase in deposits.

In this paper, we report results from an experiment with 761 micro-entrepreneurs in the city of Blantyre, Malawi, who were randomized into one of several different treatments designed to measure the savings efficacy of single versus multiple labeled accounts, which we provided either via mobile money or through lockboxes. The average respondent had 2.4 savings goals at baseline, so providing multiple labeled accounts could be beneficial in this population. One treatment group was offered simple metal lockboxes in which to save up for their goals, while a second group was offered mobile money. Both of the treatment groups were further randomized into receiving either one or more of the savings device in question (the multiple box group were offered up to 3 boxes, while the multiple mobile money were offered 2 mobile money accounts). A control group was not offered any accounts. Beyond measuring just savings effects, one of the main contributions of the paper is to carefully examine effects on a range of downstream outcomes. All respondents (including control) were given cell phones, and half of the sample was called once or twice per week to measure several outcomes at high frequency, including savings decisions, labor supply, income, expenditures, and transfers. In order to supplement the high frequency data and to collect information on the full sample, we also conducted two rounds of monitoring surveys with all respondents.

\footnotetext{
${ }^{1}$ Research on the cognitive costs of scarcity (i.e., Carvalho, Meier and Wang, 2016; Mani et al., 2013; Shah, Mullainathan, and Shafir, 2012) suggests that this task might be even harder for the poor.

${ }^{2}$ For example, see this oft-quoted anecdote cited in previous work (i.e. Zelizer 1994; Soman and Cheema 2011), from Alice Bradley (1923): "Take for instance Mrs. M's system as she told it to Women's Home Companion in the early 1920's: "I collected eight little cans, all the same size, and pasted on them the following words, in big letters: groceries, carfare, gas, laundry, rent, tithe, savings, miscellaneous.... [W]e speak of those cans now, as the grocery can, carfare can, etc."
} 
During the study period (of about 9 months), about $73 \%$ used mobile money at least once, $60 \%$ used it 5 times, and average deposits were about $\$ 9$ per month. Usage of the lockbox was even higher: at least $95 \%$ used their box at least once, $91 \%$ used it at least 5 times, and total deposits averaged about $\$ 27$ per month ${ }^{3}$ We find strong evidence that providing a second account increased savings for lockboxes, by about $40 \%$. We find no effect for mobile money, but this is likely due to design problems with the technology. In particular, the telco can offer only one account per SIM card, and so users had to switch between SIM cards to use multiple accounts, and this proved too burdensome despite having access to a dual SIM phone. This evidence is consistent with the hypothesis that having a second, labeled account is helpful to achieve savings goals (when using the account is simple enough).

Second, we find strong evidence that the saving accounts (both boxes and mobile money) had effects on a host of downstream outcomes. For outcomes pre-specified in a pre-analysis plan, we find suggestive evidence that treatment respondents reduced labor supply in their main business, and strong evidence that they increased the time spent working on their farms. This finding is related to several recent papers that find labor supply effects of an easing of credit constraints, such as Fink, Jack, and Masiye (2018), who find that providing credit to smallholder farmers decreases off-farm labor and increases own-farm labor. Our finding that saving accounts cause a reallocation of labor supply is related to Callen et al. (2014), who find that Sri Lankan households who were given access to deposit collection increase their hours in wage work but decrease hours in self-employment. We also find an increase in credit extended to customers, and some increase in certain expenditures categories, particularly education. Based on the labor supply results, we also analyze other non-prespecified outcomes related to farming (land acquisitions and the use of farm inputs) and find positive point estimates on all coefficients, with statistically significant effects on buying and renting land for the lockbox treatment.

We make three main contributions to the literature. First, our experimental design isolates the effect of an additional labeled savings place 4 While there have been many recent papers which have studied the effect of providing un(der)banked households with savings devices, there are a variety of pathways by which accounts may increase savings, including that savings accounts provide security, limit liquidity, increase the salience of saving money or because savings accounts encourage the activation of mental accounts for particular goals. Isolating a single channel in this context is challenging. In this experiment, we offer an incremental savings option which is identical to the first, and thus the design isolates the effect of an additional, physically separate savings location, since other pathways such as security or salience are equalized.5

\footnotetext{
${ }^{3}$ The figures for the box were measured earlier, about 5 months after account opening.

${ }^{4}$ There is a small literature on a related issue about partitioning consumption items between physically separated places. Soman and Cheema (2011) conduct experiments in which experimental subjects were paid in different numbers of accounts (i.e. money split into multiple envelopes or chocolates split into separate packages), and find that immediate consumption is decreasing in the number of accounts.

${ }^{5}$ Several other studies offer different accounts to different treatment groups (i.e. Brune et al. 2014; Dupas and Robinson 2013b), or (more rarely) offering a basic account and an incremental account with different features, such as a commitment account (John 2018). Other studies offer accounts to respondents who already have basic accounts at a bank (such as Ashraf, Karlan and Yin 2006), which arguably isolates the incremental effect of the new account,
} 
Second, we contribute to a nascent literature on the impacts of mobile money. Given the extensive uptake and usage of mobile money in several sub-Saharan African countries, there has been a large amount of research and policy interest in the topic. However, the popularity of mobile money makes identification challenging because of the difficulty of maintaining a control group. Consequently, the seminal studies in this research area are identified from plausibly exogenous regional differences in mobile money rollout (Jack and Suri 2014; Suri and Jack 2016). More recently, several researchers have implemented RCTs, usually by partnering directly with the telcos. These include Batista and Vicente (2020), who randomize mobile money access at the community level; Lee et al. (forthcoming), who offer mobile banking to rural-urban migrants in Bangladesh (to both the urban migrant and to the sending rural household); Wieser et al. (2019), who randomize the roll-out of mobile money agents in rural Northern Uganda, and our own companion paper (Aggarwal, Brailovskaya, and Robinson 2020), which studies the impact of mobile money (pooled across both subtreatments) ${ }^{6}$ Our study adds to this literature by randomizing basic access at the individual level in a country where mobile money infrastructure already existed but where takeup was still modest, and by measuring a number of outcomes via our survey modules. Moreover, while the vast majority of the existing literature focuses on the impact of mobile money on resilience (via a reduction in the transaction costs of transfers), the effects in our study appear to be driven primarily by savings. In fact, we observe little effect on interpersonal transfers from the mobile money treatment and only two-thirds of the mobile money respondents ever made an interpersonal transfer, while more than $80 \%$ reported using mobile money for long-term savings . This result is likely attributable to the fact that the treatment was at the individual level and so did not change mobile money access for the risk-sharing networks of treated respondents; we believe that effects would likely be present in a larger expansion of the network. Nevertheless, by muting the channel of interpersonal transfers, our study shows that mobile money can be effective in mobilizing savings. These effects will likely only be larger as telcos develop more sophisticated financial products.

Third, our experiment is well powered to find effects on downstream outcomes. While there have been a number of recent studies of savings (including several that look at boxes or mobile money specifically) 7 only a few of them find effects on downstream outcomes such as business investment and personal expenditures (Dupas and Robinson 2013a), health investment (Dupas and Robinson 2013b), educational expenditures (Prina 2015; Habyarimana and Jack 2018), labor supply (Callen et al. 2014), self-reported financial well-being (Kast and Pomeranz, 2014; Prina, 2015), risk coping (Jones and Gong 2018), and debt (Kast and Pomeranz 2014; Aker et al. 2019). However, most

even though the account itself is not experimental.

${ }^{6}$ There have been a number of interventions which layer other financial interventions on top of basic mobile money, such as labeled accounts (Aker et al. 2016, Jones and Gong 2019, Lipscomb and Schecter 2018), automatic deposits (Blumenstock et al. 2018), usage-based rewards (Bharadwaj and Suri 2020), or interest-bearing accounts (Batista and Vicente 2019). de Mel at al. (2019) layer mobile money on top of basic bank accounts to enhance the ease of making deposits, but their intervention is hampered by very low take-up. Suri (2017) provides an overview.

${ }^{7}$ A partial listing of papers that include locked savings boxes include Ashraf, Karlan and Yin (2006), Karlan and Linden (2014), Dupas, Keats and Robinson (2019), Francis (2018), Herskowitz (2018), Karlan and Zinman (2018), and Aker et al. (2018), among others. Those looking at mobile money as a savings device include Blumenstock et al. (2016), Habyarimana and Jack (2018), Jones and Gong (2018), and Lipscomb and Schechter (2018). 
of these studies find outcomes on only one of several potential outcomes, while other studies find no effects at all 8 An obvious reason why effects may be hard to detect is that statistical power is hampered by low take-up 9 For example, a tabulation in Dupas et al. (2018) finds that in many studies only $20-30 \%$ of people ever use accounts, and much lower percentages (rarely larger than $20 \%$ ) "actively" use accounts (usually defined as making more than a few deposits). But in this study, usage is dramatically higher: within the study period, at least $94 \%$ of people used the box at least once and at least $91 \%$ used it at least 5 times; for mobile money, the figures are $73 \%$ and $59 \%$.

The rest of this paper proceeds as follows. Section 2 describes the experiment and the data. Section 3 presents results and Section 4 discusses threats to validity. Section 5 concludes.

\section{Experimental Design and Data}

\subsection{Context and sampling}

The experiment took place with a representative sample of small entrepreneurs operating in Blantyre, the second largest city in Malawi. While Blantyre is an urban center with a population just over 1 million, the outskirts of the city contain farmland. Blantyre contains 26 wards and $392 \mathrm{enu}-$ meration areas (EAs). To construct a sample with coverage across the city, we aimed to randomly select three EAs in each ward, ultimately selecting 77 (one ward did not have 3 EAs).

Market structure is heterogeneous across EAs - the number of businesses ranged from 0 to 1,649 (mean 104, median 48) 10 Because of the high number of businesses in some EAs, it was not logistically possible to census every business in those EAs. We therefore decided to divide EAs between those with more than 100 and those with less than 100 businesses. In the smaller EAs, we censused all businesses; in the larger EAs, we counted all businesses but only censused a randomly selected subset of approximately $40 \%$ of businesses ${ }^{11}$ We counted a total of 9,848 businesses and classified $8,078(82.1 \%)$ of these as small businesses. ${ }^{12}$ We attempted to conduct a census survey with 3,857 businesses and completed surveys with 2,842 (74\%) 13

After the census, we imposed additional exclusion criteria. First, we excluded any business with more than 2 employees ( $6 \%$ of the census list). Second, we excluded businesses in which the business owner was a mobile money agent $(3 \%)$ to prevent confounding the mobile money treatment. Third,

\footnotetext{
${ }^{8}$ See Table 3 in Prina (2015) and Figure 5 in Dupas et al. (2018) for a summary of the effects found in these studies.

${ }^{9}$ This problem is often exacerbated by the fact that different people choose to spend money on different things, leading treatment effects to become diffused.

${ }^{10}$ Two EAs contained no small businesses. One was an industrial area and the other was farmland.

${ }^{11}$ Since we counted all businesses, we have sampling weights for all EAs.

${ }^{12}$ We excluded several classes of businesses in this exercise since they were unlikely to qualify as a small business. This included gas stations, clinics, hospitals, banks, microfinance institutions, manufacturing plants, warehouses, wholesalers and supermarkets.

${ }^{13}$ Of the $1,012(26 \%)$ businesses that were not censused, $552(14 \%)$ refused to participate (either before or after we were able to explain the study), 346 (9\%) were permanently closed, 114 (3\%) were not reached (either because the shop was closed after 3 visits or the owner was under 18 years old).
} 
we excluded businesses in which the owner was not actively involved in running operations (defined as working there at least 5 days per week) since such owners would not be able to reliably answer business-related questions (9\%). Fourth, we excluded businesses that were planning to shut down within 6 months (before the project was slated to end - 16\%) ${ }^{14}$

Once we had a sample of businesses that met our criteria, we imposed two other exclusion criteria, using data that had been collected either at the census or prior to the baseline survey. First, we removed all polygamous households, which amounted to $5 \%$ of the sample. Second, since we initially planned to collect surveys with paper-and-pencil logbooks (we eventually changed to phone surveys), we excluded business owners who were illiterate (about 20\% of the sample) and those whose eyesight prevented them from reading a printed page (about $10 \%$ of the sample).

These exclusion criteria left us with approximately 1,640 eligible businesses from which we drew our final sample, stratified by financial access (defined by having either a mobile money or bank account) and self-reported distance to the nearest mobile money agent (defined as above or below the sample median). In drawing the sample, we chose to oversample businesses connected to the electricity grid: while $26 \%$ of eligible businesses were connected to the grid, we sampled $35 \% 15$ We replaced respondents who could not be found (about 6.5\%) or refused to participate (another $6.5 \%$ ) with randomly chosen backups, ultimately yielding a sample of 801 businesses, which we randomized into the various treatment arms 16

\subsection{Experimental design}

The experimental design is summarized in Web Appendix Figure A2 and the timeline of project activities is shown in Web Appendix Figure A3. As discussed below, the experimental design cross-cut the provision of savings accounts with the frequency of surveying.

\subsubsection{Savings account treatment}

We offered two types of savings products: metal lockboxes and mobile money accounts. The lockboxes were similar to those offered in prior studies - they had a deposit slit in the top, and a latch that could be locked. The boxes were produced by a local artisan and cost about $\$ 3.40$ (at wholesale prices). Respondents were also given a lock and key, worth about $\$ 1$. While a sizeable minority of people $(22 \%)$ had lockboxes at baseline, these were of lower quality than the project boxes as they were typically made of wood or cardboard, and either could not be locked or had to be broken to be opened. Finally, as in Dupas and Robinson (2013b), respondents were given a passbook to record withdrawals and deposits, so that they could track the balance without having

\footnotetext{
${ }^{14}$ This high turnover rate is indicative of the level of churn in these types of businesses. Some businesses are seasonal and business closure is common.

${ }^{15}$ This decision was made to improve the power of the related paper, Brailovskaya (2018), which utilizes some of the data in this experiment to calculate the effect of power outages on business outcomes.

${ }^{16}$ See Web Appendix Figure A1 for the geographic distribution and spread of the various treatment arms across the city of Blantyre.
} 
to open their box(es). Respondents were also encouraged to use the project account(s) to save towards their savings goal.

Those in the mobile money treatment received mobile money accounts with Airtel Malawi, the leading telecom company in Malawi (holding a market share just over 50\%). The accounts were identical to those already commercially available, with several important differences. First, we reimbursed withdrawal fees for the duration of the project ${ }^{17}$ Second, in pilot work, we found that knowledge of mobile money was limited. Some respondents were not fully aware of fees or lacked basic knowledge about how to access and use mobile money. To address this issue, we developed training modules on how to use the accounts, which were administered at the time of accountopening ${ }^{18}$ Third, as with the boxes, we encouraged people to use the accounts to save towards their goals. While we view each of these elements as relatively light-touch actions that could easily be implemented by the telco absent our involvement, the combined mobile money intervention does differ from status-quo commercial mobile money available at the time in Malawi.

One of the key features of the project is to measure the effects of having an incremental account. Therefore, all respondents in the savings device treatments were further randomized into receiving one or multiple of the savings device in question. For the box respondents, those in the single account treatment group were offered only one box, while those in the multiple account group were offered 3 lockboxes. However, people were allowed to take less than 3 boxes if they wanted, and in fact some people did this - $24 \%$ took only 1 box, $33 \%$ took 2 boxes, and $42 \%$ took 3 boxes (1\% did not take any boxes) ${ }^{19}$ To differentiate the boxes, they were painted different colors - everyone received a silver box, while the second and third boxes were painted black and brown respectively. For those in the multiple box groups, the project passbooks allowed for separate tracking of deposits and withdrawals for each box.

In the mobile money treatment, respondents in a single mobile money group were offered only 1 account, while those in multiple account group received were given a choice to get up to 2 mobile money accounts. Each account had a separate SIM card and associated phone number due to the fact that the existing mobile money product offered exactly one account within a single phone number. To encourage people to use these with minimal hassle, the respondents were provided a dual-sim phone, discussed below. As with the boxes, the mobile money accounts were labeled as silver or black on the mobile money interface of respondents' phones, but during surveying we referred to those accounts by the last 4 digits of the account phone number..

During baseline, we asked all respondents about their current savings goals. At the time when accounts were opened (which was about 2 months after baseline), those in the treatment groups were encouraged to use the project account(s) to save towards their savings goal. Specifically,

\footnotetext{
${ }^{17}$ Fees were reimbursed weekly by making transfers equivalent to the fee amount to each account through a batch process. Therefore, respondents had to incur fees and then wait to be reimbursed, and so our treatment is not identical to a policy in which withdrawals were actually free. The average fee for transactions observed in our sample would have been about $5 \%$.

${ }^{18}$ This module, along with surveys, can be found on the authors' websites.

${ }^{19}$ It it surprising that some people chose to take less than 3 (since they were free). We can only conjecture that people might have felt guilty about taking boxes that they did not intend to use.
} 
we asked respondents to write their savings goal on a piece of paper, which was then attached to the lid on the inside of their project boxes for the box treatment, while those in the mobile money treatment, were asked to keep it with them. Summary statistics of goals are reported in Web Appendix Table A1. Column 1 shows goals elicited at baseline for the entire sample, while the next 4 columns show goals elicited at account opening. Goals are heterogeneous: at baseline, sizeable fractions listed business reinvestment, general consumption, and emergencies, while others listed a variety of other goals including land, durable goods, education, and other goals. Given the heterogeneity in goals, it is likely that accounts would have impacts on a variety of different outcomes.

\subsubsection{Phone surveys}

A primary goal of this project was to measure the effect of savings devices at high frequency. To do this, we opted to measure outcomes using high-frequency phone surveys (described in more detail in section 2.3). To implement this effectively, we gave everyone in our sample a basic feature phone, but with dual SIM capability (worth about $\$ 12$ ). Even though $95 \%$ of the sample already had a phone at baseline, we decided to give out new phones because we were concerned that the phones people already owned were of low quality and might break or need to be replaced prior to the end of the experiment. Moreover, in order to successfully implement the multiple mobile money accounts treatment, we needed people to have phones to have two slots for SIM cards, which are not commonly used.

Since it is possible that the high-frequency survey itself is a treatment (for example, by focusing attention on measured outcomes), we randomly split the study sample into two groups: one was administered the high-frequency phone survey (which we call the "HFPS") while the other was not. To measure the effect of surveying itself, we administered two monitoring surveys to the entire sample, so that we could compare responses between those given high frequency surveys and those who were not. In Section 4, we utilize the HFPS randomization to examine the effect of regular surveying on outcomes measured in the monitoring surveys but ultimately find no discernible impact.

\subsection{Data}

We utilize information from administrative data as well as a number of different types of surveys to conduct our analysis. At the start of the project, we conducted a baseline survey, which contained a standard set of questions on household and demographic characteristics, business outcomes, savings, cash flows, and related measures. At the time of account opening, we also administered a short "intake survey" which included versions of many of the questions that would later constitute our main surveys, recalled over the 3 previous days. These pre-treatment values are used as control variables, making all regressions ANCOVA (Bruhn and McKenzie 2009).

We have two main sources of data to measure treatment effects: high-frequency phone surveys (HFPS) and two monitoring surveys (all surveys are on the authors' webpages). The HFPS mea- 
sured business outcomes and labor supply at the daily level, and household expenditures, transfers, savings, credit, shocks and related outcomes at the weekly level. The HFPS was conducted in two waves, one in September-October 2017 (covering 8 weeks) and another in February-March 2018 (covering 6 weeks). In Wave 1, respondents were called twice per week, with the 2 calls being 3-4 days apart. In one of the weekly interviews, the respondent was administered a "short" survey which took about 15 minutes and which asked about business outcomes over the past 3 days (day by day). The other "long" survey took about 40 minutes and included all the questions in the short call, but also added a recall module for other outcomes that were expected to be rarer or more memorable and thus could be reliably remembered over a week. These included shocks such as household illness and funerals, deposits and withdrawals from various saving source, and transfers given and received. The long survey also included questions about expenditures over the past 7 days. For example, for deposits, a short survey which was administered on say, a Wednesday, would ask the respondent the amount of deposits they made in each savings place on each of the preceding 3 days, i.e., on Sunday, Monday and Tuesday; while a long survey done on that day would ask the same set of questions for each of the preceding 4 days ${ }^{20}$ Long-survey-only questions, such as expenditure on food, were asked for each of the preceding 7 days. Due to budgetary constraints, respondents were called only once per week in Wave 2 and were administered only the "long" version of the survey.

Respondents were randomized into which days they were to be called, and this day remained unchanged throughout the project. ${ }^{21}$ Respondents were able to pick the time of day when they wished to be called. To encourage compliance, respondents were given US $\$ 2$ in airtime for each week of the survey and were also enrolled into a lottery in which there was a $1 / 4$ chance of winning an additional US $\$ 3$. Airtime was sent directly to the respondents' phones after each phone call was completed ${ }^{22}$ We control for lottery payments in all HFPS regressions. If a respondent did not answer the phone, she was called at least twice more that day (3 times total). If the respondent was still unreachable, a make-up call was scheduled for the following day. During this call, we asked for information for the preceding 4 days in order to reconstruct the lost day.

The other surveys used to calculate treatment effects are called the "monitoring surveys." These were conducted twice, after each round of the HFPS, in January 2018 and March 2018. These were also done over the phone, but (as discussed in section 2.2) included the entire sample. These surveys took approximately 75 minutes to complete, and included a host of questions similar or identical to the HFPS, though over a longer recall period - for example, outcomes like labor supply were measured at the daily level over a week-long look back period, while deposits and withdrawals were measured at a monthly level for a 2-3 months-long lookback period. Some outcomes which were rarer (such as credit) were measured cumulatively for the entire period between survey rounds. The surveys also included a number of other questions, such as questions about self-reported financial

\footnotetext{
${ }^{20}$ The specific question for savings was "How much did put in a $\{$ source $\}$ for saving purposes on $\{$ day $\}$ ?

${ }^{21}$ Respondents were allowed to change the day of the survey at the outset of the project but only 1 of 401 respondents ultimately changed the day.

${ }^{22}$ Respondents were enrolled in the lottery even if they were not reached for a specific call, but they did not receive the US $\$ 2$ payment for survey completion.
} 
security, land purchases, and tuition payments. In addition, the second monitoring survey (the endline survey) included some debriefing questions about people's experience with the boxes and mobile money accounts, pressures to share money and experiences with the surveys themselves. Respondents were compensated $\$ 2$ USD via airtime per survey round.

As an independent verification of lockbox usage, we conducted an unannounced in-person "lockbox check" at the respondents' businesses with a random sub-sample of respondents in the box groups in December 2017. During this visit, we first asked a number of questions about usage of the project boxes, including cumulative deposits and withdrawals since the start of the project as well as the current balance. After the survey, enumerators requested to visually inspect the box (as in Dupas and Robinson 2013b) in order to verify the balance. Seventy-nine percent of respondents who we interviewed were willing and able to open at least one of the boxes ${ }^{23}$

Finally, we implemented a long term follow-up survey in September 2019, about 18 months after the conclusion of the study, to track long-term usage of the accounts. We contacted a randomly selected subsample of 200 participants drawn from the treatment groups only (the control group was not included) for a short phone survey to measure if they were still using the accounts.

In addition to all these surveys, we have access to administrative data on all the transactions made on the mobile money accounts opened as part of the project from the telco for the duration of the project (July 2017 - April 2018) as well as for 15 months after (until July 2019).

\subsection{Attrition}

Attrition from our full sample of 801 respondents is shown in Web Appendix Table A2. Columns 1-4 show attrition during the HFPS, with the odd columns showing whether a respondent appears at least once and the even columns showing the percentage of calls that were successfully completed. In round 1, 99\% of respondents completed at least one survey and $89 \%$ of calls were made; in round 2 , survey completion fell to $84 \%$ and $74 \%$, respectively. While not unexpected, lower compliance in round 2 points to the problem of conducting phone surveys in general, as people lose their phones, change phone numbers, or become fatigued with the surveys. We do not find any differences in attrition across the various treatment groups and the coefficients on the treatment indicators are not significant for any of the surveys. However, HFPS respondents were 7 percentage points less likely to complete a first monitoring survey, which might be because HFPS respondents were more likely to be fatigued by the surveying process. Survey completion for the second monitoring survey is balanced across HFPS and non-HFPS respondents. In total, 761 of 801 sampled respondents ultimately appear in our analysis sample.

\footnotetext{
${ }^{23}$ Of the remaining $21 \%, 5.4 \%$ could not open the box because they did not have the key with them, $9.4 \%$ refused to open the box or travel home to show the box to the field officer, $2.4 \%$ did not have access to the boxes at box checks, $3.3 \%$ respondents with boxes were not checked because the respondent could not travel home with the field officer on the day of the survey.
} 


\subsection{Summary statistics and randomization check}

Summary statistics and a check of randomization balance (restricted to the analysis sample of 761) are presented in Table 1 (from the baseline survey) and Web Appendix Table A3 (from the intake survey). From Table 1 Panel A, $46 \%$ of the sample is male and the average respondent is 34 years old and has 9 years of education. Ninety-three percent of respondents have an iron roof on their homes and the average value of assets owned by respondents households is $\$ 873$. Panel B shows statistics on business outcomes. Sixty-eight percent of the businesses are in retail, with the remainder predominantly in services, which includes occupations such as barbershops, tailoring, and welding. These businesses are very small: average weekly profits are about $\$ 19$ per week and the average firm has only $\$ 293$ in equipment and inventory. Nevertheless, these respondents are better off than the average Malawian. ${ }^{24}$

Panel C shows statistics on savings. Average savings across all sources was $\$ 120$ at baseline, split across an average of 2.5 savings places. We also observe that people already engage in physical separation of cash for different goals: the average respondent has 2.4 goals and saves up for these goals in different places. In particular, $78 \%$ of people have separate saving places for different goals, and only $35 \%$ save for more than 1 goal in a single savings place. The most common saving place is keeping cash at home, reported by $82 \%$ of respondents. Saving groups (VSLAs and ROSCAs) are used by $52 \%$ of the business owners, and $47 \%$ report using mobile money accounts to save. Thirty percent of the sample have access to a bank account and $22 \%$ save in saving boxes. Note that a sizable minority of the sample already saves in lockboxes; as we see by the take-up rates, however, the project lockboxes were seen as being of higher quality and were preferred to the original boxes. Sixty two percent of the sample have access to a mobile money account, defined as either owning one or using someone else's. About half of the the respondents have their own accounts at baseline.

In columns 2-4, we present p-values from F-tests of joint equality between the two box treatments and control, the two mobile money treatments and control, and all five groups together. In columns 6-8, we replicate this for those in the HFPS groups only. There is some evidence of imbalance on a few characteristics in the monitoring survey sample, while the HFPS sample is largely balanced. Specifically, for the monitoring survey sample, of the 21 variables in the table, the p-value for the joint test across all groups is below 0.1 for 2 variables in the monitoring sample (age and a dummy for saving in a bank account) and one in the HFPS (owning a cell phone). We find some evidence of imbalance within the subtreatments. For the box treatments, we find p-values below 0.1 between the box and control group for having a mobile money account and saving in a box (the probability of savings in a box is 0.22 in control, 0.23 in the one box group, and 0.12 in the multiple box group). For the mobile money treatments, we find p-values below 0.1 for age, whether the household farms, value of assets, and a dummy for whether the household saves in a bank account. To be in compliance with the pre-analysis plan, we do not include baseline controls in the regressions, however, all regressions are ANCOVA, controlling for baseline values measured in the

\footnotetext{
${ }^{24}$ According to the World Bank, GNI per capita was $\$ 340$ in 2017 in Malawi. In the 2016 Malawi Integrated Household Survey, only about half the households reported having iron sheets as the material of their roof.
} 
intake survey. ${ }^{25}$ Ultimately, the results themselves provide some level of confidence - the pattern of results is similar between the HFPS (which appears largely balanced) and monitoring surveys (which may have a few differences between groups).

\section{Results}

\subsection{Take-up}

Our primary measure of usage is the value of deposits, a flow figure, instead of a stock measure like the balance. While either measure will provide a sense of account usage (and indeed results are similar using other measures of usage including withdrawals and balance), we prefer deposits because accumulating a balance, in and of itself, was not the intended use of these accounts. Rather, we envisioned that the accounts could be used to save up for larger purchases, and therefore, we expected people to withdraw money eventually. Our expectation is that benefits should primarily accrue only after these withdrawals were made and were followed by the intended purchases, implying that the balance itself is not very informative - observing a low balance may be because usage was low, or simply because a withdrawal was made recently. For this reason, much of the prior literature has also focused on deposits 26

Figure 1 shows CDFs of deposits into the single and multiple devices. While administrative data would be the preferred data source for this analysis, we lack such data for the lockboxes, and we therefore show results for different data sources in different Panels. In each Panel, we show results separately for boxes and mobile money. Panels A and B show data from the surveys (Panel A is the monitoring survey and Panel B is the HFPS). In both Panels, we observe higher deposits among the multiple box group than the single box group, but no difference in deposits between those receiving one mobile money account and those receiving multiple. In Panel C2, we use administrative data from the telco for mobile money users, and find no difference in usage (in fact, multiple mobile money appears to be lower, at least in the left tail).

Table 2 presents summary statistics. Panel A uses records from account opening. As expected, nearly all respondents who were offered an account chose to open one. Of those offered multiple boxes, only $76 \%$ took more than 1 box and only $42 \%$ took 3 (despite the fact that the boxes were free). However, for mobile money, take-up of a second account was much lower (only 29\%), which helps to explain the results in Figure 1 which show no effect of multiple accounts. The telco was only able to link one account to each SIM card, and so using multiple accounts required people to switch between accounts. Even though people had access to dual-SIM phones, many respondents reported feeling that it was cumbersome to use more than one account, and so used only one. We therefore do not expect to find differential effects of these two treatment groups on downstream

\footnotetext{
${ }^{25}$ We also examine balance on the variables measured in the intake survey in Web Appendix Table A3. The majority of the characteristics suggest comparability of groups.

${ }^{26}$ For example, Dupas and Robinson (2013) and Dupas, Keats and Robinson (2019) report results for the value of deposits, while papers like Prina (2015) and Dupas et al. (2018) show both stocks and flows.
} 
outcomes, and the multiple mobile money treatment can be thought of as similar or identical to the single mobile money treatment.

Panel B1 displays measurement of cumulative usage from the date of receiving the box until the in-person lockbox check in December 2017, about 5 months later. As discussed above, at this visit we verified balances but had to rely on self-reports for deposit and withdrawal activity. Self-reported usage of boxes was nearly universal: $94-97 \%$ of people used a box at least once, and 91-92\% used the box at least 5 times. This level of take-up is far higher than in many prior studies, including several in Malawi with banks (Dupas et al. 2018; Brune et al. 2014) or VSLAs (i.e. Ksoll et al. 2016). Our preferred measure of usage, the value of deposits, is also substantial: mean deposits were $\$ 23$ per month in the single box group and $\$ 31$ in the multiple box group (about $34 \%$ higher than the single box group).

Panel B2 show cumulative usage from administrative data from the telco. The evidence suggests lower usage than the boxes, though figures are still substantial. About $67-79 \%$ of respondents made at least one mobile money deposit, and between $49 \%$ and $70 \%$ made more than 5 . The average value of deposits was about $\$ 9$ per month.

In Table 3, we regress the value of deposits (measured in different data sources) on an indicator for receiving multiple accounts (as well as other important background covariates). Across the three measures, we consistently observe that deposits in the multiple account group were no different in the case of mobile money, but were statistically significantly higher for boxes, with a magnitude of $24 \%$ in the lockbox check, $48 \%$ in the HFPS and $25 \%$ in the monitoring surveys. While the difference in point estimates across measures is not particularly meaningful (since deposits were measured over different windows and may reflect seasonal changes in savings behaviors), these results all point to higher savings from the introduction of an additional box ${ }^{27}$ These regressions also confirm that for the mobile money groups, receiving a second account did not cause an increase in usage.

\subsection{Treatment effects}

The main analysis for this paper is organized around a pre-analysis plan ${ }^{28}$ In the plan, we prespecified the following outcomes: savings, credit, labor supply, household expenditures, and business outcomes (however, the plan does not specifically explicate how these variables are to be defined). For both the HFPS and monitoring surveys, we report results from three intent-to-treat specifications. Our two main specification were pre-specified, and are given by Equations (1) and (2) below ${ }^{29}$ In Equation (1), we analyze the effects of each of our 4 main treatments (one box, multiple

\footnotetext{
${ }^{27}$ Among background covariates, we find some evidence that people with higher baseline savings or that had bank or mobile money accounts saved more. We find some evidence that people who are more "taxed" by their networks (i.e., people who at baseline reported giving transfers but not receiving them) and people with more assets use boxes more; women use their boxes less. We find that distance to mobile money agents is associated with lower mobile money deposits, which is in line with the hypothesis that transaction costs discourage usage. We don't find any meaningful heterogeneity by other demographic characteristics.

${ }^{28}$ The PAP can be found at https://www.socialscienceregistry.org/trials/2449.

${ }^{29}$ Note that our specifications are similar but not identical to those written in the PAP. In particular, we add 3 fixed effects that were not pre-specified. They are (1) whether the respondent won the airtime lottery, (2) whether
} 
box, one mobile money, multiple mobile money) separately:

$$
Y_{i s t}=\theta_{1}+\theta_{2} L B_{i}^{1}+\theta_{3} L B_{i}^{\text {mult }}+\theta_{4} M M_{i}^{1}+\theta_{4} M M_{i}^{\text {mult }}+\tau L_{t}+\mu_{s}+\delta_{t}+\eta_{H F}+\lambda X_{i}+\epsilon_{i s t}
$$

In our second specification, we pool the single and multiple account treatments together, to study the effects of having any box or any mobile money:

$$
Y_{i s t}=\delta_{1}+\delta_{2} L B_{i}+\delta_{3} M M_{i}+\kappa L_{t}+\mu_{s}+\delta_{t}+\eta_{H F}+\rho X_{i}+\epsilon_{i s t}
$$

Finally, for the sake of completeness, we also report results from a specification that pools all treatments together, i.e., it gives us the effect of having any account:

$$
Y_{i s t}=\beta_{1}+\beta_{2} T_{i}+\pi L_{t}+\mu_{s}+\delta_{t}+\eta_{H F}+\xi X_{i}+\epsilon_{i s t}
$$

In Equations (1) and (2), $L B_{i}$ and $M M_{i}$ are dummies for the lockbox or mobile money treatment, while superscripts 1 and mult in Equation (1) denote the single and multiple account treatments respectively. $T_{i}$ in Equation (3) is a dummy for being in any treatment.

In all of the above equations, $Y_{i s t}$ is an outcome for individual $i$ at time $t$ in strata $s, L_{t}$ is an indicator of airtime lottery wins (measured either daily or weekly), depending on the measurement window of the outcome variable, and $\mu_{s}$ is a strata fixed effect. $\delta_{t}$ is a fixed effect for the date of the interview in the case of monitoring survey regressions, and for the date of the outcome in question for HFPS regressions. $\eta_{H F}$ is a fixed effect for whether the respondent was sampled for the HFPS surveys, and is therefore estimated only for the monitoring survey regressions. $X_{i}$ denotes the individual mean of the dependent variable (over the day covered by the intake survey), making the specification ANCOVA. Standard errors are clustered at the individual level, and the regressions are estimated with population weights.

All HFPS regressions are at the day-level, i.e., we utilize the 3-4 day look-back period in the surveys to convert the data into a daily panel. Monitoring survey outcomes vary in how they are defined across outcomes. We provide detailed explanations for each outcome in the notes for relevant tables. We present two versions of all main tables, one for the HFPS and one for the monitoring surveys. In these tables, we report results from Equations (1), (2) and (3) in separate panels - A, B, and C. All monetary values are winsorized at $5 \%$ and expressed in USD 30

The separate panels provide separate, but equally important, information. Panel A is used to test whether the second account had an effect, by performing a test of equality between one and multiple accounts. This is particularly useful for savings outcomes (Table 4). However, because each treatment arm is of modest size, the pooled regressions in Panels B and C provide more power for

the respondent was sampled for the HFPS (for monitoring survey outcomes only), and (3) the date of the survey (monitoring survey) or outcome (HFPS). The results are not sensitive to these controls but including these fixed effects seem preferable due to questions about whether the lottery or HFPS has an effect, and to control for possible time trends.

${ }^{30}$ The exchange rate was about 700 MWK to $\$ 1$ US during the sample period. 
testing the separate question of whether accounts affected downstream outcomes (whether multiple or single). The main tables are limited to only outcomes that were pre-specified. We present naive $p$-values in the main tables, and sharpened $q$-values in Web Appendix Tables A5 and A6 (following the procedure in Anderson 2008) ${ }^{31}$ In addition to pre-specified variables, we collected other outcomes of interest. We perform regressions for some of these outcomes as well, in the Appendix.

\subsection{Savings}

We present effects of treatment accounts on savings in Tables 4 (the HFPS) and 5 (the monitoring surveys), where are dependent variable is daily deposits. In both Tables, Column 1 shows effects on savings in the project accounts, which are unsurprisingly statistically significant in both surveys since the control group had zero savings in those accounts by design. In Columns 2-5, we estimate the effect of treatment on savings in all boxes (or mobile money), including non-experimental accounts.

We discuss the lockbox first. In both surveys, we find that providing a single lockbox significantly increases total box savings, that providing multiple lockboxes increases box savings by more, and that the difference between treatment groups is significant. The effects are sizeable: single and multiple boxes increase box savings by $\$ 0.45$ and $\$ 1.28$ respectively in the HFPS (which is sizeable, even relative to total deposits of $\$ 2.43$ per day - Column 9$)$. In the monitoring surveys, the figures are $\$ 0.48$ and $\$ 0.78$ respectively, on a base of $\$ 1.53$. To provide some evidence on crowdout, we show effects on other savings places in Columns 6-8 (as well as Columns 3 and 5). As expected, in both surveys, we observe a statistically significant decline in cash at home for the lockbox group in the status quo, many people keep cash at home in a secret location, and in the treatment group they moved some of this money into the box. We also observe declines in some other categories such as mobile money and savings groups.

Column 9 shows total deposits, in all places. For the single box group, the treatment effect on total deposits is statistically insignificant in both surveys (and actually negative in the HFPS). For the multiple box group, the treatment effect is $\$ 0.95$ in the HFPS and $\$ 0.59$ in the monitoring surveys (significant at $5 \%$ and $10 \%$, respectively). In both surveys, we reject equality of the treatments. The total deposits for multiple box groups are large and statistically significant from zero

Turning to mobile money, we find clear evidence of usage but at a lower level than for the boxes. Total mobile money deposits increase by $\$ 0.14-\$ 0.22$ in the HFPS and $\$ 0.10-\$ 0.13$ in the monitoring surveys. We find weak evidence of an increase in total deposits. Because the second mobile money account was not used much, our preferred test is the test of joint significance, which

\footnotetext{
${ }^{31}$ We correct $p$-values across all pre-specified outcomes. There are 19 such outcomes (all listed in the tables). We also adjust for the number of regressors. At one extreme, since there are 4 individual treatment arms, there are 76 hypotheses for the individual regressors. At the other, there is only test per regression for the pooled regressions. Finally, there are 2 tests per regressions for regressions in which we pool observations within box and mobile money treatments.
} 
does not reject in the HFPS but which is significant at $5 \%$ in the monitoring survey 32

To summarize, we find clear evidence that people used the experimental accounts, and that people used multiple boxes more than a single box, but we also find evidence that much of this new savings came from crowd out of other sources. Ultimately we do not find statistically significant effects on total deposits for most treatment groups (other than for the multiple box group). Despite this, however, it is still possible that the accounts could have effects. First, it is possible that we are underpowered to observe effects on total savings, especially in each sub-treatment, due in part to the noisiness of savings (the standard deviation in both surveys is larger than the mean for total savings as well as for each individual savings place). Because savings is so noisy, it is common in this literature to not find effects on total deposits, even in cases where there is evidence of downstream effects. Thus, the ultimate indicator of usage remains downstream outcomes. Second, even if total deposits did not increase, it is possible that moving money from an insecure place like cash at home to the experimental accounts would be beneficial. To investigate these, we turn to downstream effects 33

\subsection{Labor supply, business outcomes and credit}

In Tables 6 (HFPS) and 7 (monitoring surveys), we examine pre-specified outcomes related to labor supply, business success, and credit. Labor supply is disaggregated between the main business, secondary occupations, and farming, and is shown in Columns 1-6. In both Tables, we observe negative point estimates on labor supply in the main business, though the effect is stronger in the HFPS (where pooled regressions for mobile money and all accounts suggest consistent decrease in hours worked=). We find strong evidence that hours in farming increased - joint significance tests are significant in both panels (implying that the reduction in the main business was put into farming). We also observe positive treatment effects for labor supply in a secondary occupation, but these are not precisely estimated.

Consistent with the decline in labor supply, we observe negative coefficients on business profits and revenue (Columns 7-8). This effect is particularly strong for profits in the HFPS (where point estimates are $10-15 \%$ of the control mean), though is only significant for mobile money.

The labor supply and business results suggest an increase in investment in farming, and a

\footnotetext{
${ }^{32}$ In Web Appendix B, we measure savings effects on other measures of usage. These are withdrawals (Tables B1 and B2), balance (Table B3), and net deposits (Tables B4 and B5). As discussed above, we expected effects on both deposits and withdrawals, and we find statistically significant effects for total withdrawals in the monitoring surveys (though not the HFPS) for all treatments. The effect on balances and net withdrawals is less clear. We find positive point estimates on balances for all treatments, and when pooling coefficients these effects are significant. The estimated coefficient on net deposits, however, is close to zero and not significant (which is consistent with respondents withdrawing money over the time period of the data collection).

${ }^{33}$ We show heterogeneity analysis by 3 pre-specified covariates in Appendix C, Tables C1 and C2. These are (1) pressure to share resources (i.e., if they are "taxed", which we define as giving but not receiving transfers); (2) gender; and (3) displaying hyperbolic preferences in incentivized time preference questions using the convex budget set methodology of Andreoni and Sprenger (2012). Point estimates are generally in line with our priors - people who are taxed and women save somewhat more, while hyperbolic people save less. However, many of these coefficients and F-tests are insignificant so we do not make too much of them here. Because we observe modest heterogeneity in effects on savings, we do not present results on other downstream outcomes.
} 
reallocation of labor away from the main business, which would be consistent with the marginal return to farming exceeding that of the main business. While we can only speculate as to why this might be, a possibility might be that returns to farming are risky or will only be realized in the future, and so respondents concentrate labor supply in daily business which provides immediate cash at relatively low-risk. Boxes or mobile money may help people build up a buffer that allows them to mitigate this behavior. This finding is related to several recent papers that find labor supply effects of an easing of financial constraints, such as Fink, Jack, and Masiye (2018), who find that providing credit to smallholder farmers decreases off-farm labor and increases own-farm labor. Our finding that saving accounts cause a reallocation of labor supply is related to Callen et al. (2019), who find that Sri Lankan households who were given access to deposit collection increase their hours in wage work but decrease hours in self-employment ${ }^{34}$

Finally, we find evidence of an increase in credit to customers (measured only in the monitoring surveys - Table 7, Column 11), but no change in loans taken out by respondents (Columns 9-10 in Tables 6 and 7). For credit to customers, we find statistically significant effects for three treatments, with effect sizes ranging from $\$ 0.13-\$ 0.17$, equivalent to $57-73 \%$ given the control mean of $\$ 0.23$. This result suggests that increased liquidity may have been passed on to customers, which may be a way of expanding business in a highly competitive environment. Casaburi and Reed (2019) show a similar finding, though in the different setting of traders buying cocoa from farmers in Sierra Leone.

\subsection{Expenditures}

Tables 8 and 9 show effects on a variety of expenditure categories. All outcomes are expressed in daily terms. Since there are several treatments and several types of expenditures, we start with total expenditures (the last column in each table). In both surveys, we find positive, large coefficients. While these coefficients are not statistically significant, the results are suggestive (the p-value for the pooled regression is about 0.15 for the monitoring surveys and 0.26 for the HFPS) We also examine spending on individual spending categories in the remaining columns. While many of these coefficients are positive, the only significant category is school spending in the HFPS, 35

\footnotetext{
${ }^{34}$ Given that we detect strong effects on labor supply in farming, we examine a few other farming-related outcomes in Appendix Table A7. This analysis is restricted to 3 outcomes which were measured in only the monitoring surveys: renting land, buying land, and expenditures on farm inputs. Point estimates for all treatments are positive, though significant only for the box treatments. The effects are large: respondents in the box groups are about 4 percentage points more likely to buy land (against a control mean of $2 \%$ ) and about 9 percentage points more likely to rent (against a control mean of 5\%). For farming inputs, we find effects of the order of $25 \%$ of the control mean.

${ }^{35}$ The coefficient on expenditures is slightly different (for mobile money) than that reported in our companion paper Aggarwal et al. (2020), where the coefficient on pooled mobile money was reported as 0.64 with a p-value less than 0.1 . The reason for this difference is that the other paper included a small set of baseline controls whereas this version includes no controls. The qualitative results are very similar, however.
} 


\subsection{Effect of accounts on ability to cope with shocks}

One of our pre-specified outcomes was to test whether accounts made people less susceptible to shocks. This is closely related to an extensive prior literature on the effect of mobile money, and savings accounts generally, on inter-personal transfers and risk-coping ability. Prior research on mobile money has shown evidence of strong effects on inter-personal transfers (Jack and Suri 2014; Suri and Jack 2017; Suri 2017; Munyegera and Matsumoto 2016; Riley 2018; Flory 2018; Lee et al. forthcoming), and has shown that mobile money makes people better able to cope with shocks (Jack and Suri 2014). For savings accounts more generally, a prior literature on savings has tested whether savings accounts increase transfers or whether (as discussed in papers like Ligon et al. 2000) they crowd out informal insurance networks. While a lab-based experiment in this context found no effects (Chandrasekhar, Kinnan and Larreguy 2018), empirical evidence has been mixed: papers like Comola and Prina (2018); Dupas et al. (2019); and Flory (2018) show evidence of an increase in inter-personal transfers, while other papers such as Dizon, Gong and Jones (2018) show a decrease.

Appendix Tables A8 and A9 show effects of the boxes on inter-personal transfers and loans (please note that these outcomes were not pre-specified). Columns 1-4 show effects on the likelihood of receiving / giving a transfer and their respective (unconditional) amounts. In Table A8 (the HFPS), transfers are measured over the previous week, while in Table A9 (monitoring surveys), they are measured over the past month. While several coefficients are positive, the effects are largely statistically insignificant, other than an increase in the likelihood of giving a transfer for the pooled mobile money treatment (which is consistent with the prior literature on mobile money). Notably, the effect sizes are modest across the board. A simple tabulation of usage data from the telco (in Appendix Table A10) is consistent with this pattern. While the average respondent deposited close to $\$ 120$ over the study period, they only sent about $\$ 14$ and received about $\$ 12$. Panel $\mathrm{B}$ of the table indicates that, by contrast, people used the accounts for savings more than transfers.

We then turn to our pre-specified analysis in which we regress outcomes on shocks. In this analysis, we focus on health shocks, because these are relatively common shocks that typically require cash to be treated. In addition, we collected information on whether these shocks were treated immediately and if they were treated fully (following questions adapted from Dupas and Robinson 2013b). These regressions are fixed effects specifications of the given outcome on health shocks and the interaction between health shocks and treatment. Web Appendix Table A11 shows effects on our main outcomes, while Web Appendix Table A12 shows effects on promptly and fully treating the illness ${ }^{36}$ Web Appendix Table A11, Panel A shows effects for the respondent him or herself and Panel B shows effects for other household members. In the control group, respondents spend about $\$ 1.80$ more in medical expenses when they are sick themselves and about $\$ 2.50$ more when faced with a household health shock. This is not a trivial sum, but it is not huge either (since daily profits are about $\$ 3$ per day). It does suggest however, that these households have some inbuilt

\footnotetext{
${ }^{36}$ Web Appendix Table A13 shows effects on the prevalence of sickness, and shows that people in the treatment groups were no less (or more) likely to report being sick in the past week
} 
capacity to withstand at least minor shocks. While these shocks are somewhat modest, we find evidence that people do not fully treat illness. Web Appendix Table A12 shows results for whether illness was promptly and completely treated. We find evidence that the majority of illnesses are treated fully and promptly, but not all of them - $17 \%$ of illnesses are not treated fully and $22 \%$ are not treated immediately in the control group. However, we find no evidence of improved coping in the treatment groups. While this result is in some contrast to much of the existing literature which does find improved resiliency as a result of mobile money, it could be that effects on these types of more common health shocks is smaller than on bigger events.

\subsection{Long-term usage}

There may be concerns that the observed results are short-term in nature, and that usage of accounts may peter out over the long-term as the novelty factor of the accounts wears off. In order to address this concern, we collected a long-term usage survey in September 2019 (26 months after the accounts were first opened; 18 months after the endline survey; and 16 months after the final fee reimbursements were made for the mobile money group). We supplemented the information collected through this survey with long-term usage data (up until August 2019) from the telco. Results are summarized in Table 10 (Panel A for the survey and Panel B for the telco data).

For the lockbox treatment, $70 \%$ of those in the single box group and about $60 \%$ in the multiple box group reported still using the account; with $60 \%$ and $44 \%$ in each of these groups respectively reporting having made a deposit in the past month. The deposit amounts are sizeable at $\$ 14$ for the single box group and $\$ 19$ in the multiple box group in the past month. These deposits are equivalent to just over $60 \%$ of the monthly average reported during the study period.

For mobile money, as during the study period, usage is lower than that for the boxes, but meaningful nevertheless. Across the single and multiple account treatments, $40 \%$ reported still using the account and 30\% reported having made a deposit in the past month. The reported deposits in the past month are $\$ 9$, a number similar to what was reported as the monthly average of deposits during the study period. The telco data corroborates this pattern of sustained usage, with $50 \%$ of the respondents having made at least one deposit after the study concluded and the fee waiver expired.

\section{Threats to validity}

A possible concern with our analysis is that our program effects are almost entirely based on survey responses. This is unavoidable in this context, since these small businesses do not have digital records of activity (like barcode scanners) and (worldwide) most businesses this small do not keep detailed financial records, (i.e., McKenzie and Woodruff 2017). Moreover, we are interested in some outcomes (like expenditures) which can typically only be captured in a survey.

Thus, while this research would likely be impossible without relying on surveys, their use does 
raise some questions which we address in this section ${ }^{37}$ We dedicate a separate empirical Appendix $\mathrm{V}$ to present all our analyses in this respect.

One type of concern would be experimenter demand effects or social desirability bias - i.e. that respondents felt pressure to answer questions in a certain way, because they believed that those responses would be viewed more favorably either in the context of the experiment or because they constitute appropriate behavior in general. Our read of the literature is that existing research suggests that such effects are modest in many settings (i.e. de Quidt, Haushofer and Roth 2018; Mummolo and Peterson 2018; Dhar, Jain and Jayachandran 2018); moreover, in this experiment, such effects would have to be differentially present in the treatment and control groups. Even signing social desirability bias would be difficult for some outcomes, since the effects on some key outcomes (such as the decline in labor supply or the increase in holiday spending) would have been unlikely to be perceived as desired outcomes.

For a few savings-related outcomes, it is possible for us to explore the possibility of experimenter demand effects, because we have objective measures of actual usage. In particular, for the lockbox groups, we physically verified balances at the lockbox check; for the mobile money groups, we can observe true usage in the telco's administrative data. We start with reporting integrity checks for the mobile money group, which are presented in Appendix Table V1. Here, we check correlations between the survey and the administrative data for a binary measure of making a deposit over any given period as well as for the amount deposited. The panels are organized in order of time period - Panel A is at the day level, Panel B at the week level, and Panel C is cumulative over the time period. In each regression, the coefficients are highly statistically significant but point estimates are smaller than one. Point estimates are also monotonically increasing in the time period - the coefficient on total deposits is 0.45 at the day level, 0.65 at the month week level, and 0.82 cumulatively. We interpret these results as suggestive that respondents might have mixed up the exact dates of transactions, but generally truthfully reported on their savings behavior.

For the lockboxes, at the lockbox check visit, we first asked respondents questions about usage of the lockbox, and then asked to visually inspect the box right away. In case the box was stored at the respondent's home, we requested them to travel with us immediately to their home to show us the box (so that there was no opportunity to manipulate the amount in the box). There is undeniable selection into participating in this check - for example, respondents who lived far away or who had a high opportunity cost of time would be less likely to be able to travel to their home. In total, out of those who agreed to participate in a survey (without anticipating a lockbox check), $79 \%$ of people agreed to show us the box 38 For those who opened the box, we run regressions

\footnotetext{
${ }^{37}$ A potential concern about using survey-based data, especially when those surveys are long and collected over the phone (like in this case) is that they may lead to respondent fatigue and as a result, the data may be noisy. While this is a legitimate concern, we note that survey fatigue should not be differential by treatment and therefore, should not impact internal validity. Moreover, while potentially noisy data would have lowered precision, our estimates should still be unbiased. As a general point, we also note that phone-based data collection, while common already, may increasingly become the norm, such as in the case of the COVID-19 crisis, or more generally, when data needs to be collected at a high frequency (like in our case).

${ }^{38}$ The differences in self-reported balances between those who showed lockboxes and who who did not was about -\$11 (\$30 for those who showed the box vs. $\$ 41$ for those who did not). The p-value of this difference is 0.37 .
} 
(without constant terms) of the amount in the box on the amount reported in the survey in Web Appendix Table V2. Pooling all boxes and individuals together, we find a coefficient very close to 1 (1.05), suggesting that reporting is, on the whole, accurate 39 Panels B and $\mathrm{C}$ run these regressions separately for the groups offered one box and multiple boxes. We find a pooled coefficient of 0.88 for one box and 1.10 in multiple boxes, meaning that for any given amount reported in the survey, people in the multiple box group actually had more in the box, potentially suggestive of difficulty remembering balances across multiple saving source. Thus, while we would view any differences in reporting behavior across treatment groups to be minimal, if anything they would work against finding larger survey measures of savings of multiple boxes. 40

We plot the amount in the box against the amount reported in Web Appendix Figure V1. Panel A shows all values, while Panel B focuses only below the 75 th percentile (since there are some very large values). As can be seen, the relationship is strong, but many values do not lie on the 45 degree line. We find that $50 \%$ report the exact sum in the box, $37 \%$ over-report, and $14 \%$ under-report. Thus, there is some evidence of over-reporting, but there does not seem to be evidence that this would have substantially biased our results.

A separate concern with our study is that the HFPS itself changed behavior or reporting. We examine this in Web Appendix Table V3 where we examine whether estimated treatment effects on the monitoring surveys differ between HFPS respondents and non-respondents (which we examine by regressing our main outcomes on the HFPS, the treatment indicators, and interactions between treatment and the HFPS. In all specifications, a joint test of the significance of the interaction terms yields a p-value far over 0.054

\section{Discussion and Conclusion}

People throughout the world save up simultaneously for multiple goals of varying amounts and duration. A simple strategy for saving concurrently towards several goals might be to create multiple physically separated accounts, but this may be challenging in developing countries like Malawi where two thirds of the adult population lacks even a single bank account (see the 2017 Findex - Demirgüç-Kunt et al. 2018). In this paper, we experimentally vary the number of accounts that respondents are given, and we find that entrepreneurs who receive multiple lockboxes saved

\footnotetext{
${ }^{39}$ Columns $2-4$ show similar coefficients in regressions box-by-box.

${ }^{40}$ There may also be concerns about there being incremental experimenter demand effects for people given multiple accounts (i.e. respondents may have felt compelled to report positive usage for each account separately). This is not likely - the multiple mobile money treatment was not effective in the administrative data, and indeed we observe no incremental reported effect of the second account.

${ }^{41}$ There may also be concerns that effects may partly be driven by the lottery payments that were made to respondents during our surveys. To explore this, we interact each of our treatments with a dummy for having received a lottery payment, and run fixed effect regressions (with fixed effects at the individual level). We code the lottery win as being relevant if it was won in the previous period. Results are presented in Web Appendix Table C3. We find modest effects of the lottery in the control group: we see no effect on labor supply, though we observe evidence of an increase in revenues. We see some evidence of a differential labor supply response in the treatment group, but the sign of the treatment effect is not consistent. We conclude that there is little evidence of consistent differential effects by treatment status.
} 
about $30 \%$ more than those given only one. By contrast, providing a second mobile money account had no effect, because of technical challenges. These results strongly suggest that a simple policy of providing multiple accounts with labeled goals may cost-effectively increase savings, as long as the accounts are simple to use.

In addition, we find robust evidence that getting access to savings accounts had strong impacts on downstream outcomes. In particular, we observe that entrepreneurs who received savings accounts invested more in farming (possibly by substituting labor supply away from their small business), increased expenditures, and gave out more credit to customers. However, we do not find differential impacts of an additional box on downstream outcome (the effect of an additional mobile money account is expected to be minimal based on take-up). While this could be for power reasons, it is also possible that the first box was often used for immediate expenses while the second box was for longer-term goals, and so effects would take longer to manifest. This is purely speculative however.

Our results lend support to the optimism around mobile money, and provide new evidence that mobile money can be effective as a tool for mobilizing savings (above and beyond its value as a transfer system). However, our work does leave some important questions open for future research. In our experiment, we waived withdrawal fees, provided training, and encouraged people to save for their goals. Each of these components was light-touch, and we conjecture that they had a modest effect on usage; however, the evidence on this is not conclusive. For the withdrawal fees, we examine how usage changed in the period after fees were reimbursed (May 2018) in Web Appendix Figure A5. We observe a decline in activity shortly after fees were removed, but a resumption of activity in the following months. Future work could more deeply explore the role of fees in explaining usage. The training we provided was very basic and consisted mostly of basic literacy on how to use mobile money. This is something agents are already supposed to be doing, but in practice this training is not provided. Finally, we conjecture that simply encouraging people to save for their goals would not have been effective in isolation, but perhaps the combined effect of encouragement and mobile money was more effective than mobile money alone. Future work might explore these channels more deeply. 


\section{References}

[1] Agarwal, Sumit, Shashwat Alok, Pulak Ghosh, Soumya Ghosh, Tomasz Piskorski, and Amit Seru (2017). "Banking the Unbanked: What Do 255 Million New Bank Accounts Reveal about Financial Access?" Unpublished.

[2] Aggarwal, Shilpa, Valentina Brailovskaya and Jonathan Robinson (2020). "Cashing In (and Out): Experimental Evidence on the Effects of Mobile Money in Malawi." Forthcoming, AEA Papers and Proceedings.

[3] Aker, Jenny C, Melita Sawyer, Markus Goldstein, Michael O'Sullivan and Margaret McConnell (2019). "Just a Bit of Cushion: The Role of a Simple Savings Device in Meeting Planned and Unplanned Expenses in Rural Niger." Forthcoming, World Development.

[4] Ainslie, George (2001). Breakdown of Will. Cambridge: Cambridge University Press.

[5] Andreoni, James, and Charles Sprenger (2012). "Estimating time preferences from convex budgets." American Economic Review 102 (7): 3333-56.

[6] Anderson, Michael L. (2008). "Multiple inference and gender differences in the effects of early intervention: A reevaluation of the Abecedarian, Perry Preschool, and Early Training Projects." Journal of the American Statistical Association 103 (484): 1481-1495.

[7] Ashraf, Nava, Dean Karlan, and Wesley Yin (2006). "Tying Odysseus to the Mast: Evidence from a Commitment Savings Product in the Philippines." Quarterly Journal of Economics 121 (2): 673-97.

[8] Benabou, Roland and Jean Tirole (2004). "Willpower and Personal Rules." Journal of Political Economy 112 (4): 848-886.

[9] Benjamini, Yoav, Abba M. Krieger, and Daniel Yekutieli (2006). "Adaptive linear step-up procedures that control the false discovery rate." Biometrika 93 (3): 491-507.

[10] Beshears, John, James Choi, Christopher Harris, David Laibson, Brigitte C. Madrian, and Jung Sakong (2015). "Self Control and Commitment: Can Decreasing the Liquidity of a Savings Account Increase Deposits?" NBER Working Paper No. 21474.

[11] Blumenstock, Joshua, Michael Callen, and Tarek Ghani (2018). "Why Do Defaults Affect Behavior? Experimental Evidence from Afghanistan." American Economic Review 108 (10): 2868-2901.

[12] Bradley, Alice (1923). Fifty family budgets. New York: Woman's Home Companion.

[13] Brailovskaya, Valentina (2018). "Unreliable Electricity: Effects of Power Outages on Small Businesses in Urban Malawi." Unpublished.

[14] Bruhn, Miriam and David McKenzie (2009). "In pursuit of balance: Randomization in practice in development field experiments." American Economic Journal: Applied Economics 1 (4): 200-232. 
[15] Brune, Lasse, Xavier Giné, and Jessica Goldberg, and Dean Yang (2014). "Facilitating Savings for Agriculture: Field Experimental Evidence from Malawi." Economic Development and Cultural Change 64 (2): 187-220.

[16] Buehren, Niklas, Markus Goldstein, Leora Klapper, Tricia Koroknay-Palicz, and Simone Schaner (2018). "The Limits of Commitment: Who Benefits from Illiquid Savings Products?" Unpublished.

[17] Callen, Michael Suresh De Mel, Craig McIntosh and Christopher Woodruff (2019). "What are the Headwaters of Formal Savings? Experimental Evidence from Sri Lanka." Review of Economic Studies 86 (6): 2491-2529.

[18] Carroll, Gabriel, James Choi, David Laibson, Brigitte Madrian, and Andrew Metrick (2009). "Optimal Defaults and Active Decisions." Quarterly Journal of Economics 124 (4): 1639 1674 .

[19] Carvalho, Leandro S., Stephan Meier, and Stephanie W. Wang (2016). "Poverty and Economic Decision-Making: Evidence from Changes in Financial Resources at Payday." American Economic Review,106 (2): 260-84.

[20] Casaburi, Lorenzo and Tristan Reed (2019). "Interlinked Transactions and Competition: Experimental Evidence from Cocoa Markets." Unpublished.

[21] Chandrasekhar, Arun, Cynthia Kinnan, and Horacio Larreguy (2018). "Social Networks as Contract Enforcement: Evidence from a Lab Experiment in the Field." American Economic Journal: Applied Economics 10 (4): 43-78.

[22] Comola, Margherita and Silvia Prina (2015). "Treatment Effect Accounting for Network Changes: Evidence from a Randomized Intervention." Forthcoming, Review of Economics and Statistics.

[23] de Mel, Suresh, Craig McIntosh, Ketki Sheth, and Christopher Woodruff (2019). "Can MobileLinked Bank Accounts Bolster Savings? Evidence from a Randomized Controlled Trial in Sri Lanka." NBER Working Paper 25354.

[24] de Quidt, Jonathan, Johannes Haushofer and Christopher Roth (2018). "Measuring and Bounding Experimenter Demand." American Economic Review 108 (11): 3266-3302.

[25] Demirgüç-Kunt, Asli, Leora Klapper, Dorothe Singer, Saniya Ansar, and Jake Hess (2018). The Global Findex Database 2017: Measuring Financial Inclusion and the Fintech Revolution. https://globalfindex.worldbank.org.

[26] Dizon, Felipe, Erick Gong and Kelly Jones (2018). "Does Financial Inclusion Exclude? The Effect of Access to Savings on Informal Risk-Sharing in Kenya." Unpublished.

[27] Dhar, Diva, Tarun Jain and Seema Jayachandran (2018). "Reshaping Adolescents' Gender Attitudes: Evidence from a School-Based Experiment in India." NBER Working Paper 25331. 
[28] Dupas, Pascaline and Jonathan Robinson (2013a). "Savings Constraints and Microenterprise Development: Evidence from a Field Experiment in Kenya." American Economic Journal: Applied Economics 5 (1): 163-192.

[29] Dupas, Pascaline and Jonathan Robinson (2013b). "Why Don't the Poor Save More? Evidence from Health Savings Experiments." American Economic Review 103 (4): 1138-1171.

[30] Dupas, Pascaline, Sarah Green, Anthony Keats, and Jonathan Robinson (2016). "Challenges in Banking the Rural Poor: Evidence from Kenya's Western Province." NBER Volume African Successes: Modernization and Development, Volume 3, Sebastian Edwards, Simon Johnson, and David N. Weil, editors, University of Chicago Press.

[31] Dupas, Pascaline, Anthony Keats and Jonathan Robinson (2019). "The Effect of Savings Accounts on Interpersonal Financial Relationships: Evidence from a Field Experiment in Rural Kenya." Economic Journal 129 (617): 273-310.

[32] Dupas, Pascaline, Dean Karlan, Jonathan Robinson and Diego Ubfal (2018). "Banking the Unbanked? Evidence from three countries." American Economic Journal: Applied Economics $10(2): 257-297$.

[33] Fink, Gunther, B. Kelsey Jack and Felix Masiye (2018). "Seasonal Liquidity, Rural Labor Markets and Agricultural Production.” NBER Working Paper 24564.

[34] Flory, Jeffrey (2018). "Formal Finance and Informal Safety Nets of the Poor: Evidence from a Savings Field Experiment." Journal of Development Economics 135: 517-533.

[35] Francis, Eilin (2018). "Paying to Repay? Experimental Evidence on Repayment Commitment." Unpublished.

[36] Garlick, Rob, Kate Orkin, and Simon Quinn (2019). "Call Me Maybe: Experimental Evidence on Using Mobile Phones to Survey Microenterprises." Working Paper.

[37] GSMA (2017). State of the Industry Report on Mobile Money, 2016. GSMA, London, UK.

[38] Habyarimana, James and William Jack (2018). "High Hopes: Experimental Evidence on Saving and the Transition to High School in Kenya." Unpublished.

[39] Herskowitz, Sylvan (2018). "Gambling, Saving, and Lumpy Expenditures: Sports Betting in Uganda." Unpublished.

[40] Jack, William and Tavneet Suri (2014). "Risk sharing and transactions costs: Evidence from Kenya's mobile money revolution." American Economic Review 104 (1): 183-223.

[41] Jakiela, Pamela, and Owen Ozier (2016). "Does Africa Need a Rotten Kin Theorem? Experimental Evidence from Village Economies." Review of Economic Studies 83 (1): 231-268.

[42] John, Anett (2018). "When Commitment Fails - Evidence from a Field Experiment." Forthcoming, Management Science.

[43] Karlan, Dean and Leigh Linden (2016). "Loose Knots: Strong versus Weak Commitments to Save for Education in Uganda." NBER Working Paper 19863. 
[44] Karlan, Dean and Jonathan Zinman (2018). "Price and control elasticities of demand for savings." Journal of Development Economics 130: 145-159.

[45] Kast, Felipe, and Dina Pomeranz (2018). "Saving More to Borrow Less: Experimental Evidence from Access to Formal Savings Accounts in Chile.” NBER Working Paper 20239.

[46] Kast, Felipe, Stephan Meier, and Dina Pomeranz (2018). "Saving more in groups: Field experimental evidence from Chile." Journal of Development Economics 133: 275-294.

[47] Koch, Alexander and Julia Nafziger (2016). "Goals and Bracketing under Mental Accounting." Journal of Economic Theory 162: 305-351.

[48] Kochar, Anjini (2018). "Branchless banking: Evaluating the Doorstep Delivery of Financial Services in Rural India." Journal of Development Economics 135: 160-175.

[49] Ksoll, Christopher, Helene Bie Lilleør, Jonas Helth Lønborg, and Ole Dahl Rasmussen (2016). "Impact of Village Savings and Loan Associations: Evidence from a cluster randomized trial." Journal of Development Economics 120: 70-85.

[50] Ligon, Ethan, Jonathan P. Thomas, and Tim Worrall (2000). "Mutual Insurance, Individual Savings, and Limited Commitment." Review of Economic Dynamics 3 (2): 216-246.

[51] Madrian, Brigitte and Dennis Shea (2001). "The Power of Suggestion: Inertia in 401(k) Participation and Savings Behavior." Quarterly Journal of Economics 116 (4): 1149-1187.

[52] Mani, Anandi, Sendhil Mullainathan, Eldar Shafir, and Jiyaying Zhao (2017). "Poverty Impedes Cognitive Function," Science 341: 976-980.

[53] McKenzie, David and Chris Woodruff (2017). "Business Practices in Small Firms in Developing Countries." Management Science 63(9): 2967-81.

[54] Mummolo, Jonathan, and Erik Peterson (2018). "Demand effects in survey experiments: An empirical assessment." American Political Science Review 113 (2): 1-13

[55] Platteau, Jean-Philippe (2000). Institutions, Social Norms, and Economic Development. Amsterdam: Harwood Academic Publishers

[56] Prina, Silvia (2015). "Banking the Poor via Savings Accounts: Evidence from a Field Experiment." Journal of Development Economics 115: 16-31.

[57] Schaner, Simone (2018). "The Persistent Power of Behavioral Change: Long-Run Impacts of Temporary Savings Subsidies for the Poor." American Economic Journal: Applied Economics 10 (3): 67-100.

[58] Shah, Anuj, Sendhil Mullainathan, and Eldar Shafir (2012). "Some Consequences of Having Too Little," Science 338: 682-685.

[59] Soman, Dilp and Amar Cheema (2011). "Earmarking and partitioning: increasing saving by low-income households." Journal of Marketing Research 48 (SPL): S14-S22.

[60] Somville, Vincent and Lore Vandewalle, "Saving by Default: Evidence from a Field Experiment in Rural india," American Economic Journal: Applied Economics 10(3): 39-66. 
[61] Suri, Tavneet (2017). "Mobile Money." Annual Review of Economics 9: 497-520.

[62] Suri, Tavneet and William Jack (2016). "The Long-run Poverty and Gender Impacts of Mobile Money." Science 354 (6317): 1288-1292.

[63] Thaler, Richard (1990). "Anomalies: Saving, Fungibility, and Mental Accounts." Journal of Economic Perspectives 4 (1): 193-205.

[64] Thaler, Richard (1999). "Mental Accounting Matters." Journal of Behavioral Decision Making 12: $183-206$.

[65] Zelizer, Viviana A. (1994). "The Creation of Domestic Currencies," American Economic Review (Papers and Proceedings) 84 (2): 138-142. 
Panel A. High Frequency Phone Surveys

A1. Boxes

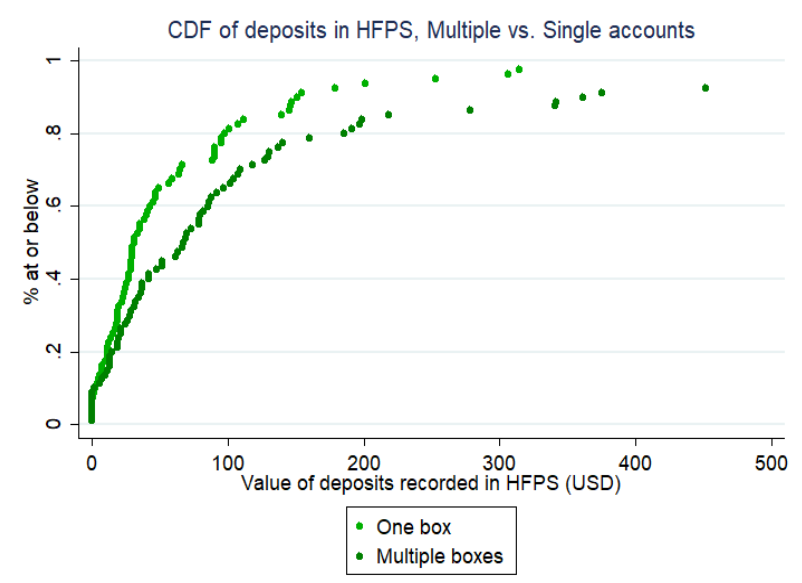

A2. Mobile Money

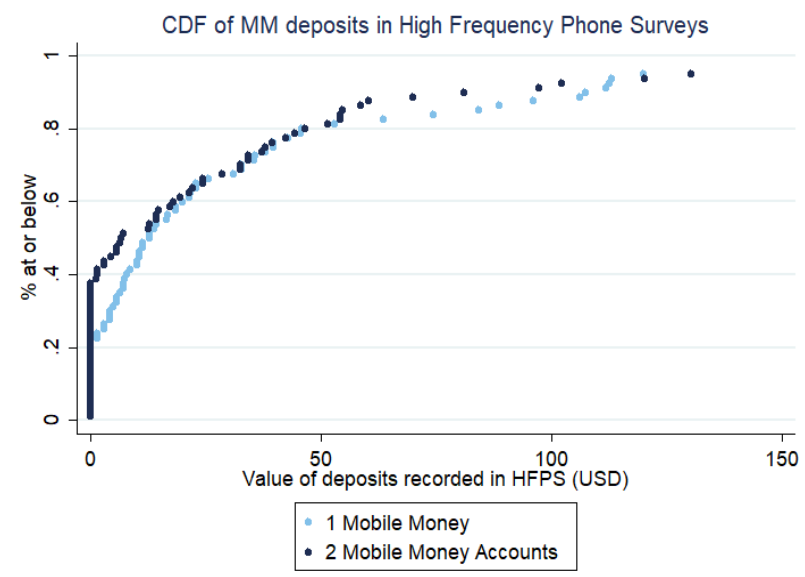

Panel B. Monitoring Surveys

B1. Boxes

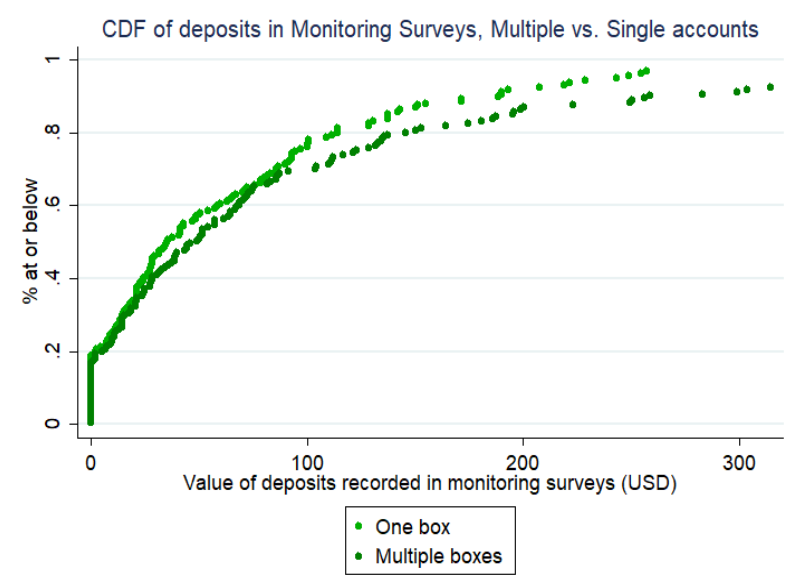

B2. Mobile Money

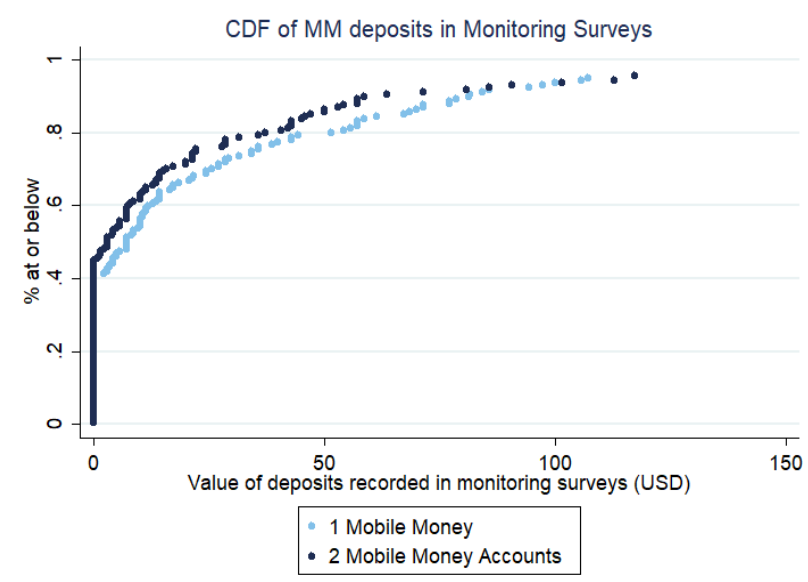

Panel C. Objective Measures

C1. Boxes (Visual Balance Check)

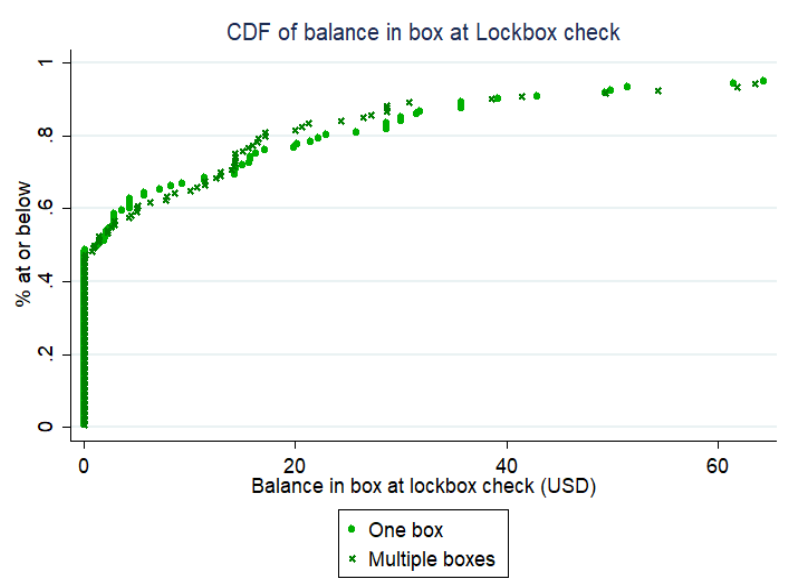

C2. Mobile Money (Administrative Data on Deposits)

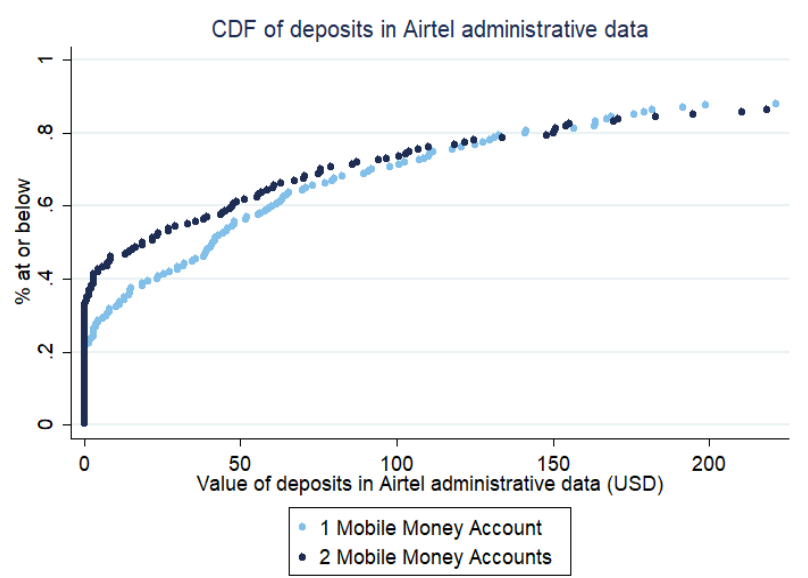

Notes: In Panel A, data is from the high frequency phone surveys; in Panel B, data is from monitoring surveys. Monetary values are in USD and CDF shows only below 95th percentile (since there are several large values). 
(1) (2)

(2) (3)

(4)

Full Sample

\begin{tabular}{l}
\hline \\
\cline { 2 - 3 } Control \\
Mean
\end{tabular}

pvalue for F-test of joint equality

\begin{tabular}{|c|c|c|}
\hline $\begin{array}{c}1 \text { Box }= \\
\text { Multi Box } \\
\quad=0\end{array}$ & $\begin{array}{c}1 \mathrm{MM}= \\
\text { Multi MM } \\
=0\end{array}$ & $\begin{array}{c}\text { Joint } \\
\text { equality }\end{array}$ \\
\hline
\end{tabular}

Panel A. Demographic information and asset ownership

Age

Married

Male

Household Farms

Years of Education

Land Owned (Acres)

34.42

(10.16)

0.30

0.81

$(0.40)$

0.46

0.35

$0.017 * *$

$0.062 *$

0.29

0.63

0.71

0.97

$0.039 * *$

0.10

0.97

0.32

9.05

(2.83)

0.66

(1.18)

Value of Durable Assets and Livestock

872.60

(1547)

House has iron roof

0.93

0.94

0.75

0.87

0.36

$0.06^{*}$

0.86

0.14

0.79

0.26

0.22

0.28

0.71

0.46

$0.048 * *$

0.64

0.62

0.44

11.32

(14.25)

money agent (minutes)

Panel B: Business

$=1$ if Retail

0.68

0.82

0.39

0.49

0.50

0.82

0.78

(99.00)

18.77

0.94

(23.20)

199.10

(401.20)

0.92

0.81

0.97

0.32

0.22

0.96

0.17

0.47

(196.70)

Saves in:

Mobile money

0.32

0.38

0.65

0.70

0.36

$0.044 * *$

$0.059^{*}$

0.97

0.86

0.75

0.79

0.58

0.28

0.22

$0.085^{*}$

761

Observations

Notes: Means are population weighted. Random a monitoring survey or at least one phone survey). Monetary values are winsorized at $1 \%$ and expressed in USD. In Columns 1 and 4 , standard deviations in parentheses; in the other columns, standard errors in parentheses. *, **, and *** indicate significance at $10 \%, 5 \%$, and $1 \%$ respectively.
(5)
(6)
(7)

HFPS sample only

(8) pvalue for F-test of joint equality

$\begin{array}{cccc}\text { Control } & 1 \text { Box }= & 1 \mathrm{MM}= & \\ \text { Mean } & \text { Multi Box } & \text { Multi MM } & \text { Joint } \\ & =0 & =0 & \text { equality }\end{array}$

33.68

(9.27)

0.79

0.20

0.11

0.24

(0.41)

0.57

0.46

0.42

0.58

0.70

0.21

0.48

0.68

0.19

0.64

0.41

9.15

(2.97)

0.59

(0.93)

976.10

(1620)

0.92

0.91

0.69

0.92

0.35

0.44

0.29

0.24

0.33

0.28

0.20

0.47

0.10

0.92

0.69

0.14

$0.078 *$

0.53

0.29

0.47

0.63

9.78

0.64

0.40

0.73

(9.29)

0.66

0.37

0.58

0.65

67.28

0.42

0.69

0.59

(107.30)

17.98

0.59

0.88

0.88

(23.33)

151.40

0.15

0.86

0.44

(247.60)

120.40

(222.00)

0.52

0.31

0.54

0.32

0.81

0.80

0.89

0.32

0.62

0.28

0.45

0.48

0.59

0.98

0.88

0.80

0.96

0.89

0.97

0.29

0.14

0.16

0.28
392 


\section{Panel A. Initial take-up June 2017}

Took at least one account

If offered multiple accounts: took more than 1 account

If offered multiple boxes: took 3 boxes

Observations

\section{Panel B1. Lockbox check visit in December 2017}

Reported at least 1 deposit since receiving box(es)

Reported at least 5 deposits since receiving box(es)

Total value of deposits (monthly average)

Number of deposits (monthly average)

Total value of withdrawals (monthly average)

Number of withdrawals (monthly average)

Balance

Observations
(2)

(1)

Box groups

\begin{tabular}{cc}
\hline One box $\begin{array}{c}\text { Multiple } \\
\text { boxes }\end{array}$ \\
\hline
\end{tabular}

0.99

-

$-$

160
(3)

Mobile money

\begin{tabular}{cc}
\hline $\begin{array}{c}\text { One } \\
\text { account }\end{array}$ & $\begin{array}{c}\text { Multiple } \\
\text { accounts }\end{array}$ \\
\hline 1.00 & 0.98 \\
- & 0.29 \\
- & - \\
160 & 160
\end{tabular}

Panel B2. Telecom administrative data (July 2017 - April 2018)

$\begin{array}{ll}0.94 & 0.97\end{array}$

$0.91 \quad 0.92$

$23.39 \quad 31.30$

(30.58) (36.18)

$9.83 \quad 14.20$

(10.74) (13.45)

$16.46 \quad 23.96$

(24.95) (31.37)

$1.48 \quad 2.61$

(3.52) (4.32)

$15.87 \quad 14.70$

(34.26) (30.97)

$121 \quad 120$

Made at least 1 deposit

Made at least 5 deposits

$\begin{array}{ll}0.79 & 0.67\end{array}$

$0.70 \quad 0.49$

Total value of deposits (monthly average)

$8.72 \quad 9.34$

(12.25) (15.56)

$1.11 \quad 1.06$

(1.36) (1.42)

$9.09 \quad 10.34$

(13.55) (18.13)

$1.18 \quad 1.19$

(1.49) (1.75)

$3.21 \quad 2.79$

(5.42) (5.40)

$160 \quad 160$

Observations

Notes: See text for discussion of data sources. Means are presented, with standard deviations in parentheses. 


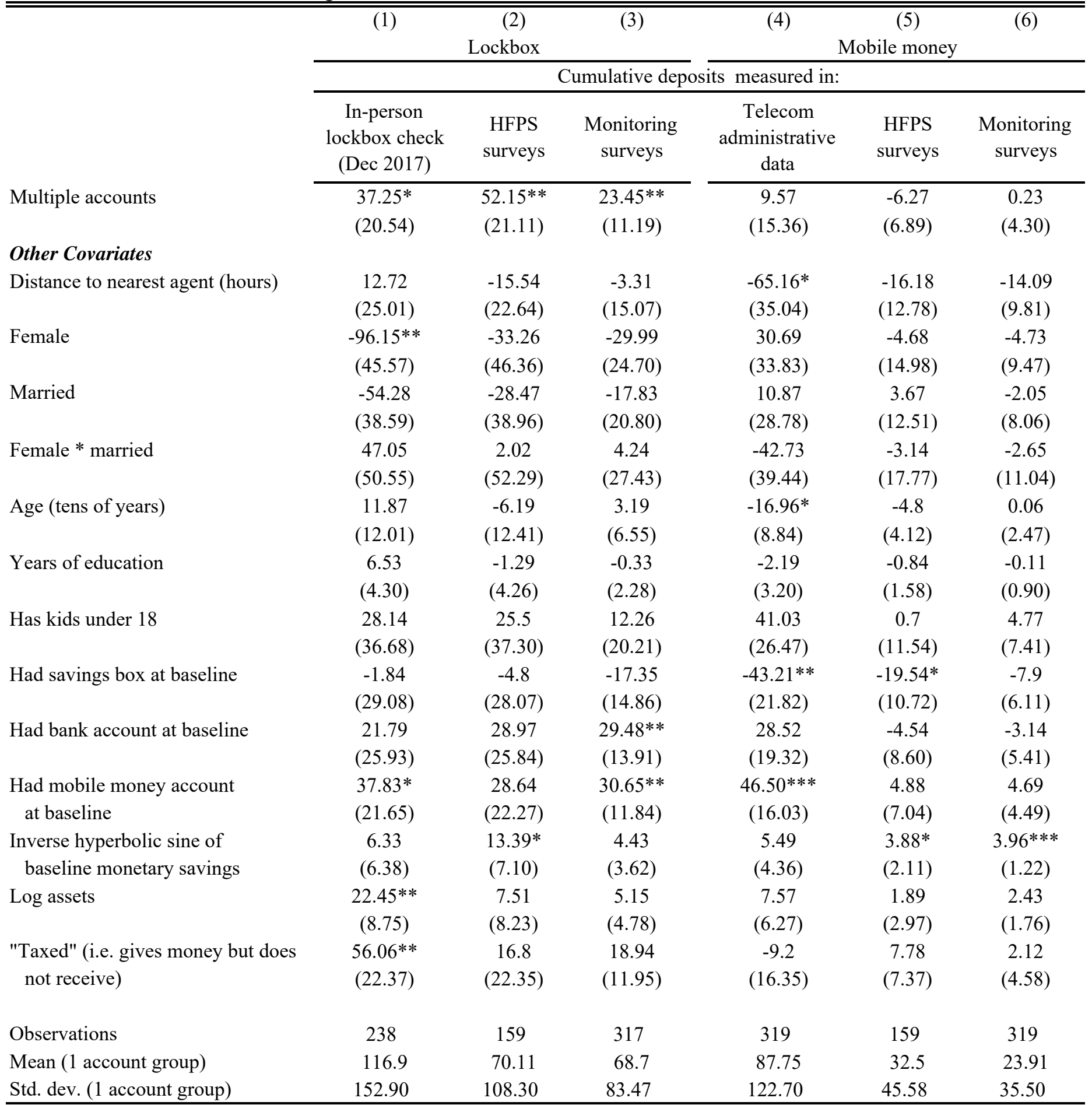

Notes: Values are in USD and winsorized at 5\%. Columns 1-3 are for the lockbox groups only and Columns 4-6 are for the mobile money groups only. See text for discussion of data sources. Deposits are winsorized at $5 \%$. Standard errors in parentheses.

$*, * *$, and $* * *$ indicate significance at $10 \%, 5 \%$, and $1 \%$ respectively. 


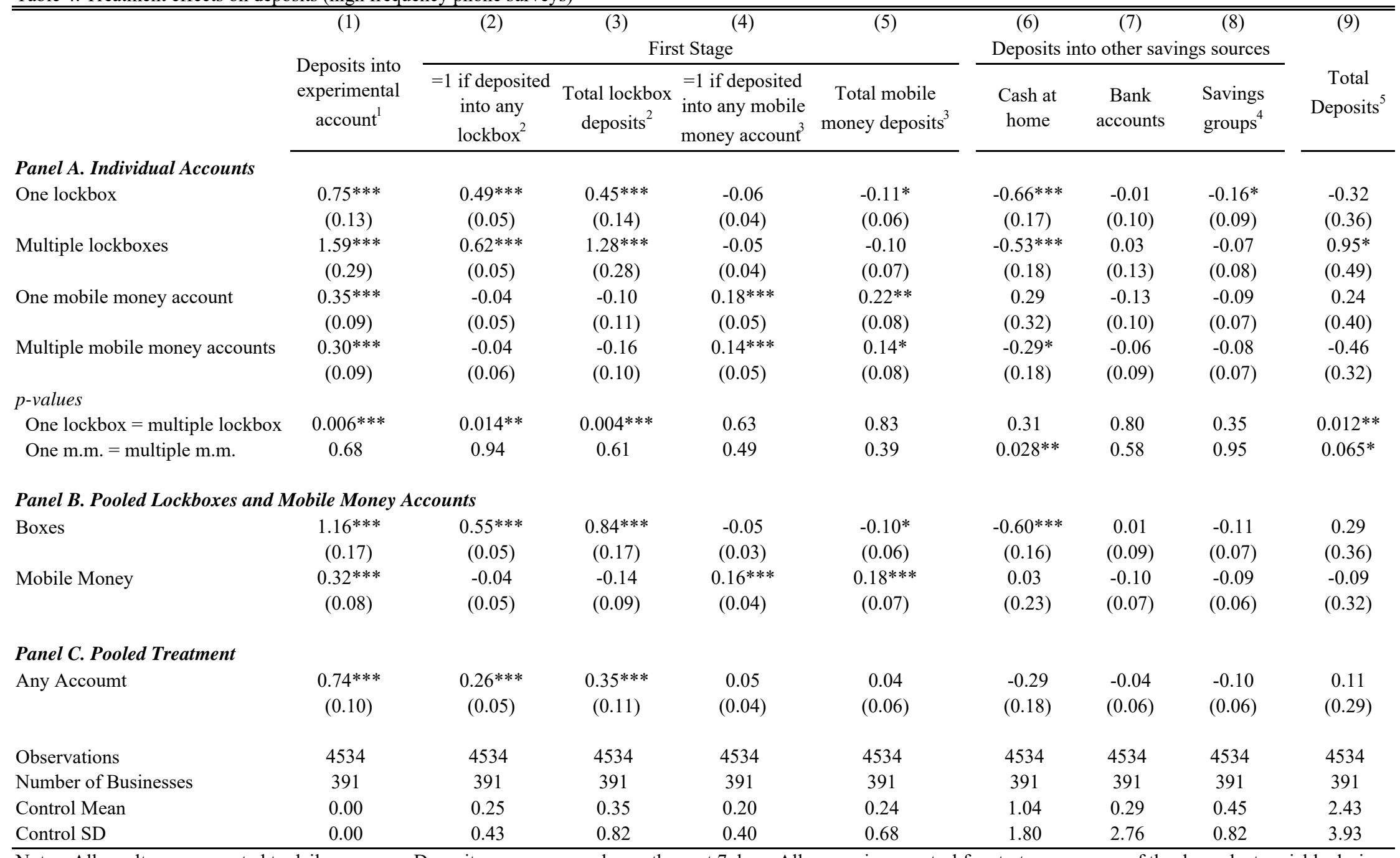

Notes: All results are converted to daily averages. Deposits were measured over the past 7 days. All regressions control for strata, a measure of the dependent variable during the intake survey (where applicable), date fixed effects, assignment to high frequency group and are probability weighted (see in the text for details). All monetary variables are expressed in USD and are winsorized at $5 \%$.

Standard errors clustered at individual level in parentheses. $*$, **, and $* * *$ indicate significance at $10 \%, 5 \%$, and $1 \%$ respectively.

${ }^{1}$ Experimental account is the mobile money or box, depending on the treatment group, and is mechanically 0 for the control group.

${ }^{2}$ Includes non-project lockbox

${ }^{3}$ Includes non-project mobile money accounts

${ }^{4}$ Savings groups include VSLAs and ROSCAs.

${ }^{5}$ Total deposits is the sum of the other columns, as well as other less common types of savings (such as safekeeping with shopkeepers or friends). 


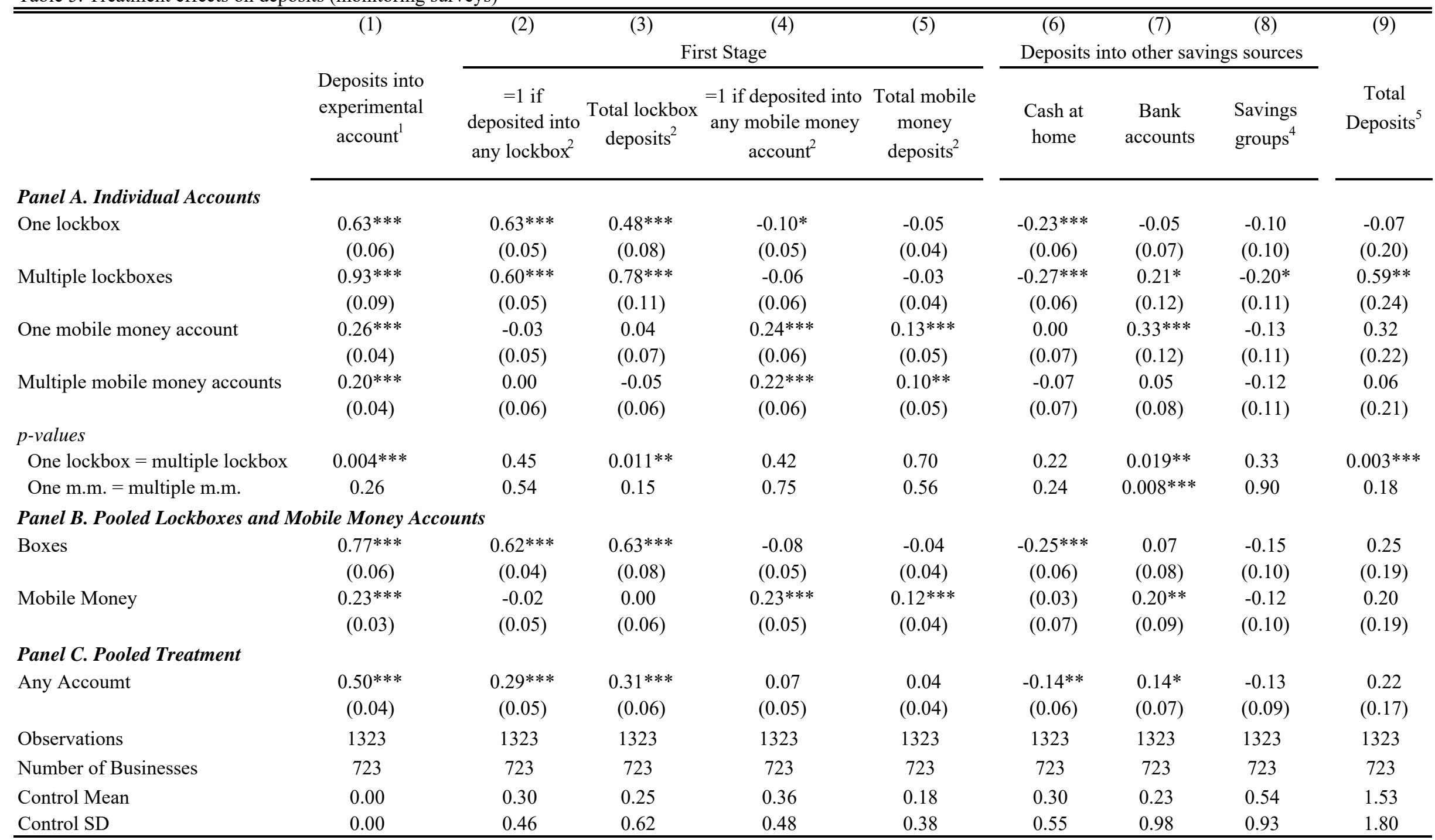

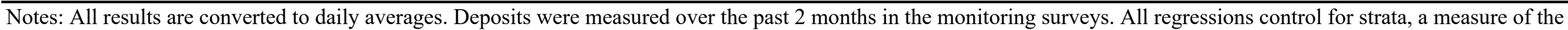

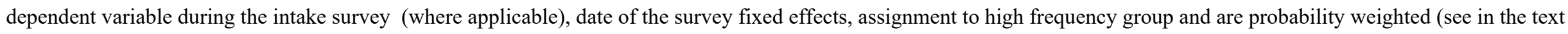
for details). All monetary variables are expressed in USD and are winsorized at 5\%.

Standard errors clustered at individual level in parentheses. *,**, and *** indicate significance at $10 \%, 5 \%$, and $1 \%$ respectively.

${ }^{1}$ Experimental account is the mobile money or box, depending on the treatment group, and is mechanically 0 for the control group.

${ }^{2}$ Includes non-project lockbox and/or mobile money accounts.

${ }^{3}$ Savings groups include VSLAs and ROSCAs.

${ }^{4}$ Total deposits is the sum of the other columns, as well as other less common types of savings (such as safekeeping with shopkeepers or friends). 
Table 6. Treatment effects on labor supply and business outcomes (high frequency phone surveys)

\begin{tabular}{|c|c|c|c|c|c|c|c|c|c|c|}
\hline & (1) & (2) & (3) & (4) & $(5)$ & (6) & (7) & $(8)$ & (9) & $(10)$ \\
\hline & \multicolumn{6}{|c|}{ Labor Supply } & \multicolumn{2}{|c|}{ Business outcomes } & \multicolumn{2}{|c|}{ Credit Taken ${ }^{1}$} \\
\hline & \multicolumn{2}{|c|}{ Main Business } & \multicolumn{2}{|c|}{ Other occupations } & \multicolumn{2}{|c|}{ Farming } & & & & \\
\hline & $\begin{array}{c}=1 \text { if } \\
\text { worked }\end{array}$ & Hours & $=1$ if worked & Hours & $\begin{array}{c}=1 \text { if } \\
\text { farmed }\end{array}$ & Hours & Profits & Revenues & $\begin{array}{l}\text { look out } \\
\text { loan }\end{array}$ & Value \\
\hline \multicolumn{11}{|l|}{ Panel A. Individual Accounts } \\
\hline One lockbox & $\begin{array}{c}-0.08 * * \\
(0.03)\end{array}$ & $\begin{array}{c}-0.83 * * \\
(0.42)\end{array}$ & $\begin{array}{l}-0.02 \\
(0.04)\end{array}$ & $\begin{array}{l}-0.90 \\
(0.92)\end{array}$ & $\begin{array}{c}0.02 \\
(0.02)\end{array}$ & $\begin{array}{l}0.20^{*} \\
(0.11)\end{array}$ & $\begin{array}{l}-0.37 \\
(0.33)\end{array}$ & $\begin{array}{l}-0.54 \\
(0.96)\end{array}$ & $\begin{array}{l}-0.03 \\
(0.05)\end{array}$ & $\begin{array}{c}0.41 \\
(0.45)\end{array}$ \\
\hline Multiple lockboxes & $\begin{array}{c}0.00 \\
(0.03)\end{array}$ & $\begin{array}{l}0.13 \\
(0.36)\end{array}$ & $\begin{array}{l}0.05 \\
(0.05)\end{array}$ & $\begin{array}{l}2.53 \\
(2.05)\end{array}$ & $\begin{array}{c}0.08 * * * \\
(0.03)\end{array}$ & $\begin{array}{c}0.51 * * * \\
(0.19)\end{array}$ & $\begin{array}{l}-0.30 \\
(0.39)\end{array}$ & $\begin{array}{l}-0.64 \\
(1.12)\end{array}$ & $\begin{array}{c}0.00 \\
(0.05)\end{array}$ & $\begin{array}{l}-0.07 \\
(0.36)\end{array}$ \\
\hline One mobile money account & $\begin{array}{l}-0.05 \\
(0.03)\end{array}$ & $\begin{array}{l}-0.55 \\
(0.42)\end{array}$ & $\begin{array}{c}0.03 \\
(0.04)\end{array}$ & $\begin{array}{l}-1.23 \\
(0.82)\end{array}$ & $\begin{array}{c}0.09 * * * \\
(0.03)\end{array}$ & $\begin{array}{c}0.56 * * * \\
(0.17)\end{array}$ & $\begin{array}{l}-0.42 \\
(0.34)\end{array}$ & $\begin{array}{l}-0.13 \\
(1.07)\end{array}$ & $\begin{array}{l}0.04 \\
(0.05)\end{array}$ & $\begin{array}{c}0.13 \\
(0.33)\end{array}$ \\
\hline Multiple mobile money accounts & $\begin{array}{l}-0.06 \\
(0.04)\end{array}$ & $\begin{array}{l}0.09 \\
(0.58)\end{array}$ & $\begin{array}{l}0.00 \\
(0.04)\end{array}$ & $\begin{array}{l}-0.46 \\
(0.82)\end{array}$ & $\begin{array}{c}0.00 \\
(0.02)\end{array}$ & $\begin{array}{l}0.13 \\
(0.11)\end{array}$ & $\begin{array}{l}-0.58 * \\
(0.33)\end{array}$ & $\begin{array}{l}0.34 \\
(1.15)\end{array}$ & $\begin{array}{l}-0.05 \\
(0.05)\end{array}$ & $\begin{array}{l}-0.23 \\
(0.34)\end{array}$ \\
\hline \multicolumn{11}{|c|}{ Panel B. Pooled Lockboxes and Mobile Money Accounts } \\
\hline Boxes & $\begin{array}{l}-0.04 \\
(0.03)\end{array}$ & $\begin{array}{l}-0.37 \\
(0.33)\end{array}$ & $\begin{array}{c}0.02 \\
(0.04)\end{array}$ & $\begin{array}{c}0.84 \\
(1.29)\end{array}$ & $\begin{array}{c}0.05 * * * \\
(0.02)\end{array}$ & $\begin{array}{c}0.35 * * * \\
(0.12)\end{array}$ & $\begin{array}{l}-0.34 \\
(0.30)\end{array}$ & $\begin{array}{l}-0.59 \\
(0.85)\end{array}$ & $\begin{array}{l}-0.02 \\
(0.04)\end{array}$ & $\begin{array}{c}0.17 \\
(0.33)\end{array}$ \\
\hline Mobile Money & $\begin{array}{l}-0.06^{*} \\
(0.03)\end{array}$ & $\begin{array}{l}-0.28 \\
(0.40)\end{array}$ & $\begin{array}{c}0.02 \\
(0.03)\end{array}$ & $\begin{array}{l}-0.88 \\
(0.76)\end{array}$ & $\begin{array}{c}0.05 * * \\
(0.02)\end{array}$ & $\begin{array}{c}0.36^{* * * *} \\
(0.12)\end{array}$ & $\begin{array}{l}-0.49 * \\
(0.29)\end{array}$ & $\begin{array}{c}0.08 \\
(0.91)\end{array}$ & $\begin{array}{c}0.00 \\
(0.04)\end{array}$ & $\begin{array}{l}-0.03 \\
(0.29)\end{array}$ \\
\hline \multicolumn{11}{|l|}{ Panel C. Pooled Treatment } \\
\hline Any Accoumt & $\begin{array}{l}-0.05 * \\
(0.03)\end{array}$ & $\begin{array}{l}-0.32 \\
(0.31)\end{array}$ & $\begin{array}{c}0.02 \\
(0.03)\end{array}$ & $\begin{array}{l}-0.04 \\
(0.89)\end{array}$ & $\begin{array}{c}0.05 * * * \\
(0.02)\end{array}$ & $\begin{array}{c}0.36 * * * \\
(0.10)\end{array}$ & $\begin{array}{l}-0.41 \\
(0.26)\end{array}$ & $\begin{array}{l}-0.26 \\
(0.75)\end{array}$ & $\begin{array}{l}-0.01 \\
(0.04)\end{array}$ & $\begin{array}{c}0.07 \\
(0.27)\end{array}$ \\
\hline Observations & 31472 & 31471 & 4605 & 4605 & 4541 & 4541 & 26086 & 26256 & 4544 & 4632 \\
\hline Number of Businesses & 392 & 392 & 391 & 391 & 391 & 391 & 392 & 392 & 391 & 391 \\
\hline Control Mean & 0.81 & 8.21 & 0.18 & 1.78 & 0.06 & 0.20 & 3.37 & 11.86 & 0.33 & 0.97 \\
\hline Control SD & 0.39 & 4.67 & 0.38 & 7.23 & 0.23 & 1.20 & 3.59 & 15.78 & 0.47 & 4.24 \\
\hline
\end{tabular}

Notes: The main business outcomes (in Columns 1-2 and 7-8) were measured at the daily level. Labor supply in secondary occupations, farming, credit

(Columns 3-4, 5-6 and 9-10) are presented over a week since this is how it was measured in the surveys and it is the only way to present the extensive margin. There are fewer observations for profits/revenues (compared to main business) because this was only asked for the past 4 days in the second round of HFPS

(labor supply was asked for a 7 day recall). All regressions control for strata, a measure of the dependent variable during the intake survey (where applicable), date fixed effects, assignment to high frequency group and are probability weighted (see in the text for details). All monetary variables are expressed in USD and are winsorized at $5 \%$.

Standard errors clustered at individual level in parentheses. * $* *$, and $* * *$ indicate significance at $10 \%, 5 \%$, and $1 \%$ respectively.

${ }^{1}$ Credit include digital loans and loans from VSLAs, ROSCAs, banks, microfinance institutions, and moneylenders. 
Table 7. Treatment effects on labor supply and business outcomes (monitoring surveys)

\begin{tabular}{|c|c|c|c|c|c|c|c|c|c|c|c|}
\hline & $(1)$ & $(2)$ & (3) & (4) & $(5)$ & (6) & (7) & $(8)$ & (9) & (10) & $\overline{(11)}$ \\
\hline & \multicolumn{6}{|c|}{ Labor Supply } & \multicolumn{2}{|c|}{ Business outcomes } & \multicolumn{2}{|c|}{ Credit Taken ${ }^{1}$} & \multirow{3}{*}{$\begin{array}{l}\text { Credit to } \\
\text { Customers }\end{array}$} \\
\hline & \multicolumn{2}{|c|}{ Main Business } & \multicolumn{2}{|c|}{ Other occupations } & \multicolumn{2}{|c|}{ Farming } & & & & & \\
\hline & $\begin{array}{c}=1 \text { if } \\
\text { worked }\end{array}$ & Hours & $=1$ if worked & Hours & $\begin{array}{c}=1 \text { if } \\
\text { farmed }\end{array}$ & Hours & Profits & Revenues & $\begin{array}{l}\text { Took out } \\
\text { loan }\end{array}$ & Value & \\
\hline \multicolumn{12}{|l|}{ Panel A. Individual Accounts } \\
\hline One lockbox & $\begin{array}{l}-0.04 \\
(0.03)\end{array}$ & $\begin{array}{l}-0.26 \\
(0.40)\end{array}$ & $\begin{array}{l}-0.02 \\
(0.03)\end{array}$ & $\begin{array}{l}-0.62 \\
(0.79)\end{array}$ & $\begin{array}{c}0.05 \\
(0.05)\end{array}$ & $\begin{array}{c}0.81 \\
(0.59)\end{array}$ & $\begin{array}{l}-0.42 \\
(0.37)\end{array}$ & $\begin{array}{l}-2.21^{*} \\
(1.30)\end{array}$ & $\begin{array}{c}0.01 \\
(0.05)\end{array}$ & $\begin{array}{c}1.29 \\
(1.14)\end{array}$ & $\begin{array}{l}0.14 * \\
(0.08)\end{array}$ \\
\hline Multiple lockboxes & $\begin{array}{l}-0.01 \\
(0.03)\end{array}$ & $\begin{array}{l}-0.29 \\
(0.41)\end{array}$ & $\begin{array}{l}0.09 * * \\
(0.04)\end{array}$ & $\begin{array}{c}1.51 \\
(1.23)\end{array}$ & $\begin{array}{l}0.09 \\
(0.06)\end{array}$ & $\begin{array}{l}1.64 * * \\
(0.69)\end{array}$ & $\begin{array}{l}-0.16 \\
(0.36)\end{array}$ & $\begin{array}{l}-0.95 \\
(1.19)\end{array}$ & $\begin{array}{l}-0.03 \\
(0.06)\end{array}$ & $\begin{array}{l}1.43 \\
(1.81)\end{array}$ & $\begin{array}{l}0.17^{*} \\
(0.09)\end{array}$ \\
\hline One mobile money account & $\begin{array}{l}-0.06 \\
(0.04)\end{array}$ & $\begin{array}{c}-0.83^{*} \\
(0.48)\end{array}$ & $\begin{array}{c}0.04 \\
(0.04)\end{array}$ & $\begin{array}{c}1.20 \\
(1.05)\end{array}$ & $\begin{array}{l}0.11^{*} \\
(0.06)\end{array}$ & $\begin{array}{c}1.92 * * * \\
(0.66)\end{array}$ & $\begin{array}{l}-0.44 \\
(0.35)\end{array}$ & $\begin{array}{l}-1.84 \\
(1.23)\end{array}$ & $\begin{array}{l}0.02 \\
(0.05)\end{array}$ & $\begin{array}{l}1.40 \\
(1.31)\end{array}$ & $\begin{array}{l}0.13^{*} \\
(0.07)\end{array}$ \\
\hline Multiple mobile money accounts & $\begin{array}{l}-0.03 \\
(0.04)\end{array}$ & $\begin{array}{l}-0.49 \\
(0.40)\end{array}$ & $\begin{array}{c}0.02 \\
(0.03)\end{array}$ & $\begin{array}{c}0.55 \\
(0.80)\end{array}$ & $\begin{array}{l}-0.03 \\
(0.05)\end{array}$ & $\begin{array}{l}0.89 \\
(0.72)\end{array}$ & $\begin{array}{l}-0.47 \\
(0.35)\end{array}$ & $\begin{array}{l}-1.31 \\
(1.26)\end{array}$ & $\begin{array}{l}0.00 \\
(0.05)\end{array}$ & $\begin{array}{l}-0.10 \\
(1.22)\end{array}$ & $\begin{array}{l}0.10 \\
(0.08)\end{array}$ \\
\hline \multicolumn{12}{|c|}{ Panel B. Pooled Lockboxes and Mobile Money Accounts } \\
\hline Boxes & $\begin{array}{l}-0.03 \\
(0.03)\end{array}$ & $\begin{array}{l}-0.27 \\
(0.35)\end{array}$ & $\begin{array}{c}0.03 \\
(0.03)\end{array}$ & $\begin{array}{c}0.42 \\
(0.85)\end{array}$ & $\begin{array}{c}0.07 \\
(0.05)\end{array}$ & $\begin{array}{l}1.21 * * \\
(0.51)\end{array}$ & $\begin{array}{l}-0.29 \\
(0.31)\end{array}$ & $\begin{array}{l}-1.60 \\
(1.08)\end{array}$ & $\begin{array}{c}0.01 \\
(0.05)\end{array}$ & $\begin{array}{c}1.29 \\
(1.14)\end{array}$ & $\begin{array}{l}0.14 * \\
(0.08)\end{array}$ \\
\hline Mobile Money & $\begin{array}{l}-0.05 \\
(0.03)\end{array}$ & $\begin{array}{c}-0.67 * \\
(0.37)\end{array}$ & $\begin{array}{c}0.03 \\
(0.03)\end{array}$ & $\begin{array}{c}0.88 \\
(0.73)\end{array}$ & $\begin{array}{c}0.04 \\
(0.05)\end{array}$ & $\begin{array}{c}1.44 * * * \\
(0.55)\end{array}$ & $\begin{array}{l}-0.46 \\
(0.31)\end{array}$ & $\begin{array}{l}-1.62 \\
(1.09)\end{array}$ & $\begin{array}{c}0.01 \\
(0.05)\end{array}$ & $\begin{array}{c}0.71 \\
(1.09)\end{array}$ & $\begin{array}{l}0.11^{*} \\
(0.06)\end{array}$ \\
\hline \multicolumn{12}{|l|}{ Panel C. Pooled Treatment } \\
\hline Any Accoumt & $\begin{array}{l}-0.04 \\
(0.03)\end{array}$ & $\begin{array}{l}-0.47 \\
(0.32)\end{array}$ & $\begin{array}{c}0.03 \\
(0.03)\end{array}$ & $\begin{array}{c}0.65 \\
(0.63)\end{array}$ & $\begin{array}{c}0.06 \\
(0.04)\end{array}$ & $\begin{array}{c}1.33 * * * \\
(0.46)\end{array}$ & $\begin{array}{l}-0.38 \\
(0.29)\end{array}$ & $\begin{array}{l}-1.61 \\
(1.01)\end{array}$ & $\begin{array}{c}0.00 \\
(0.04)\end{array}$ & $\begin{array}{c}1.03 \\
(0.99)\end{array}$ & $\begin{array}{c}0.13 * * \\
(0.06)\end{array}$ \\
\hline Observations & 9261 & 9261 & 1321 & 1321 & 1323 & 1321 & 1308 & 1317 & 1323 & 1323 & 1317 \\
\hline Number of Businesses & 723 & 723 & 723 & 723 & 723 & 723 & 721 & 722 & 723 & 723 & 719 \\
\hline Control Mean & 0.74 & 7.35 & 0.13 & 1.82 & 0.24 & 2.05 & 3.02 & 10.07 & 0.67 & 5.57 & 0.23 \\
\hline Control SD & 0.44 & 5.08 & 0.33 & 8.34 & 0.43 & 5.76 & 3.37 & 13.51 & 0.47 & 10.71 & 0.54 \\
\hline \multicolumn{12}{|c|}{$\begin{array}{l}\text { Notes: Labor supply in the main business (columns 1-2) was measured at the daily level (for } 4 \text { days prior to the survey date), other variables were measured over the past } \\
\text { week. Labor supply in secondary occupations, farming, credit (Columns } 3-4,5-6 \text { and } 9-10 \text { ) are presented over a week since this is how it was measured in the surveys and it is } \\
\text { the only way to present the extensive margin. Profits and revenues (columns } 7-8 \text { ) are measured at the weekly level, but are converted to daily averages. Credit to customers } \\
\text { (column } 11 \text { ) is measured over a month but converted to daily averages. All regressions control for strata, a measure of the dependent variable during the intake survey (where } \\
\text { applicable), date of the survey fixed effects, assignment to high frequency group and are probability weighted (see in the text for details). All monetary variables are } \\
\text { expressed in USD and are winsorized at } 5 \% \text {. } \\
\text { Standard errors clustered at individual level in parentheses. } *, * * \text {, and } * * * \text { indicate significance at } 10 \%, 5 \% \text {, and } 1 \% \text { respectively. }\end{array}$} \\
\hline
\end{tabular}




\begin{tabular}{|c|c|c|c|c|c|}
\hline & $\begin{array}{c}(1) \\
\text { Staple } \\
\text { foods }\end{array}$ & $\begin{array}{c}(2) \\
\text { Personal } \\
\text { expenses }\end{array}$ & $\begin{array}{c}(3) \\
\text { Household } \\
\text { expenses }\end{array}$ & $\begin{array}{c}(4) \\
\text { School } \\
\text { expenses }\end{array}$ & $\begin{array}{c}(5) \\
\text { Total }\end{array}$ \\
\hline \multicolumn{6}{|l|}{ Panel A. Individual Accounts } \\
\hline One lockbox & $\begin{array}{c}0.07 \\
(0.12)\end{array}$ & $\begin{array}{c}0.05 \\
(0.07)\end{array}$ & $\begin{array}{c}0.05 \\
(0.08)\end{array}$ & $\begin{array}{c}0.13^{* * *} \\
(0.05)\end{array}$ & $\begin{array}{c}0.38 \\
(0.36)\end{array}$ \\
\hline Multiple lockboxes & $\begin{array}{c}0.05 \\
(0.13)\end{array}$ & $\begin{array}{c}0.00 \\
(0.08)\end{array}$ & $\begin{array}{c}0.11 \\
(0.10)\end{array}$ & $\begin{array}{c}0.16^{* * *} \\
(0.06)\end{array}$ & $\begin{array}{c}0.53 \\
(0.43)\end{array}$ \\
\hline One mobile money account & $\begin{array}{c}0.03 \\
(0.14)\end{array}$ & $\begin{array}{c}0.03 \\
(0.08)\end{array}$ & $\begin{array}{l}0.17^{*} \\
(0.10)\end{array}$ & $\begin{array}{l}0.13 * * \\
(0.06)\end{array}$ & $\begin{array}{c}0.57 \\
(0.44)\end{array}$ \\
\hline Multiple mobile money accounts & $\begin{array}{l}-0.03 \\
(0.12)\end{array}$ & $\begin{array}{l}-0.04 \\
(0.07)\end{array}$ & $\begin{array}{l}-0.05 \\
(0.07)\end{array}$ & $\begin{array}{c}0.01 \\
(0.04)\end{array}$ & $\begin{array}{l}-0.22 \\
(0.34)\end{array}$ \\
\hline \multicolumn{6}{|c|}{ Panel B. Pooled Lockboxes and Mobile Money Accounts } \\
\hline Boxes & $\begin{array}{c}0.06 \\
(0.11)\end{array}$ & $\begin{array}{c}0.03 \\
(0.06)\end{array}$ & $\begin{array}{c}0.08 \\
(0.07)\end{array}$ & $\begin{array}{c}0.14 * * * \\
(0.04)\end{array}$ & $\begin{array}{c}0.45 \\
(0.32)\end{array}$ \\
\hline Mobile Money & $\begin{array}{c}0.00 \\
(0.12)\end{array}$ & $\begin{array}{c}0.00 \\
(0.06)\end{array}$ & $\begin{array}{c}0.07 \\
(0.07)\end{array}$ & $\begin{array}{l}0.08^{*} \\
(0.04)\end{array}$ & $\begin{array}{c}0.21 \\
(0.34)\end{array}$ \\
\hline \multicolumn{6}{|l|}{ Panel C. Pooled Treatment } \\
\hline Any Account & $\begin{array}{c}0.03 \\
(0.10)\end{array}$ & $\begin{array}{c}0.01 \\
(0.06)\end{array}$ & $\begin{array}{c}0.07 \\
(0.06)\end{array}$ & $\begin{array}{c}0.11 * * * \\
(0.04)\end{array}$ & $\begin{array}{c}0.33 \\
(0.29)\end{array}$ \\
\hline Observations & 4530 & 4544 & 4544 & 4544 & 4544 \\
\hline Number of Businesses & 391 & 391 & 391 & 391 & 391 \\
\hline Control Mean & 1.47 & 0.50 & 0.54 & 0.22 & 3.93 \\
\hline Control SD & 0.90 & 0.59 & 0.91 & 0.58 & 2.87 \\
\hline \multicolumn{6}{|c|}{$\begin{array}{l}\text { Note: Expenditures are measured over the } 7 \text { days prior to the survey and are expressed in daily } \\
\text { values. Total expenditures include the other columns in addition to other categories not shown } \\
\text { here. All regressions control for strata, a measure of the dependent variable during the intake } \\
\text { survey (where applicable), date fixed effects, assignment to high frequency group and are } \\
\text { probability weighted (see in the text for details). All monetary variables are expressed in USD } \\
\text { and are winsorized at } 5 \% \text {. } \\
\text { Standard errors clustered at individual level in parentheses. } *, * * \text {, and } * * * \text { indicate significance } \\
\text { at } 10 \%, 5 \% \text {, and } 1 \% \text { respectively. }\end{array}$} \\
\hline
\end{tabular}




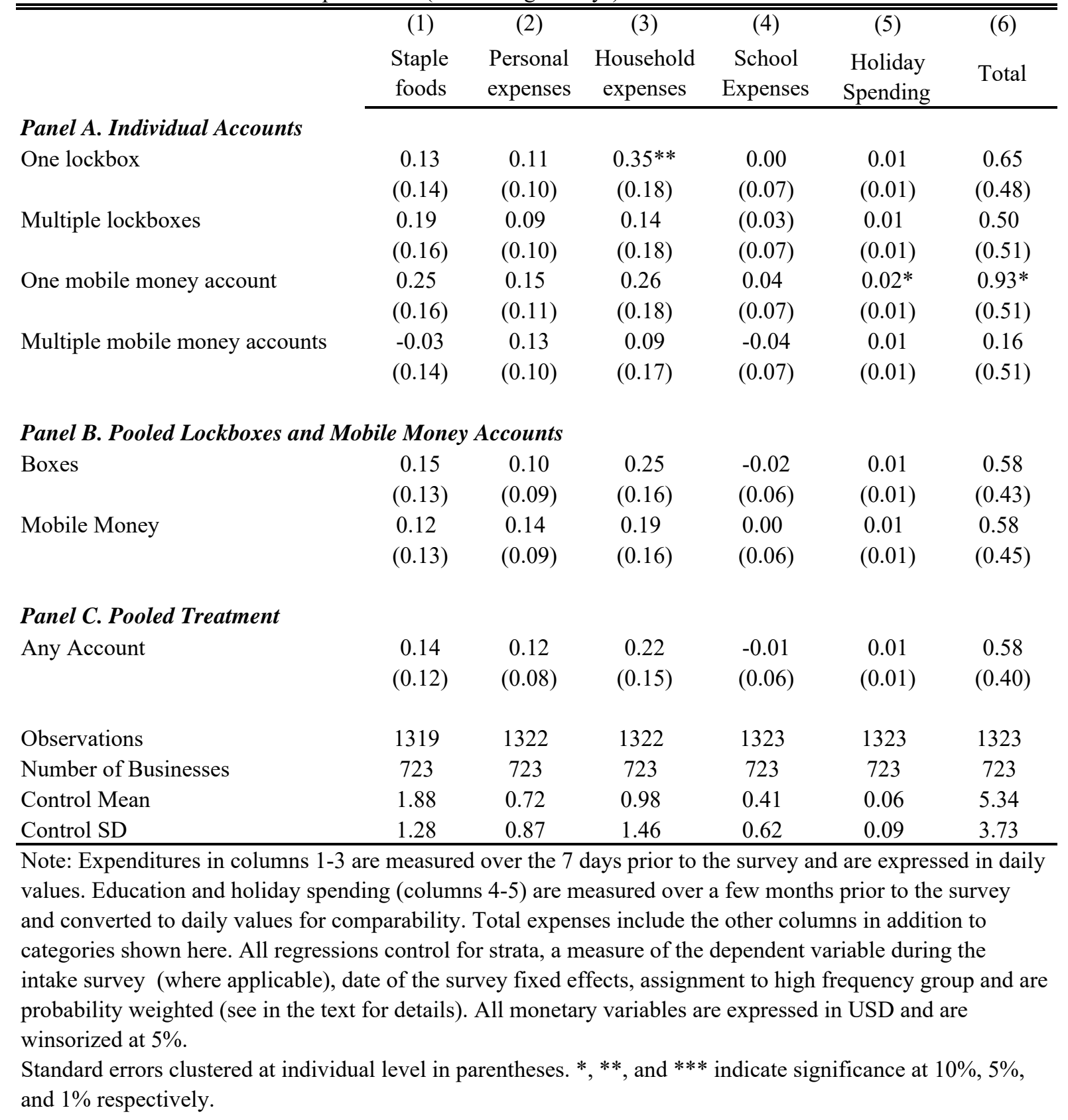




\section{Panel A. Survey conducted in September 2019}

Still uses the account

Reported at least 1 deposit in the last 1 month

Value of deposits in the past 1 month

Reported at least 1 withdrawal in the last 1 month

Value of withdrawals in the past 1 month

Has a non-zero balance in the account

Current Balance in the account
(1) (2)

Box groups

\begin{tabular}{cc}
\hline One box & $\begin{array}{c}\text { Multiple } \\
\text { boxes }\end{array}$ \\
\hline
\end{tabular}

0.69

0.60

14.40

(27.85)

0.37

5.89

$(15.42)$

0.53

31.57

(82.84)

35

0.56
0.44
18.87
$(39.89)$
0.33
6.95
$(15.57)$
0.51
13.63
$(27.59)$

39
(3)

(4)

Mobile money

\begin{tabular}{cc}
\hline $\begin{array}{c}\text { One } \\
\text { account }\end{array}$ & $\begin{array}{c}\text { Multiple } \\
\text { accounts }\end{array}$ \\
\hline & \\
0.39 & 0.44 \\
0.28 & 0.29 \\
9.27 & 9.02 \\
$(23.21)$ & $(23.34)$ \\
0.28 & 0.35 \\
6.49 & 7.76 \\
$(16.21)$ & $(19.34)$ \\
0.33 & 0.32 \\
7.28 & 9.87 \\
$(18.95)$ & $(24.25)$ \\
36 & 34
\end{tabular}

Observations

36

Panel B. Telecom administrative data (June 2018-August 2019)

Made at least 1 deposit after June 2018

Value of Deposits (monthly average)

Average Running Monthly Balance

\begin{tabular}{cccc}
- & - & 0.53 & 0.54 \\
- & - & 5.93 & 7.17 \\
- & - & $(12.40)$ & $(13.83)$ \\
- & - & 1.80 & 1.71 \\
- & - & $(3.32)$ & $(3.38)$ \\
& & 160 & 160 \\
\hline
\end{tabular}

Observations

Notes: In Panel A, data comes from the follow up phone survey conducted in September 2019 and collected information on usage in the past 1 month with a randomly selected 200 participants. About $72 \%$ of the random sample was reached. Attrition rates were not different between groups. In Panel B, data comes from the administrative Airtel data for all subjects in the mobile money group. The value and number of deposits and withdrawals are winsorized at $5 \%$ level. 


\section{Web Appendix A - Main Appendix Figures and Tables}

Saving for Multiple Financial Needs: Evidence from Lockboxes and Mobile
Money in Malawi

Shilpa Aggarwal, Valentina Brailovskaya and Jonathan Robinson 


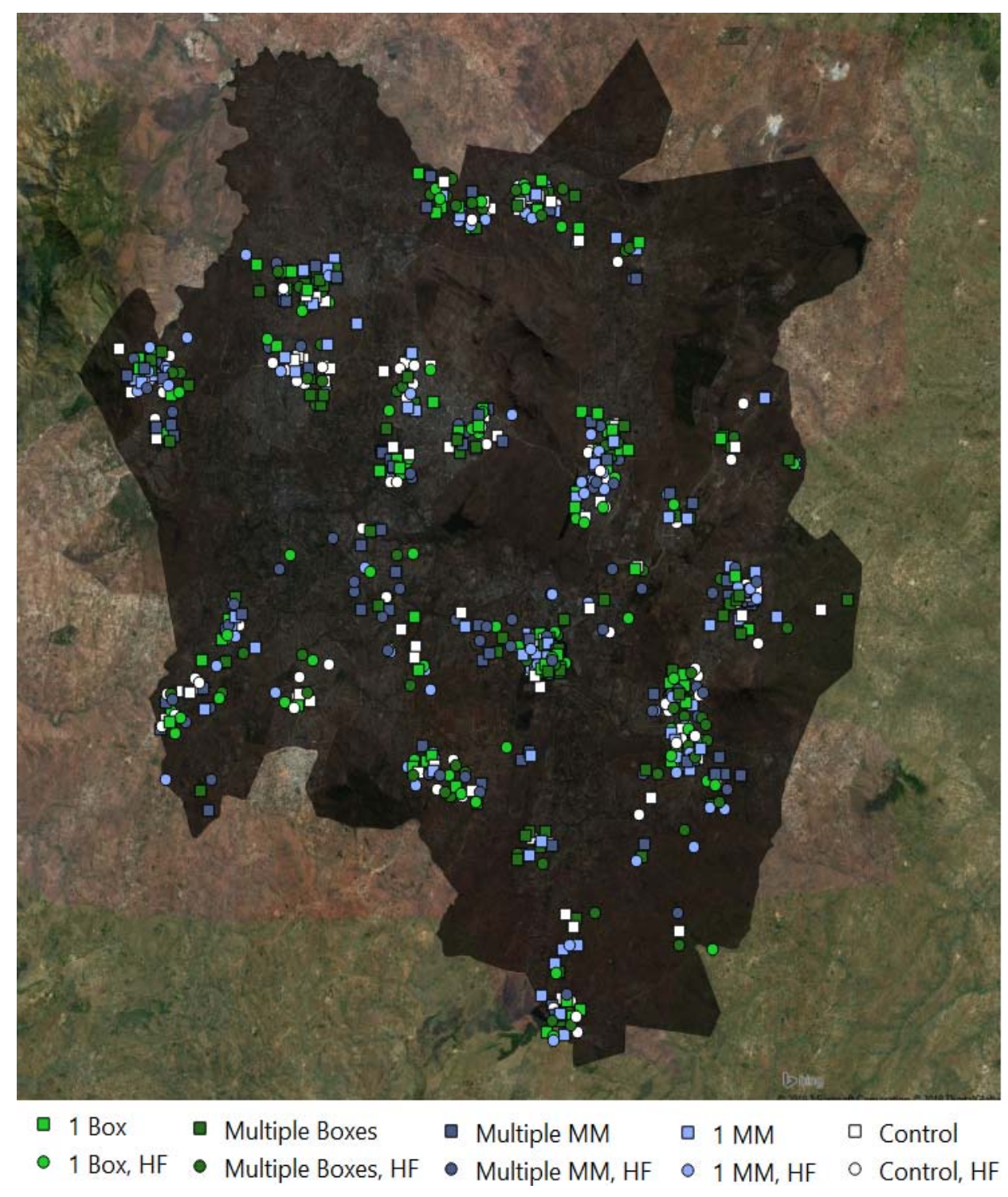

Notes: GPS coordinates are shown with added random noise for visibility. 


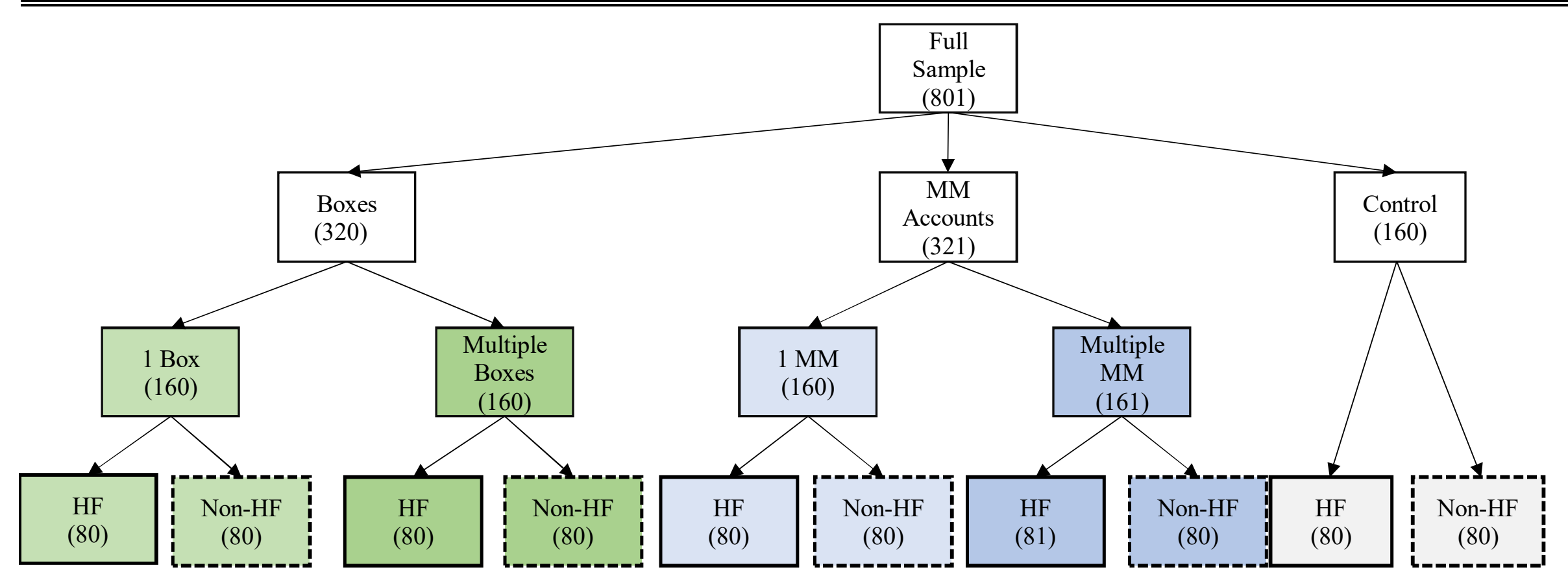




2017 Jan 2

May 
Panel A. Cumulative usage: Deposits and Withdrawals

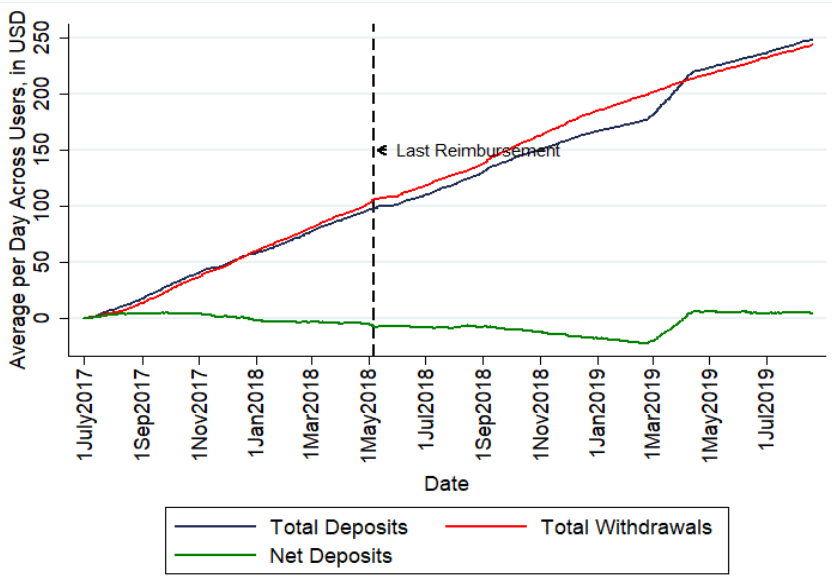

Panel B. Deposits and Withdrawals (averages per day, smoothed over 2 week period)

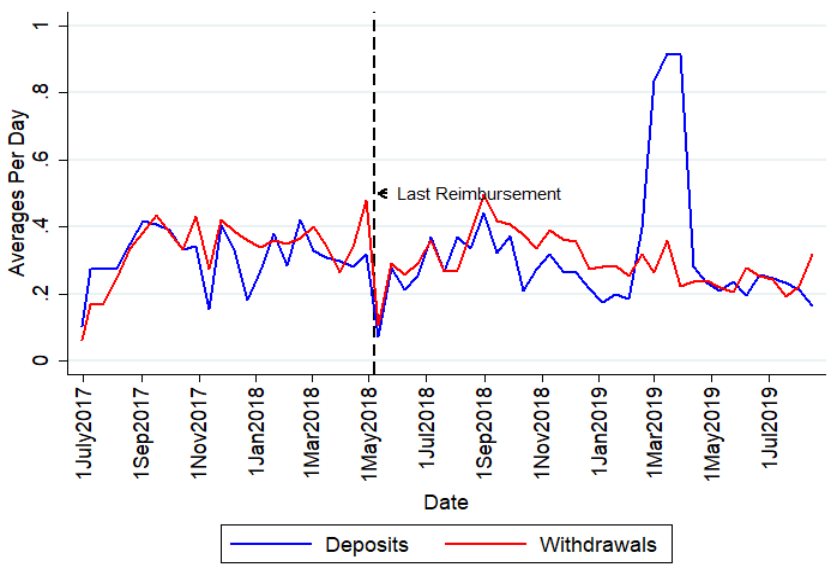

Panel C. Running Balance (averages per day, smoothed over 2 week period)

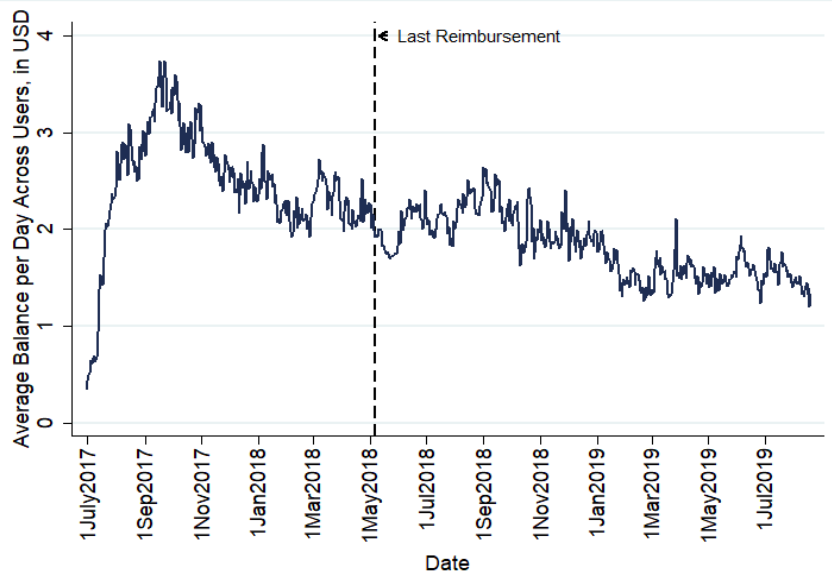

Notes: Data taken from administrative data from telecom company for mobile money accounts. Panel A shows average (per-person) cumulative deposits, withdrawals and net deposits (the difference) over time. Panel B shows average deposits and withdrawals during the study period. The values are daily averages collapsed into 2 week periods. Panel C shows running balances. The dashed line represents the date at which withdrawals stopped being reimbursed. 


\begin{tabular}{|c|c|c|c|c|c|}
\hline & (1) & (2) & (3) & (4) & $(5)$ \\
\hline & Savings goals listed at & \multicolumn{4}{|c|}{ Savings goals listed for treatment accounts } \\
\hline & $\begin{array}{l}\text { baseline (all } \\
\text { respondents) }\end{array}$ & $\begin{array}{l}\text { One } \\
\text { box }\end{array}$ & $\begin{array}{c}\text { Multiple } \\
\text { boxes }\end{array}$ & $\begin{array}{l}\text { One mobile } \\
\text { money }\end{array}$ & $\begin{array}{c}\text { Multiple } \\
\text { mobile money }\end{array}$ \\
\hline $\begin{array}{l}\text { Expand business, start new business, } \\
\text { or invest in inventory }\end{array}$ & 0.64 & 0.33 & 0.55 & 0.36 & 0.49 \\
\hline General consumption & 0.40 & 0.03 & 0.16 & 0.04 & 0.08 \\
\hline Emergencies & 0.40 & 0.11 & 0.43 & 0.18 & 0.21 \\
\hline Buying land & 0.18 & 0.25 & 0.28 & 0.26 & 0.22 \\
\hline Durable goods & 0.11 & 0.08 & 0.12 & 0.02 & 0.03 \\
\hline Children's education & 0.12 & 0.12 & 0.24 & 0.09 & 0.16 \\
\hline Home improvement & 0.07 & 0.04 & 0.13 & 0.04 & 0.04 \\
\hline Home expenses (rent, utilities, etc.) & 0.07 & 0.01 & 0.02 & 0.01 & 0.03 \\
\hline Agriculture & 0.04 & 0.04 & 0.08 & 0.01 & 0.03 \\
\hline Observations & 801 & 159 & 160 & 160 & 156 \\
\hline
\end{tabular}

Notes: The unit of observation is the individual. List is restricted to goals that were named by at least $5 \%$ of people at baseline. At baseline (in column 1), goals were measured by asking respondents about their current savings in various sources. If the amount saved in a source was non-zero, respondents were asked about what the savings were for. 


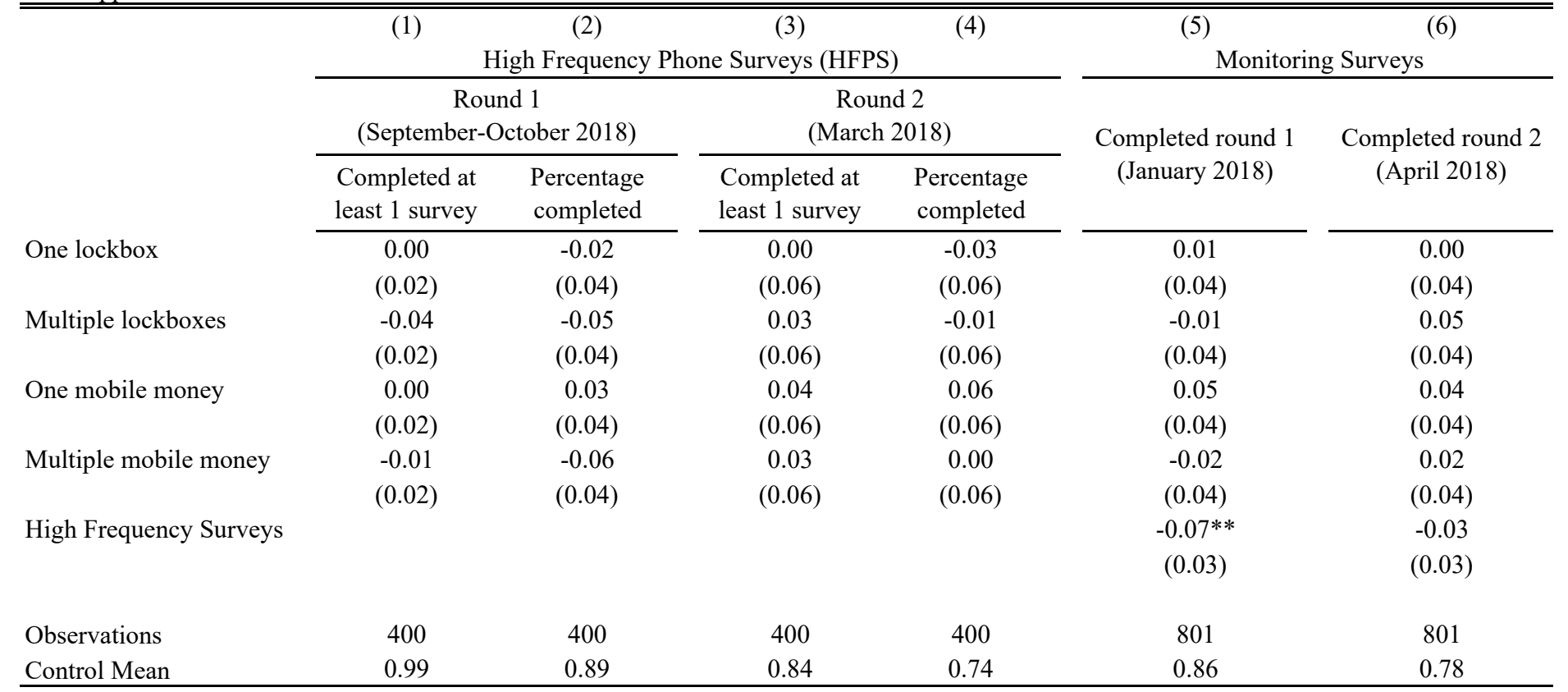

Notes: See text for discussion of surveys and Figure A3 for a project timeline. Standard errors in parentheses. $*, * *$, and $* * *$ indicate significance at $10 \%, 5 \%$, and $1 \%$ respectively. 
Web Appendix Table A3. Summary statistics and randomization check from intake survey

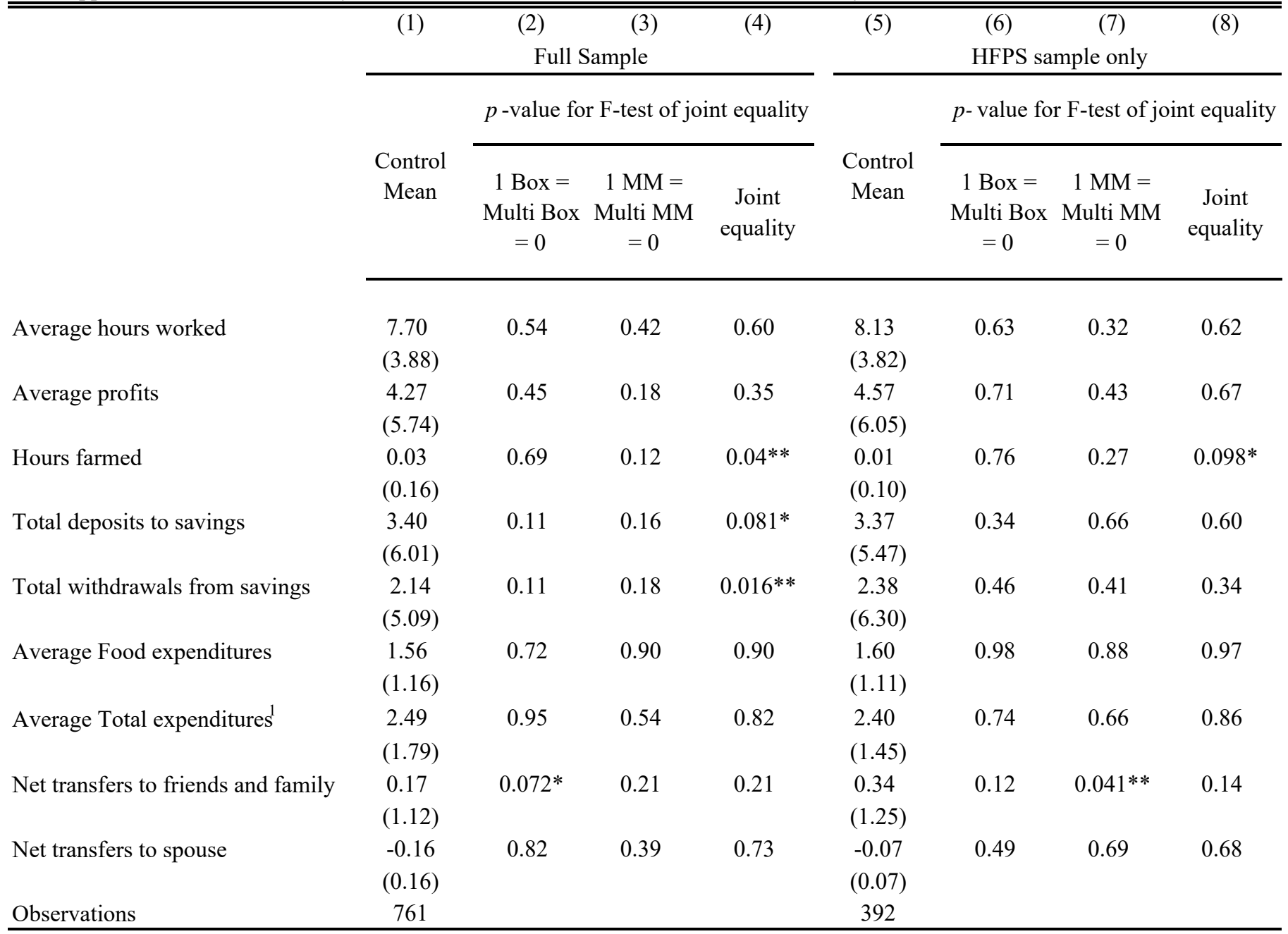

Note: Variables are converted to daily values. Means are population weighted. Randomization check_intake is performed only for businesses that appear in the analysis sample (i.e. completed a monitoring survey or at least one phone survey). Monetary values are winsorized at $1 \%$ and expressed in USD.

${ }^{1}$ Fxnenditures measured at the intake survev are a suhset of those in later survevs. and include fond. nersonal items. household items 


\begin{tabular}{|c|c|c|c|c|}
\hline & (1) & (2) & (3) & (4) \\
\hline & \multicolumn{2}{|c|}{ Box groups } & \multicolumn{2}{|c|}{ Mobile money } \\
\hline & One box & $\begin{array}{c}\text { Multiple } \\
\text { boxes }\end{array}$ & $\begin{array}{l}\text { One } \\
\text { account }\end{array}$ & $\begin{array}{l}\text { Multiple } \\
\text { accounts }\end{array}$ \\
\hline \multicolumn{5}{|c|}{ Panel A. HFPS (covering approximately 3.5 months in total) } \\
\hline Made at least 1 transaction & 0.94 & 0.91 & 0.79 & 0.63 \\
\hline Total value of deposits (monthly average) & $\begin{array}{c}20.03 \\
(30.96)\end{array}$ & $\begin{array}{c}33.27 \\
(43.31)\end{array}$ & $\begin{array}{c}32.13 \\
(45.41)\end{array}$ & $\begin{array}{c}25.68 \\
(39.12)\end{array}$ \\
\hline Total value of withdrawals (monthly average) & $\begin{array}{c}4.23 \\
(10.80)\end{array}$ & $\begin{array}{c}14.04 \\
(39.40)\end{array}$ & $\begin{array}{c}23.21 \\
(36.22)\end{array}$ & $\begin{array}{c}16.58 \\
(29.76)\end{array}$ \\
\hline Observations & 80 & 80 & 80 & 80 \\
\hline \multicolumn{5}{|c|}{ Panel B. Monitoring surveys (covering approximately 4 months in total) } \\
\hline Made at least 1 transaction & 0.81 & 0.83 & 0.59 & 0.56 \\
\hline Total value of deposits (monthly average) & $\begin{array}{c}33.08 \\
(37.47)\end{array}$ & $\begin{array}{c}42.30 \\
(49.54)\end{array}$ & $\begin{array}{c}25.38 \\
(39.50)\end{array}$ & $\begin{array}{c}25.68 \\
(39.12)\end{array}$ \\
\hline Total value of withdrawals (monthly average) & $\begin{array}{c}23.76 \\
(36.38)\end{array}$ & $\begin{array}{c}33.72 \\
(51.28)\end{array}$ & $\begin{array}{c}19.94 \\
(35.07)\end{array}$ & $\begin{array}{c}16.58 \\
(29.76)\end{array}$ \\
\hline Observations & 160 & 161 & 160 & 160 \\
\hline
\end{tabular}

Notes: See text for discussion of data sources. Means are presented, with standard deviations in parentheses. The value of deposits and withdrawals are winsorized at $5 \%$ level. 
Web Appendix Table A5. FDR-adjusted q-values for pre-specified outcomes (high frequency phone survey)

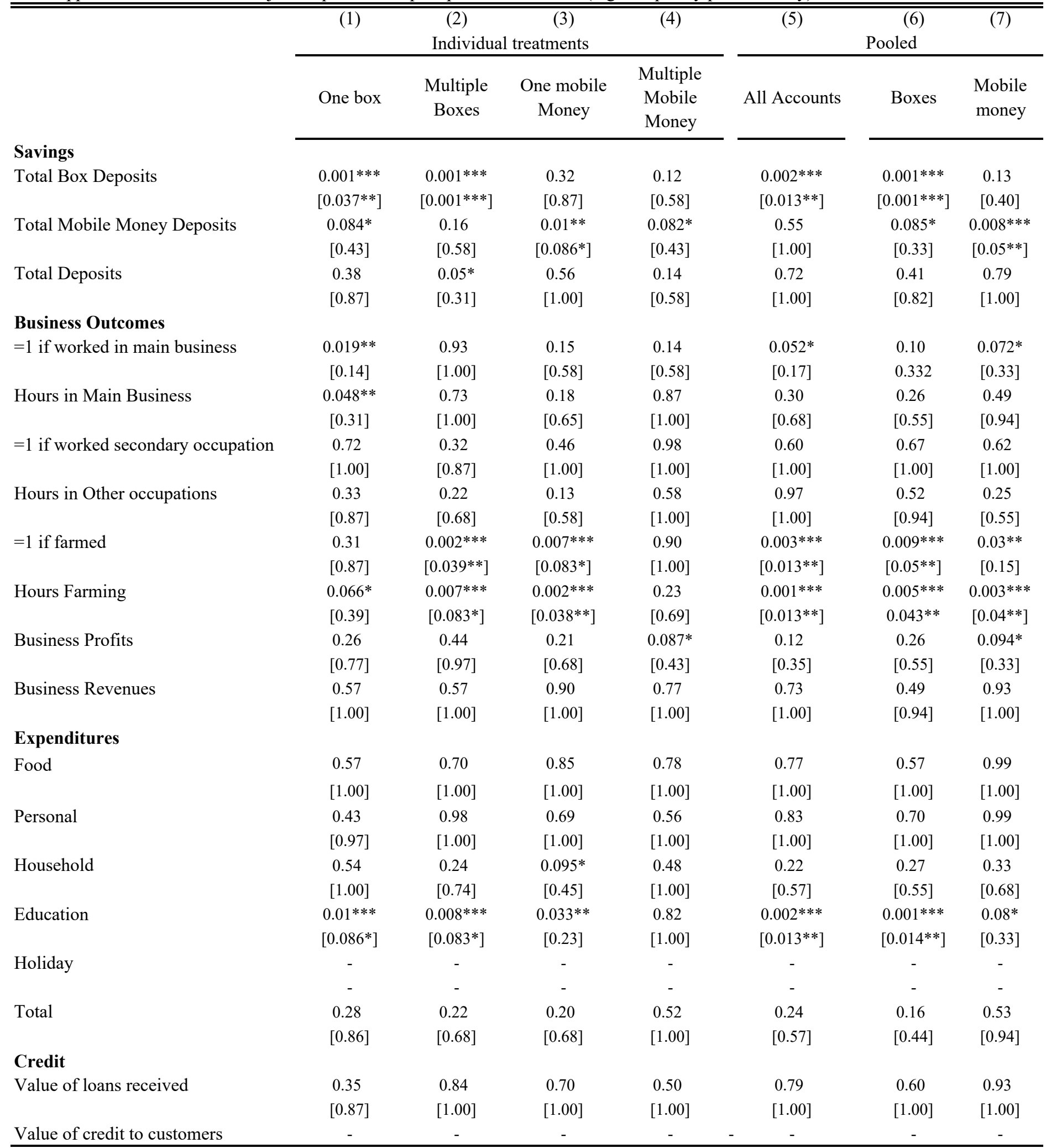

Notes: Naïve p-values are presented first, with q-values in square brackets. Standard errors are adjusted using the procedure in Anderson (2008). Regressions are population weighted.

$*, * *$, and $* * *$ indicate significance at $10 \%, 5 \%$, and $1 \%$ respectively. 


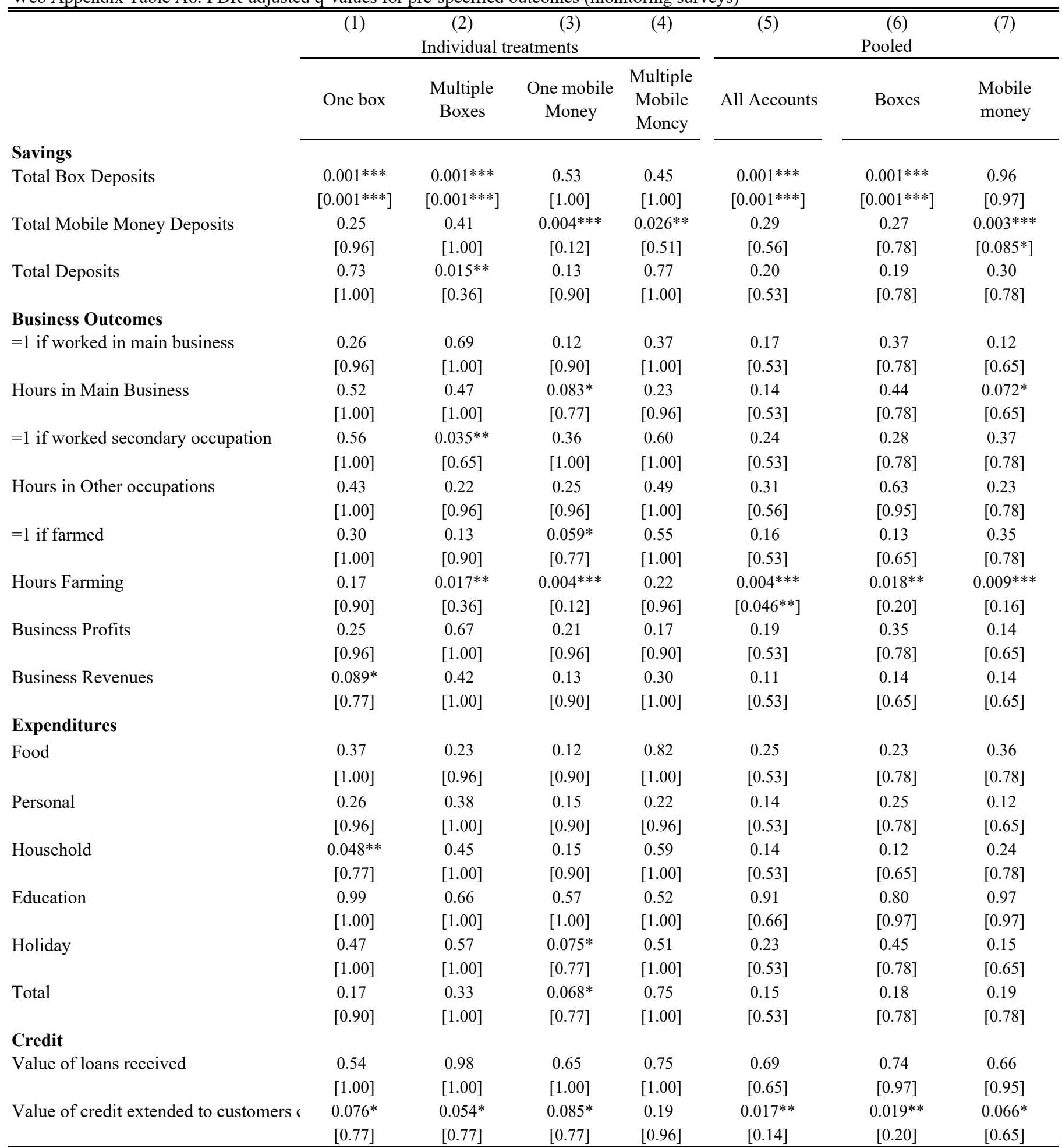

Notes: Naïve p-values are presented first, with q-values in square brackets. Standard errors are adjusted using the procedure in Anderson (2008). Regressions are population weighted.

$*, * *$, and $* * *$ indicate significance at $10 \%, 5 \%$, and $1 \%$ respectively. 
Web Appendix Table A7. Treatment effects on other measures of farming activity

Panel A. Individual Accounts

One lockbox

(1)

\begin{tabular}{ccc}
$\begin{array}{c}y \\
\begin{array}{c}\text { if bought } \\
\text { land }\end{array}\end{array}$ & $\begin{array}{c}=1 \text { if rented } \\
\text { land }\end{array}$ & $\begin{array}{c}\text { Farm } \\
\text { inputs }\end{array}$ \\
\hline 0.02 & $0.09^{*}$ & 8.13 \\
$(0.02)$ & $(0.05)$ & $(4.94)$ \\
$0.06^{* *}$ & $0.09^{*}$ & 7.10 \\
$(0.03)$ & $(0.05)$ & $(5.55)$ \\
0.03 & 0.06 & $10.92^{* *}$ \\
$(0.03)$ & $(0.05)$ & $(4.93)$ \\
0.04 & 0.03 & 1.83 \\
$(0.02)$ & $(0.04)$ & $(4.47)$
\end{tabular}

Multiple mobile money accounts

$(0.02)$

$(0.04)$

$(4.47)$

Panel B. Pooled Lockboxes and Mobile Money Accounts

Boxes

$\begin{array}{lll}0.04^{*} & 0.09^{* *} & 7.61^{*} \\ (0.02) & (0.04) & (4.47) \\ 0.03 & 0.05 & 6.79 \\ (0.02) & (0.04) & (4.18)\end{array}$

Panel C. Pooled Treatment

Any Accoumt

$\begin{array}{lll}0.03 * * & 0.07 * & 7.20^{*} \\ (0.02) & (0.04) & (3.92)\end{array}$

Observations

$\begin{array}{ccc}645 & 646 & 1302 \\ 645 & 646 & 719 \\ 0.02 & 0.05 & 27.67 \\ 0.13 & 0.21 & 40.90\end{array}$

Number of Businesses

Control Mean

0.13

0.90

Notes: All regressions control for strata, date fixed effects and are probability weighted (see in the text for details). All monetary variables are expressed in USD and are winsorized at $5 \%$.

Standard errors clustered at individual level in parentheses. *, **, and *** indicate significance at $10 \%, 5 \%$, and $1 \%$ respectively. 


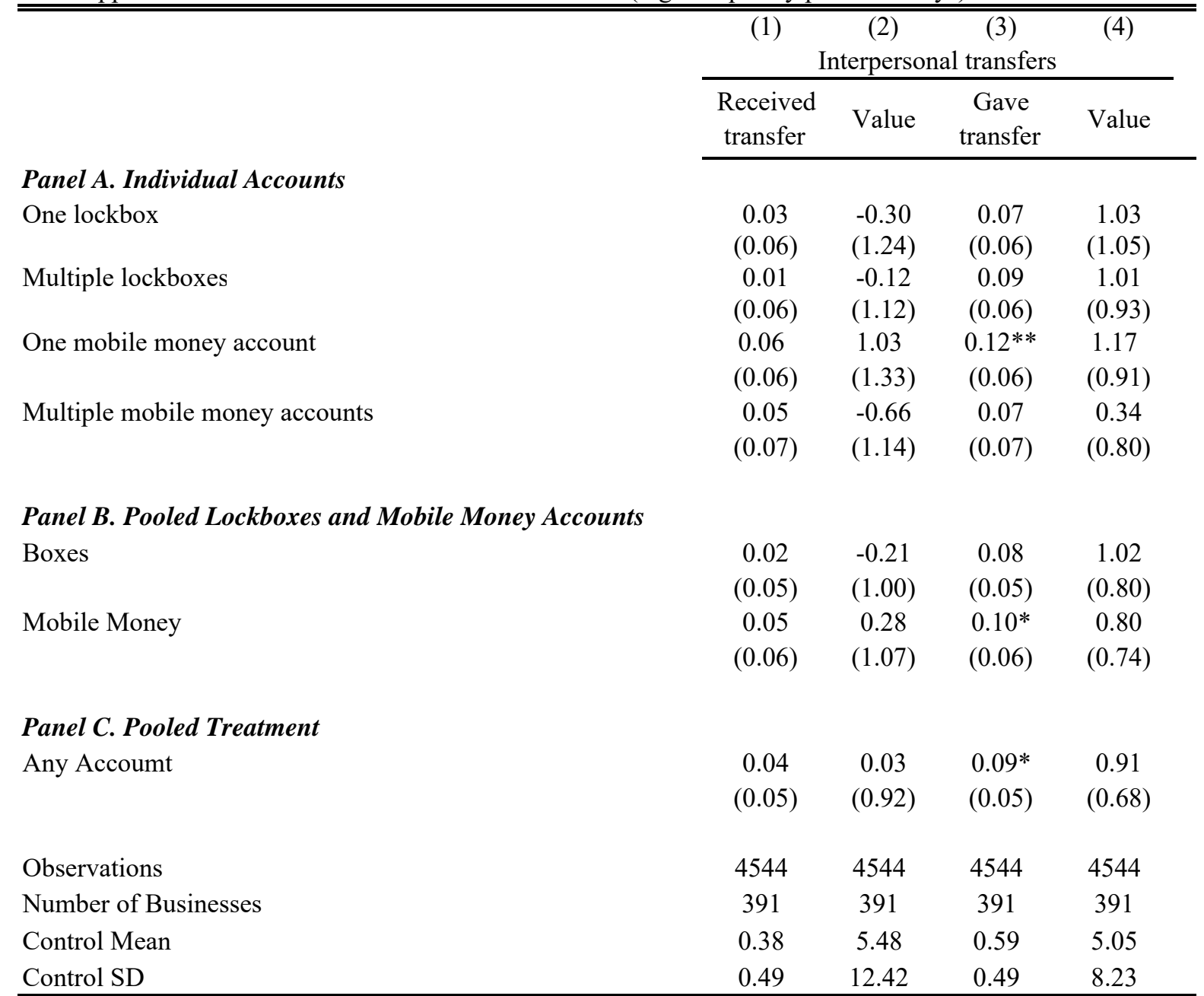

Notes: Transfers include gifts and loans, and both cash and in-kind payments and do not include survey compensation. Variables are measured over the 7 days prior to the survey and converted to daily averages. All regressions control for strata, a measure of the dependent variable during the intake survey (where applicable), assignement to high frequency group and are probability weighted (see in the text for details). Date fixed effects are included. All monetary variables are expressed in USD and are winsorized at 5\%. Standard errors clustered at individual level in parentheses. *, **, and *** indicate significance at $10 \%, 5 \%$, and $1 \%$ respectively. 
Web Appendix Table A9. Treatment effects on transfers (monitoring surveys)

\begin{tabular}{lcccc}
\hline \hline & \multicolumn{4}{c}{$\begin{array}{c}(2) \\
\text { Interpersonal transfers }\end{array}$} \\
\cline { 2 - 5 } & $\begin{array}{c}\text { Received } \\
\text { transfer }\end{array}$ & Value & $\begin{array}{c}\text { Gave } \\
\text { transfer }\end{array}$ & Value \\
\cline { 2 - 5 } Panel A. Individual Accounts & & & & \\
One lockbox & -0.05 & -0.05 & -0.04 & 0.02 \\
& $(0.05)$ & $(0.08)$ & $(0.06)$ & $(0.05)$ \\
Multiple lockboxes & $-0.11^{*}$ & 0.00 & $(0.01)$ & 0.03 \\
& $(0.06)$ & $(0.08)$ & $(0.06)$ & $(0.06)$ \\
One mobile money account & -0.01 & $(0.03)$ & 0.00 & 0.08 \\
& $(0.05)$ & $(0.08)$ & $(0.06)$ & $(0.05)$ \\
Multiple mobile money accounts & 0.01 & $(0.02)$ & $(0.03)$ & 0.01 \\
& $(0.06)$ & $(0.08)$ & $(0.06)$ & $(0.05)$ \\
Panel B. Pooled Lockboxes and Mobile Money & Accounts & & \\
Boxes & $-0.08^{*}$ & -0.02 & -0.02 & 0.03 \\
& $(0.05)$ & $(0.07)$ & $(0.05)$ & $(0.04)$ \\
Mobile Money & 0.00 & $(0.03)$ & $(0.02)$ & 0.05 \\
& $(0.05)$ & $(0.07)$ & $(0.05)$ & $(0.04)$ \\
Panel C. Pooled Treatment & & & & \\
Any Accoumt & & & & \\
Control Mean & -0.04 & -0.03 & -0.02 & 0.04 \\
Observations & $(0.04)$ & $(0.07)$ & $(0.04)$ & $(0.04)$ \\
Number of Businesses & & & & \\
Notrol SD & 1323 & 1323 & 1323 & 1323 \\
& 723 & 723 & 723 & 723 \\
& 0.58 & 0.43 & 0.59 & 0.26 \\
& 0.49 & 0.73 & 0.49 & 0.39 \\
\hline
\end{tabular}

Notes: Transfers include gifts and loans, and both cash and in-kind payments and do not include survey compensation. Variables are measured over the 7 days prior to the survey and converted to daily averages. All regressions control for strata, a measure of the dependent variable during the intake survey (where applicable), assignement to high frequency group and are probability weighted (see in the text for details). Survey date fixed effects are included. All monetary variables are expressed in USD and are winsorized at 5\%.

Standard errors clustered at individual level in parentheses. *, **, and *** indicate significance at $10 \%, 5 \%$, and $1 \%$ respectively. 


\begin{tabular}{lc} 
Panel A. Airtel Transactional History & \\
Used Mobile Money to Deposit/Withdraw Cash & 0.95 \\
Average Amount Deposited & 117.96 \\
& $(149.82)$ \\
Average Amount Withdrawn & 130.64 \\
& $(176.54)$ \\
Used Mobile Money to make transfers & 0.67 \\
Transfers Sent & 14.17 \\
& $(26.01)$ \\
Transfers Received & 12.29 \\
& $(29.41)$ \\
Used Mobile Money to make payments & 0.73 \\
Transactions Made & 10.76 \\
& $(17.15)$ \\
Observations & 264 \\
Panel B. Debriefing questions about mobile money & \\
Used Mobile Money for longer-term savings & 0.83 \\
Used Mobile Money to store money temporarily & 0.12 \\
Observations & 259 \\
\hline
\end{tabular}

Notes: Panel A comes from Airtel administrative data. Data is restricted to accounts with non-zero usage. Panel B comes from responses collected during a debriefing section of the endline survey, at the conclusion of the project. Data is restricted to the mobile money treatment group in the experiment. 


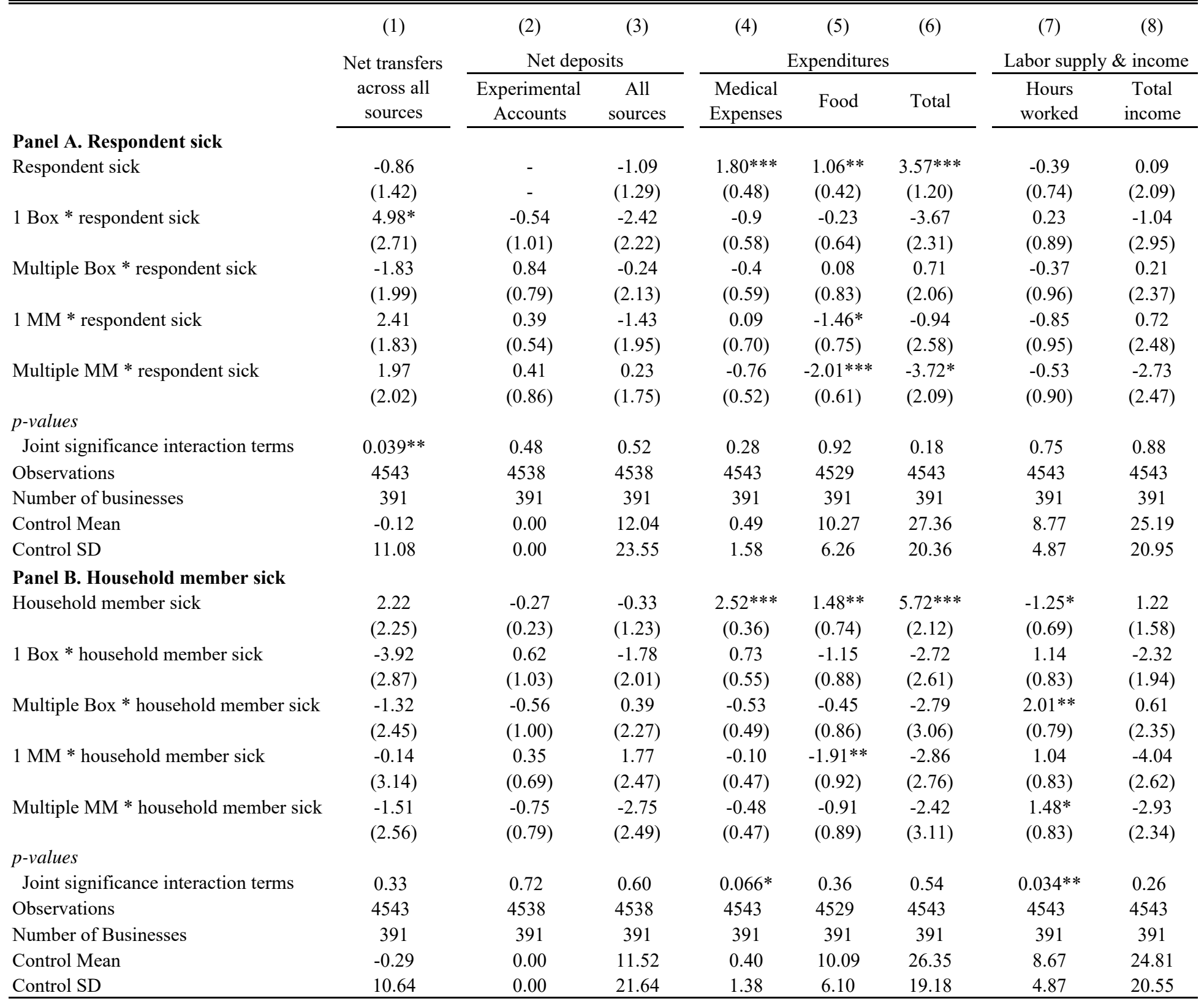

Notes: Regression are at the week level. Fixed effects regressions with survey date fixed effects. Regressions are population weighted. Transfers include gifts and loans, and both cash and in-kind payments. Net transfers and withdrawals are positive for inflows and negative for outflows.

Standard errors clustered at individual level in parentheses. $*$, **, and $* * *$ indicate significance at $10 \%, 5 \%$, and $1 \%$ respectively. 


$$
\begin{array}{cl}
=1 \text { if fully } & =1 \text { if treated } \\
\text { treated illness } & \text { immediately }
\end{array}
$$

Panel A. Respondent sick

One lockbox

$0.02-0.17 *$

$(0.07)$

$(0.09)$

Multiple lockboxes

0.06

$-0.04$

$(0.06)$

$(0.09)$

One mobile money account

$-0.06$

0.05

Multiple mobile money accounts

$-0.04$

$-0.08$

$(0.07)$

p-values

Joint significance all accounts

0.44

$0.036^{* *}$

Observations

500

500

Number of businesses

249

249

Control Mean

0.83

0.78

Control SD

\section{Panel B. Household member sick}

One lockbox
Multiple lockboxes
One mobile money account
Multiple mobile money accounts
p-values
Joint significance all accounts
Observations
Number of businesses
Control Mean
Control SD

$\begin{array}{ll}-0.07 & -0.03\end{array}$

$(0.05) \quad(0.07)$

$0.02 \quad 0.12 *$

$(0.05) \quad(0.07)$

$-0.08 \quad 0.1$

$(0.06) \quad(0.06)$

$0.05 \quad 0.12 *$

$(0.04) \quad(0.07)$

Notes: Regressions are restricted to observations in which the respondent (or a household member was sick). The dependent variable in column 1 is an indicator for treating an illness fully, and the dependent variable in column 2 is an indicator for treating the illness immediately. All regressions control for strata and are probability weighted (see in the text for details). Standard errors clustered at individual level in parentheses. ${ }^{*}, * *$, and $* * *$ indicate significance at $10 \%, 5 \%$, and $1 \%$ respectively. 
Web Appendix Table A13. Treatment effects on prevalence of sickness

\begin{tabular}{lcc}
\hline \hline & $\begin{array}{c}(1) \\
=1 \text { if member of } \\
\text { household sick in } \\
\text { past week }\end{array}$ & $\begin{array}{c}(2) \\
\text { if respondent sick } \\
\text { in past week }\end{array}$ \\
\hline One lockbox & 0.01 & 0.02 \\
Multiple lockboxes & $(0.03)$ & $(0.03)$ \\
One mobile money account & 0.02 & 0.01 \\
Multiple mobile money accounts & $(0.03)$ & $(0.02)$ \\
& 0.01 & 0.03 \\
Observations & $(0.02)$ & $(0.03)$ \\
Number of businesses & -0.02 & -0.02 \\
Control Mean & $(0.02)$ & $(0.02)$ \\
\hline Nit Stan & & \\
Nert & 4543 & 4543 \\
& 391 & 391 \\
\end{tabular}

Notes: Standard errors clustered at individual level in parentheses. All regressions control for strata and are probability weighted (see in the text for details).

Standard errors clustered at individual level in parentheses. *,**, and *** indicate significance at $10 \%, 5 \%$, and $1 \%$ respectively. 


\section{Web Appendix B - Additional Measures of Savings}

\section{Saving for Multiple Financial Needs: Evidence from Lockboxes and Mobile Money in Malawi}

Shilpa Aggarwal, Valentina Brailovskaya and Jonathan Robinson 


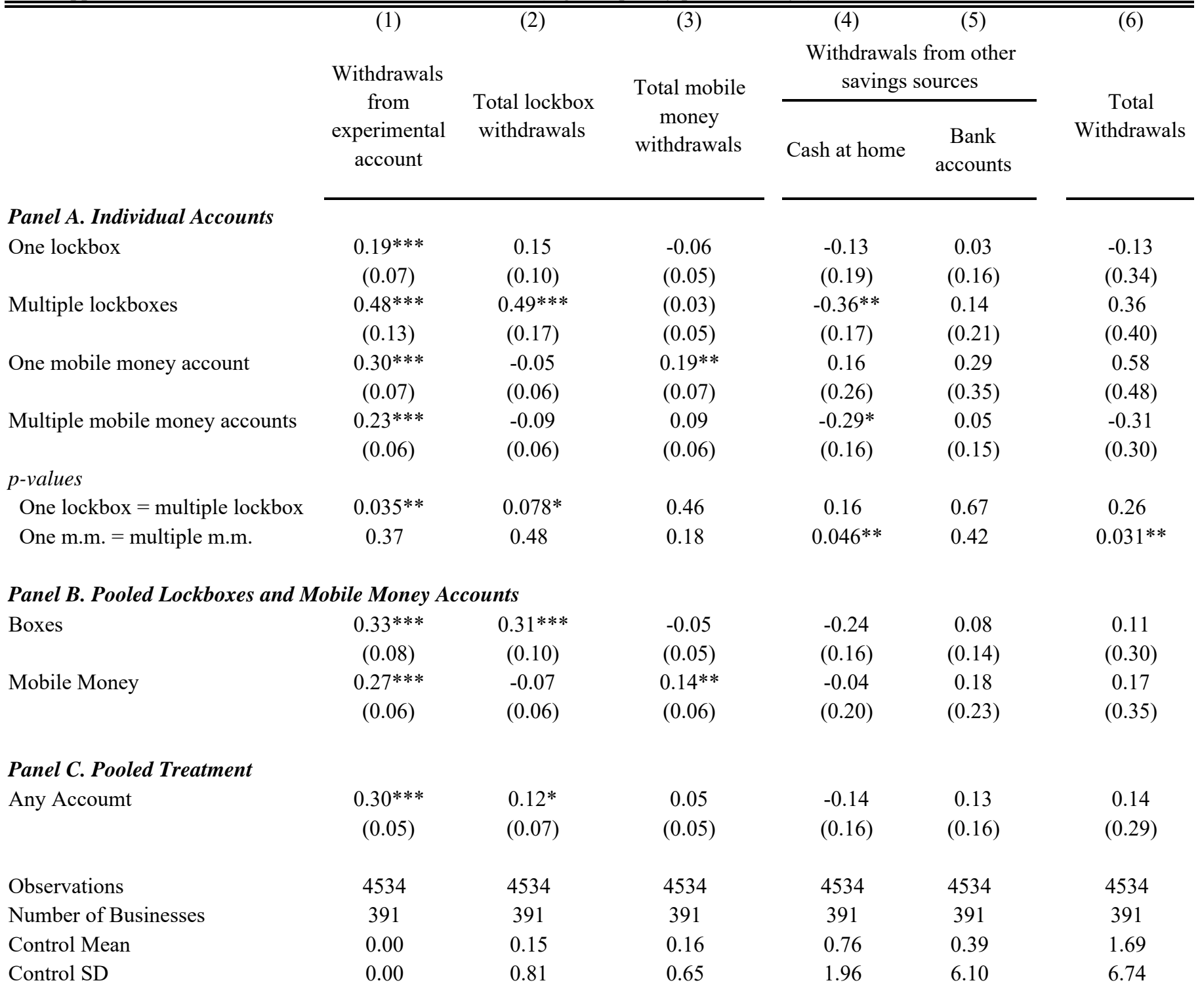

Note: All results are converted to daily averages. Withdrawals were measured over the past 7 days. All regressions control for strata, a measure of the dependent variable during the intake survey (where applicable), assignement to high frequency group and are probability weighted (see in the text for details). Date and date survey fixed effects are included in Panel A and B, respecitvely. All monetary variables are expressed in USD and are winsorized at $5 \%$.

Standard errors clustered at individual level in parentheses. *,**, and *** indicate significance at $10 \%, 5 \%$, and $1 \%$ respectively. 


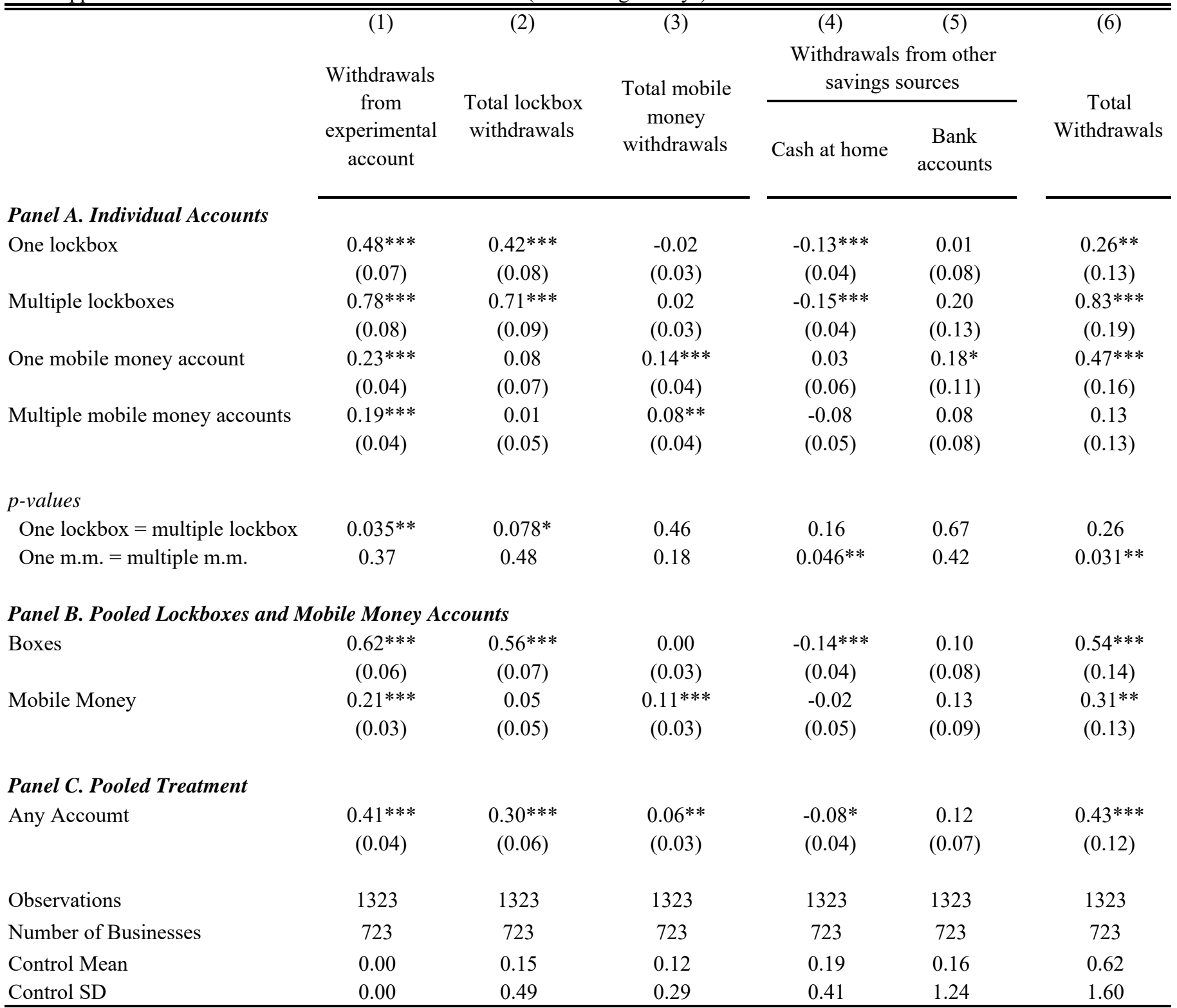

Note: All results are converted to daily averages. Withdrawals were measured over the past 2 months. All regressions control for strata, a measure of the dependent variable during the intake survey (where applicable), assignement to high frequency group and are probability weighted (see in the text for details). Date and date survey fixed effects are included in Panel A and B, respecitvely. All monetary variables are expressed in USD and are winsorized at 5\%.

Standard errors clustered at individual level in parentheses. *,**, and *** indicate significance at $10 \%, 5 \%$, and $1 \%$ respectively. 


\begin{tabular}{|c|c|c|c|c|c|c|c|c|}
\hline & $\begin{array}{l}(1) \\
\end{array}$ & (2) & (3) & $(4)$ & $\overline{(5)}$ & (6) & (7) & (8) \\
\hline & \multicolumn{2}{|c|}{ Balance in Lockboxes } & \multicolumn{2}{|c|}{ Balance in Mobile Money } & \multicolumn{3}{|c|}{ Balance in other savings sources } & \multirow{2}{*}{$\begin{array}{c}\text { Total } \\
\text { Balance }\end{array}$} \\
\hline & $\begin{array}{c}\text { Project } \\
\text { lockboxes }\end{array}$ & All lockboxes & $\begin{array}{c}\text { Project Mobile } \\
\text { money }\end{array}$ & $\begin{array}{c}\text { All mobile } \\
\text { money accounts }\end{array}$ & $\begin{array}{l}\text { Cash at } \\
\text { home }\end{array}$ & $\begin{array}{c}\text { Bank } \\
\text { accounts }\end{array}$ & $\begin{array}{l}\text { Savings } \\
\text { groups }\end{array}$ & \\
\hline \multicolumn{9}{|l|}{ Panel A. Individual Accounts } \\
\hline One lockbox & $\begin{array}{c}49.16^{* * *} \\
(7.27)\end{array}$ & $\begin{array}{c}49.05 * * * \\
\quad(7.48)\end{array}$ & $\begin{array}{c}0.44 \\
(0.94)\end{array}$ & $\begin{array}{l}-4.20 \\
(3.47)\end{array}$ & $\begin{array}{c}-7.99 * * \\
(3.94)\end{array}$ & $\begin{array}{c}-7.10 \\
(15.28)\end{array}$ & $\begin{array}{c}4.27 \\
(6.38)\end{array}$ & $\begin{array}{c}26.96 \\
(20.95)\end{array}$ \\
\hline Multiple lockboxes & $\begin{array}{c}58.27 * * * \\
(6.71)\end{array}$ & $\begin{array}{c}57.26^{* * *} \\
(6.89)\end{array}$ & $\begin{array}{c}0.35 \\
(1.07)\end{array}$ & $\begin{array}{l}-3.47 \\
(3.52)\end{array}$ & $\begin{array}{c}-10.36^{* * *} \\
(3.46)\end{array}$ & $\begin{array}{c}23.53 \\
(21.74)\end{array}$ & $\begin{array}{l}-1.46 \\
(7.54)\end{array}$ & $\begin{array}{l}61.45 * * \\
(24.88)\end{array}$ \\
\hline One mobile money account & $\begin{array}{c}0.47 \\
(2.61)\end{array}$ & $\begin{array}{c}18.37 * * * \\
(5.68)\end{array}$ & $\begin{array}{c}10.42 * * * \\
(2.85)\end{array}$ & $\begin{array}{c}3.83 \\
(4.31)\end{array}$ & $\begin{array}{c}0.10 \\
(4.17)\end{array}$ & $\begin{array}{c}38.22 \\
(24.62)\end{array}$ & $\begin{array}{l}-5.10 \\
(5.78)\end{array}$ & $\begin{array}{l}50.47 * \\
(28.11)\end{array}$ \\
\hline Multiple mobile money accounts & $\begin{array}{l}-0.64 \\
(2.30)\end{array}$ & $\begin{array}{l}9.48 * \\
(5.47)\end{array}$ & $\begin{array}{c}15.91 * * * \\
(3.23)\end{array}$ & $\begin{array}{l}9.00 * * \\
(4.18)\end{array}$ & $\begin{array}{c}0.27 \\
(4.33)\end{array}$ & $\begin{array}{c}2.48 \\
(16.33)\end{array}$ & $\begin{array}{l}-5.85 \\
(6.56)\end{array}$ & $\begin{array}{c}8.66 \\
(20.53)\end{array}$ \\
\hline \multicolumn{9}{|l|}{ p-values } \\
\hline One lockbox $=$ multiple lockbox & 0.35 & 0.40 & 0.93 & 0.78 & 0.34 & $0.092 *$ & 0.41 & 0.16 \\
\hline One m.m. = multiple m.m. & 0.69 & 0.20 & 0.17 & 0.21 & 0.97 & $0.081^{*}$ & 0.89 & $0.099 *$ \\
\hline \multicolumn{9}{|c|}{ Panel B. Pooled Lockboxes and Mobile Money Accounts } \\
\hline Boxes & $\begin{array}{c}53.56 * * * \\
(5.09)\end{array}$ & $\begin{array}{c}52.98 * * * \\
(5.32)\end{array}$ & $\begin{array}{c}0.42 \\
(0.85)\end{array}$ & $\begin{array}{l}-3.82 \\
(3.23)\end{array}$ & $\begin{array}{c}-9.14 * * * \\
(3.50)\end{array}$ & $\begin{array}{c}7.48 \\
(16.25)\end{array}$ & $\begin{array}{c}1.50 \\
(6.01)\end{array}$ & $\begin{array}{c}43.47 * * \\
(19.42)\end{array}$ \\
\hline Mobile Money & $\begin{array}{l}-0.25 \\
(2.07)\end{array}$ & $\begin{array}{c}14.04 * * * \\
(4.36)\end{array}$ & $\begin{array}{c}12.97 * * * \\
(2.29)\end{array}$ & $\begin{array}{l}6.22 * \\
(3.70)\end{array}$ & $\begin{array}{c}0.23 \\
(3.76)\end{array}$ & $\begin{array}{c}20.79 \\
(18.57)\end{array}$ & $\begin{array}{l}-5.32 \\
(5.52)\end{array}$ & $\begin{array}{c}30.21 \\
(21.46)\end{array}$ \\
\hline \multicolumn{9}{|l|}{ Panel C. Pooled Treatment } \\
\hline Any Accoumt & $\begin{array}{c}26.11 * * * \\
(3.25)\end{array}$ & $\begin{array}{c}33.12 * * * \\
(3.85)\end{array}$ & $\begin{array}{c}6.82 * * * \\
(1.52)\end{array}$ & $\begin{array}{c}1.30 \\
(3.28)\end{array}$ & $\begin{array}{l}-4.38 \\
(3.42)\end{array}$ & $\begin{array}{c}14.20 \\
(16.23)\end{array}$ & $\begin{array}{l}-1.98 \\
(5.31)\end{array}$ & $\begin{array}{c}36.70 * * \\
(18.55)\end{array}$ \\
\hline Observations & 648 & 648 & 647 & 648 & 645 & 633 & 648 & 648 \\
\hline Number of Businesses & 648 & 648 & 647 & 648 & 645 & 633 & 648 & 648 \\
\hline Control Mean & 0.00 & 3.50 & 0.00 & 12.17 & 13.60 & 38.04 & 22.98 & 94.76 \\
\hline Control SD & 0.00 & 15.47 & 0.00 & 27.12 & 24.76 & 108.40 & 45.24 & 126.90 \\
\hline
\end{tabular}

Note: Balances were measured as of the date of the endline survey only. All regressions control for strata, a measure of the dependent variable during the intake survey survey (where applicable), date of the survey fixed effects, assignement to high frequency group and are probability weighted (see in the text for details). All monetary variables are expressed in USD and are winsorized at 5\%. Standard errors clustered at individual level in parentheses.

Standard errors clustered at individual level in parentheses. * $* *$, and *** indicate significance at $10 \%, 5 \%$, and $1 \%$ respectively. 


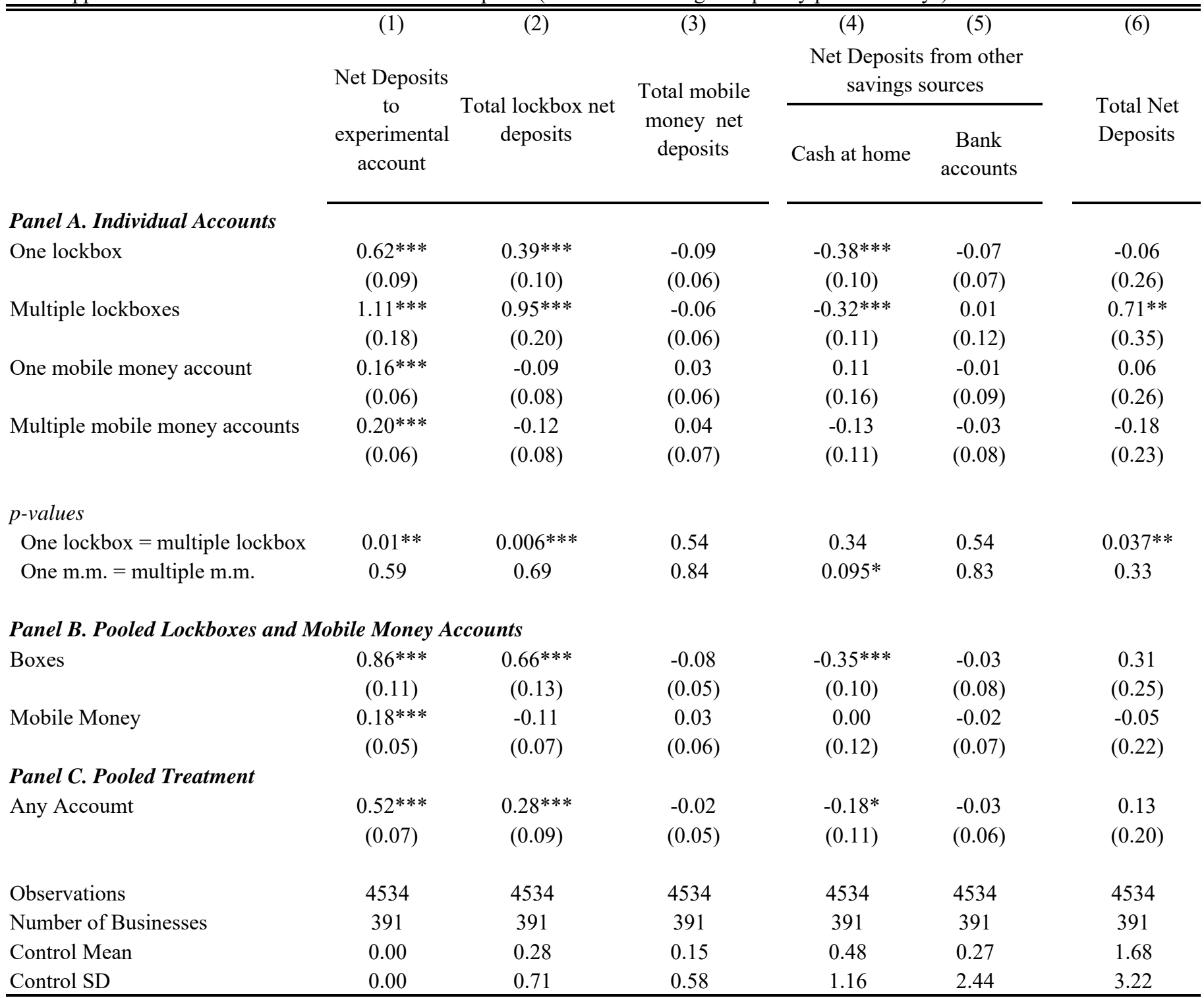

Note: All results are converted to daily averages. Deposits and withdrawals were measured over the past 7 days. All regressions control for strata, a measure of the dependent variable during the intake survey (where applicable), assignement to high frequency group and are probability weighted (see in the text for details). Date fixed effects are included. All monetary variables are expressed in USD and are winsorized at $5 \%$.

Standard errors clustered at individual level in parentheses. $*$, **, and *** indicate significance at $10 \%, 5 \%$, and $1 \%$ respectively. 


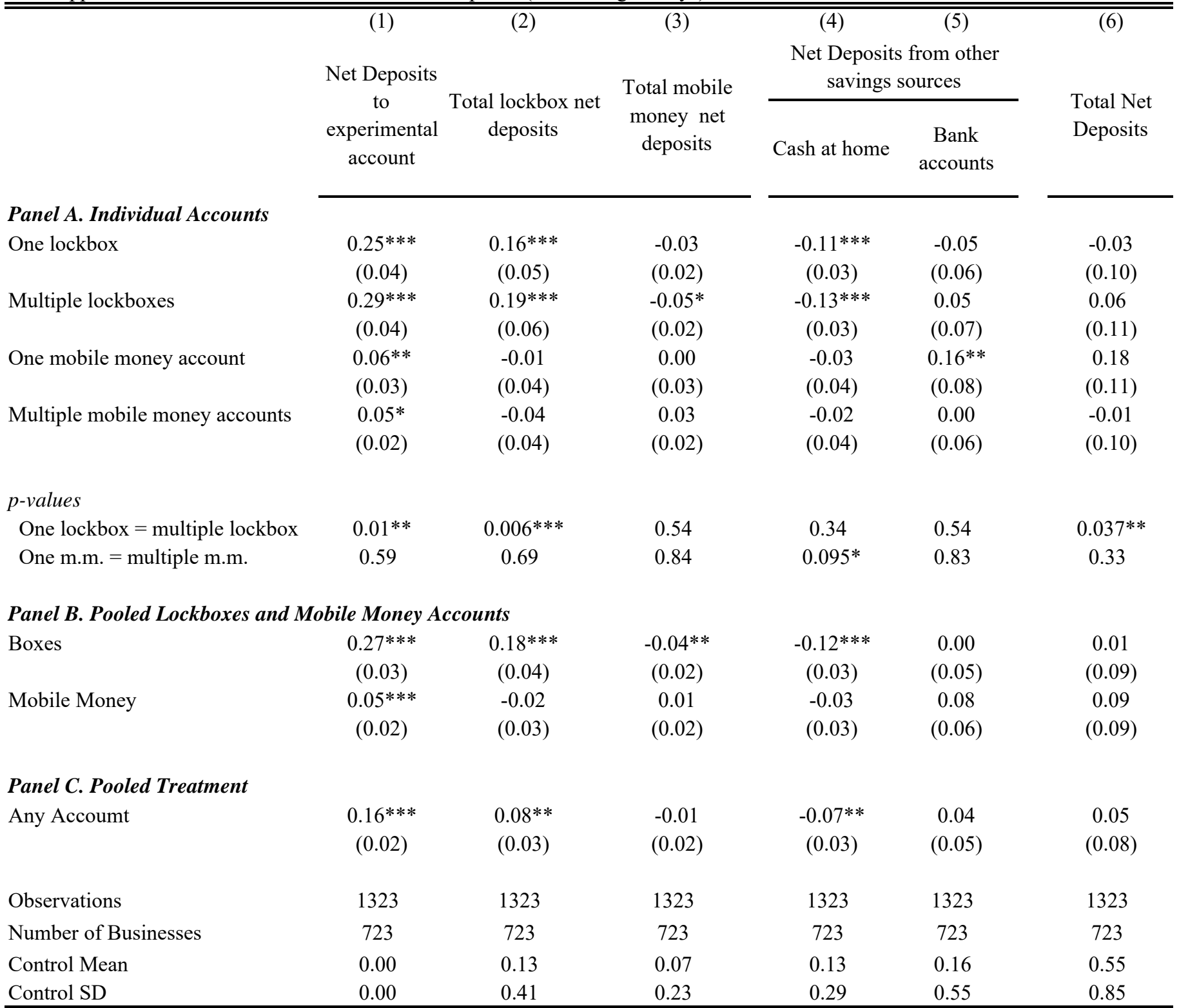

Note: All results are converted to daily averages. Deposits and withdrawals over the past 2 months in the monitoring surveys. All regressions control for strata, a measure of the dependent variable during the intake survey (where applicable), assignement to high frequency group and are probability weighted (see in the text for details). Survey date fixed effects are included. All monetary variables are expressed in USD and are winsorized at 5\%.

Standard errors clustered at individual level in parentheses. *, **, and *** indicate significance at $10 \%, 5 \%$, and $1 \%$ respectively. 


\section{Web Appendix V - Assessing Possible Threats to Validity}

\section{Saving for Multiple Financial Needs: Evidence from Lockboxes and Mobile Money in Malawi}

Shilpa Aggarwal, Valentina Brailovskaya and Jonathan Robinson 
Panel A. Verified vs. reported balance (all boxes)

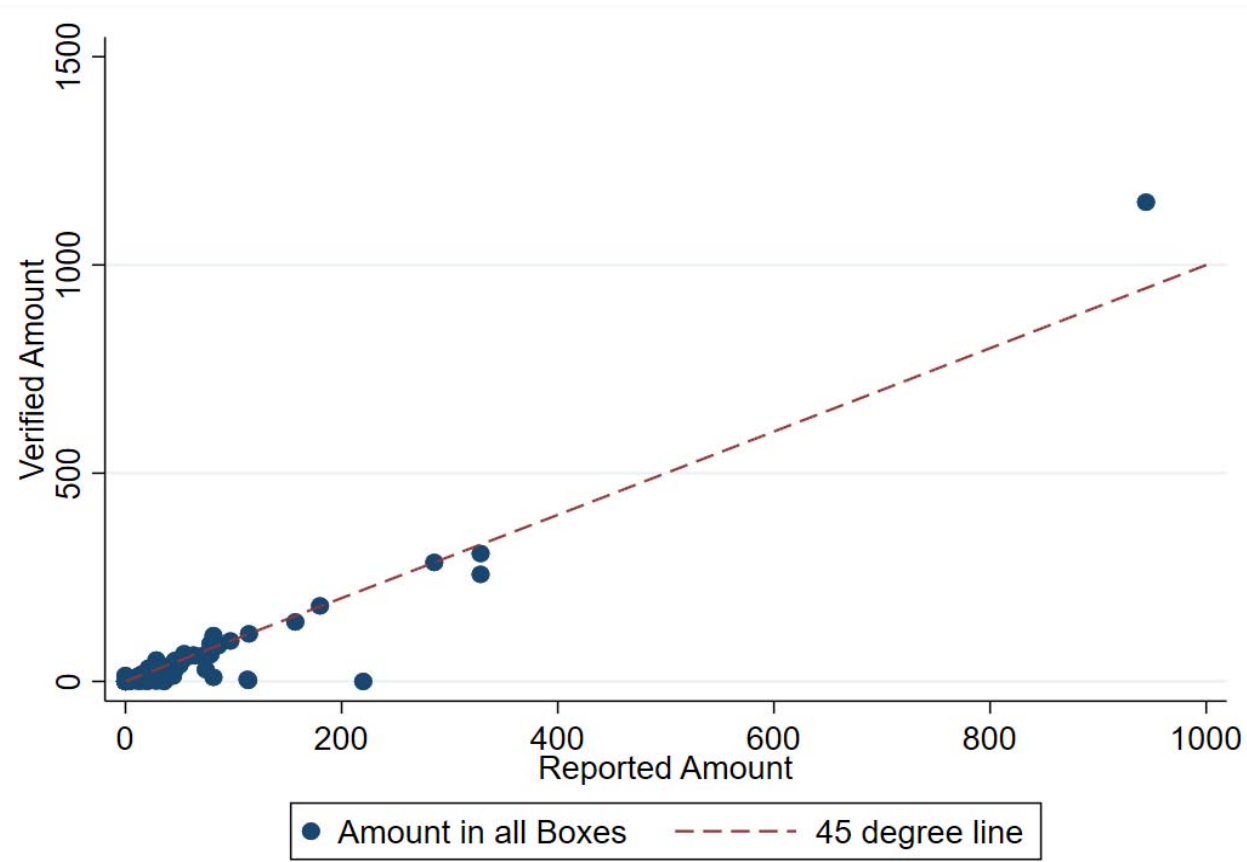

Panel B. Verified vs. reported balances (below 75th percentile)

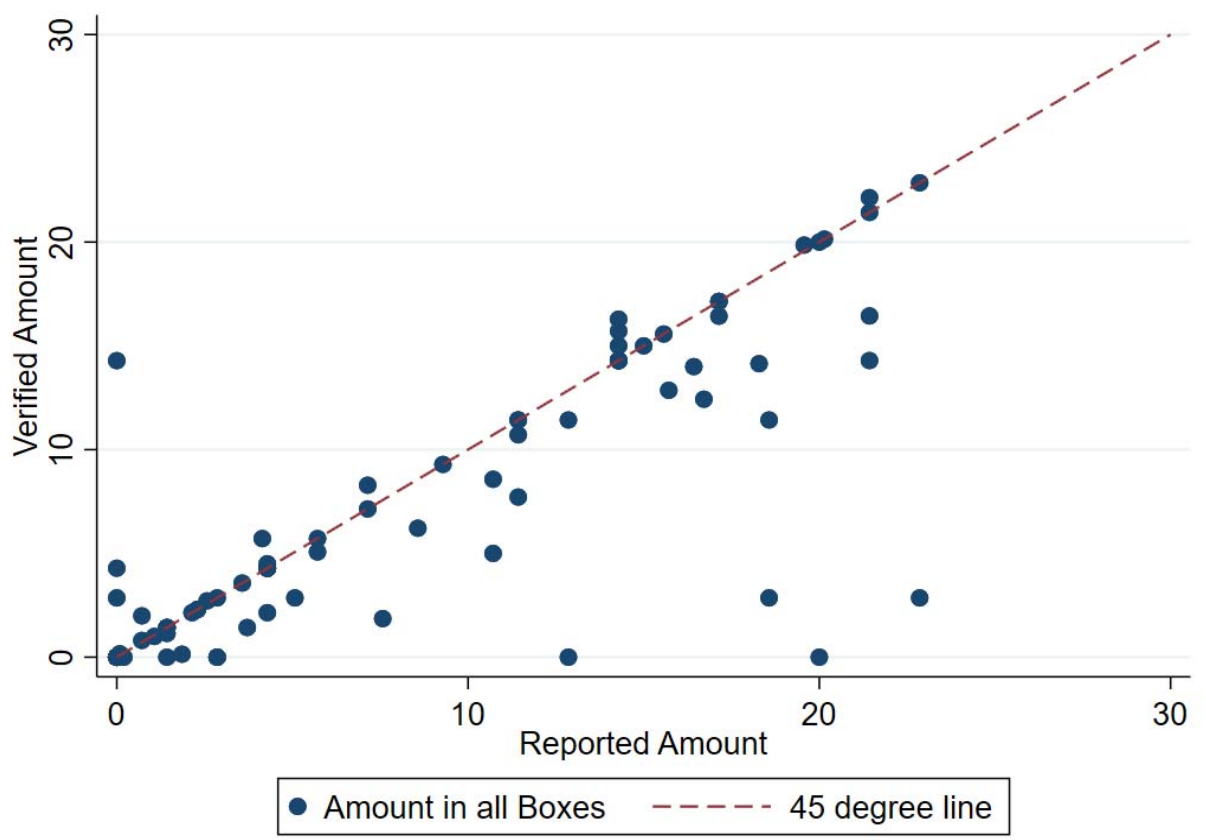

Notes: The y-axis is the amount actually found in the lockbox during the check in December 2018 and the $\mathrm{x}$-axis is the amount reported as the balance (prior to opening the box). 260 Respondents were assigned to the lockbox check group, and 241 completed pre-lockbox check survey, 215 consented to show us the lockbox, 190 consented to open the lockbox. Panel A shows all boxes, Panel B shows only those below the 75th percentile for both measures. About $50 \%$ of users reported the exact balance in the boxes, $14 \%$ under-reported, and $37 \%$ over-reported. 
Mobile money transaction data from telecom

$=1$ if deposit appears in
telco data

\section{Values reported in HFPS survey}

\section{Panel A. Day Level}

$=1$ if reported a deposit

Total value of reported deposits

Observations

Number of respondents

Mean of dependent variable

SD of dependent variable

Panel B. Week Level

$=1$ if reported a deposit

Total value of reported deposits

Observations

Number of respondents

Mean of dependent variable

SD of dependent variable

Panel C. Cumulative over entire HFPS period

Total value of reported deposits

Observations

Number of respondents

Mean of dependent variable

SD of dependent variable

\section{Panel D. Long Term Usage Survey}

$=1$ if reported a deposit in the last month

Total Value of Deposits in the last month

Observations

Number of Respondents

Mean of dependent variable

SD of dependent variable

$\begin{array}{cc}0.344 * * * & - \\ (0.01) & - \\ - & 0.452 * * * \\ - & (0.02) \\ 3,704 & 3,704 \\ 156 & 156 \\ 0.0473 & 0.314 \\ 0.212 & 2.14\end{array}$

$0.525 * * *$

(0.02)

$-$

$0.653 * * *$

$-$

(0.02)

1,851

1,851

156

156

0.226

2.4

0.418

6.707

$-$

$0.823 * * *$

$-$

294

156

18.17

32.42

$0.600 * * *$

(0.09)

$\begin{array}{cc} & 0.445^{* * *} \\ & (0.07) \\ 70 & 70 \\ 70 & 70 \\ 0.201 & 2.738 \\ 0.4 & 7.702\end{array}$

Notes: Independent variables are from high-frequency phone surveys. Dependent variables are from administrative data of mobile money transactions from the telecom company. The regressions are run without a constant term. All monetary variables are expressed in USD and are winsorized at 5\%.*,**, and *** indicate significance at $10 \%$, $5 \%$, and $1 \%$ respectively. 
Web Appendix Table V2. Correlations between reported and verified balances in boxes

\begin{tabular}{|c|c|c|c|c|}
\hline & $(1)$ & (2) & (3) & (4) \\
\hline & \multicolumn{4}{|c|}{ Independently Verified Balance in Boxes } \\
\hline & $\begin{array}{l}\text { All Boxes } \\
\text { (pooled) }\end{array}$ & Silver & Black & Brown \\
\hline \multicolumn{5}{|l|}{ Panel A. All box groups } \\
\hline \multirow[t]{2}{*}{ Self Reported balance in survey } & 1.047 & 0.927 & 0.803 & 1.357 \\
\hline & $(0.02)$ & $(0.01)$ & $(0.08)$ & $(0.01)$ \\
\hline Observations & 190 & 185 & 65 & 46 \\
\hline \multicolumn{5}{|l|}{ Panel B. One box group } \\
\hline \multirow[t]{2}{*}{ Self Reported balance in survey } & 0.881 & - & - & - \\
\hline & $(0.01)$ & - & - & - \\
\hline Observations & 94 & - & - & - \\
\hline \multicolumn{5}{|l|}{ Panel C. Multiple box group } \\
\hline \multirow[t]{2}{*}{ Self Reported balance in survey } & 1.096 & 0.986 & 0.803 & 1.357 \\
\hline & $(0.03)$ & $(0.01)$ & $(0.08)$ & $(0.01)$ \\
\hline Observations & 96 & 91 & 65 & 46 \\
\hline
\end{tabular}

Note: Regressions are run without a constant term. 260 Respondents were assigned to the lockbox check group, and 241 completed pre-lockbox check survey, 215 consented to show us the lockbox, 190 consented to open the lockbox. 


\section{HFPS}

One lockbox

Multiple lockboxes

One mobile money account

Multiple mobile money accounts

\section{Interactions}

One lockbox*HFPS

\section{Multiple lockboxes*HFPS}

One mobile money account*HFPS

Multiple mobile money accounts*HFPS

p-values

Joint significance of interaction terms

Observations

Number of Businesses

Control mean

Control sd

(2)

(3)
(4) Labor

$\begin{array}{cc}\begin{array}{c}\text { Deposits into } \\ \text { experimental } \\ \text { account }^{1}\end{array} & \text { Total } \\ \text { Deposits }\end{array}-$

Main business
$=1$ if
worked Hours

(5)

(6)

Farming

0.0

(0.04)

$0.73 * * *$

(0.09)

$1.05 * * *$

(0.13)

$0.27 * * *$

(0.06)

$0.27 * * *$

(0.06)

(0.31)

$-0.05$

(0.29)

\section{$0.58 *$}

(0.35)

$$
0.31
$$

$$
\text { (0.35) }
$$

$(0.35)$
0.39

0.39
$(0.32)$

$-0.21 *$

(0.13)

$-0.26$

(0.18)

$-0.01$

(0.08)

$-0.12$

(0.08)

0.19
1323

1323
723

0.00

0.00

\section{$-0.01$}

$$
\text { (0.40) }
$$

0.06

$$
\text { (0.46) }
$$

$$
0.04
$$$$
\text { (0.43) }
$$

$$
-0.67
$$

$$
\text { (0.41) }
$$

0.01

0.23

fa

$=1$ if

(0.05)

0.01

(0.59)

(0.04)

$-0.02$

0.14

(0.54)

(0.04)

$-0.07$

(0.06)

0.00

(0.04)

$-0.41$

(0.56)

$-0.93$

(0.72)

$-0.65$

(0.55)

$-0.11$

(0.07)

$-0.87$

0.03

(0.07)

0.02

(0.08)

$-0.06$

(0.07)

(0.80)

0.29

(0.83)

0.19

(0.93)

0.35

(0.86)

\subsection{5}

9261

723

0.74

0.44

$-0.14^{*}-1.00$

(7)

(7)

(8)

Business outcomes

(9)

Total

Profits Revenues expenditures

$\begin{array}{lll}0.44 & 0.87 & -8.21\end{array}$

Notes: Deposits (columns 1-2), business earnings (columns 7-8) and total expenditures (column 9) are measured over the past week and converted to daily values. Labor supply in the main business (columns 3-4) is measured at the daily level in the past 7 days prior to the survey date. Farming is presented over a week since this is how it was measured in the surveys and it is the only way to present the extensive margin. All regressions control for strata, a measure of the dependent variable during the intake survey (where applicable), date of the survey fixed effects, assignment to high frequency group and are probability weighted (see in the text for details). All monetary variables are expressed in USD and are winsorized at 5\%.

Standard errors clustered at individual level in parentheses. * $* *$, and *** indicate significance at $10 \%, 5 \%$, and $1 \%$ respectively.

${ }^{1}$ Experimental account is the mobile money or box, depending on the treatment group. 


\section{Web Appendix C - Additional Pre-specified Analyses}

Saving for Multiple Financial Needs: Evidence from Lockboxes and Mobile Money in Malawi

Shilpa Aggarwal, Valentina Brailovskaya and Jonathan Robinson 


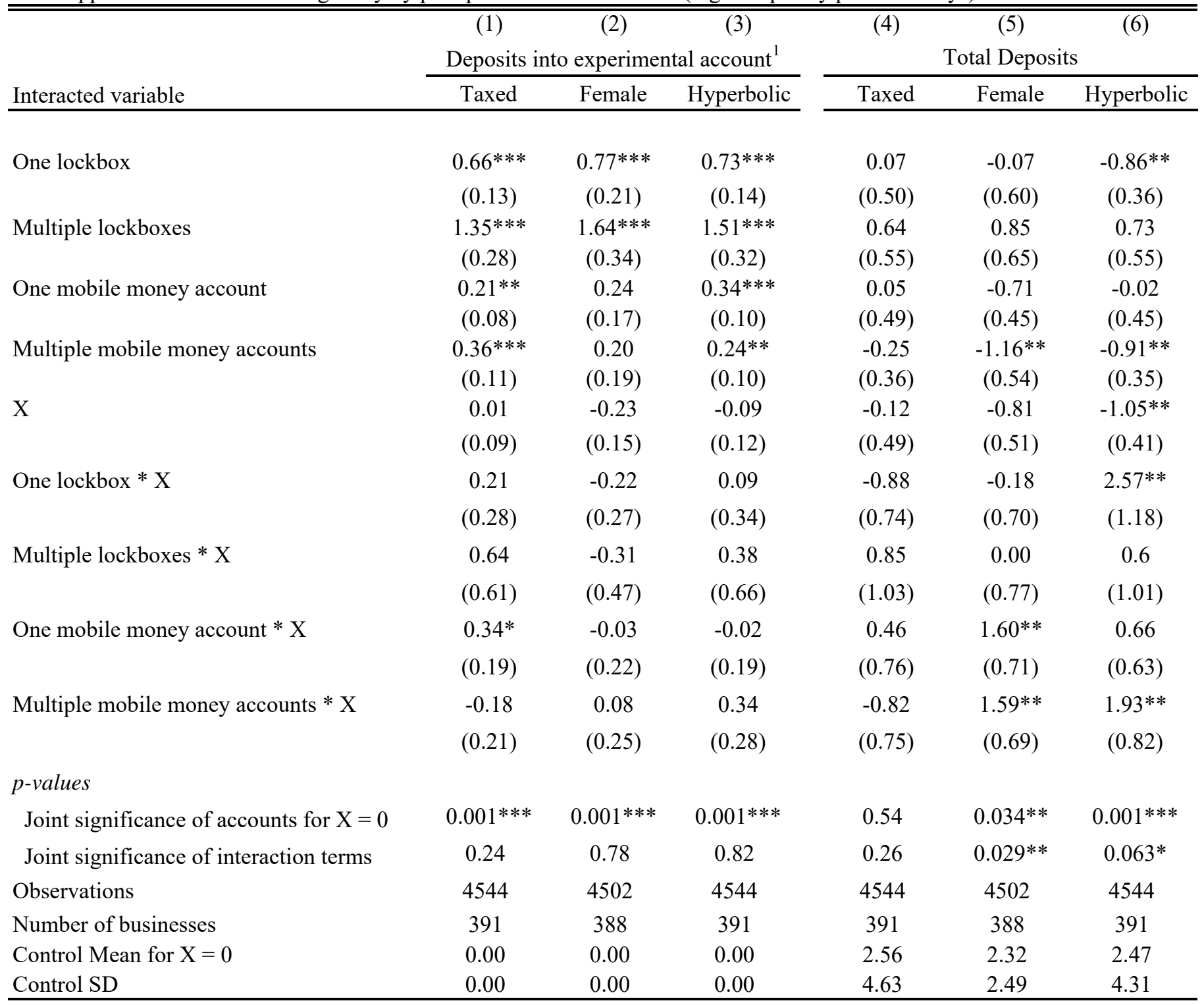

Notes: Each column is a separate regression of the outcome on the treatments, the given variable, and the interactions between the treatments and variable. The coefficient labeled as " $\mathrm{X}$ " is the variable, and the interactions "account * $\mathrm{X}$ " are the interactions. The variable "taxed" is equal to 1 if the respondent gave money at baseline but didn't receive. Deposits are measured over the past week and converted to daily values. All regressions control for strata, a measure of the dependent variable during the intake survey (where applicable), assignment to high frequency group and are probability weighted (see in the text for details). Date fixed effects are included.

Standard errors clustered at individual level in parentheses. *, **, and *** indicate significance at 10\%, 5\%, and $1 \%$ respectively.

${ }^{1}$ Experimental account is the mobile money or box, depending on the treatment group. 


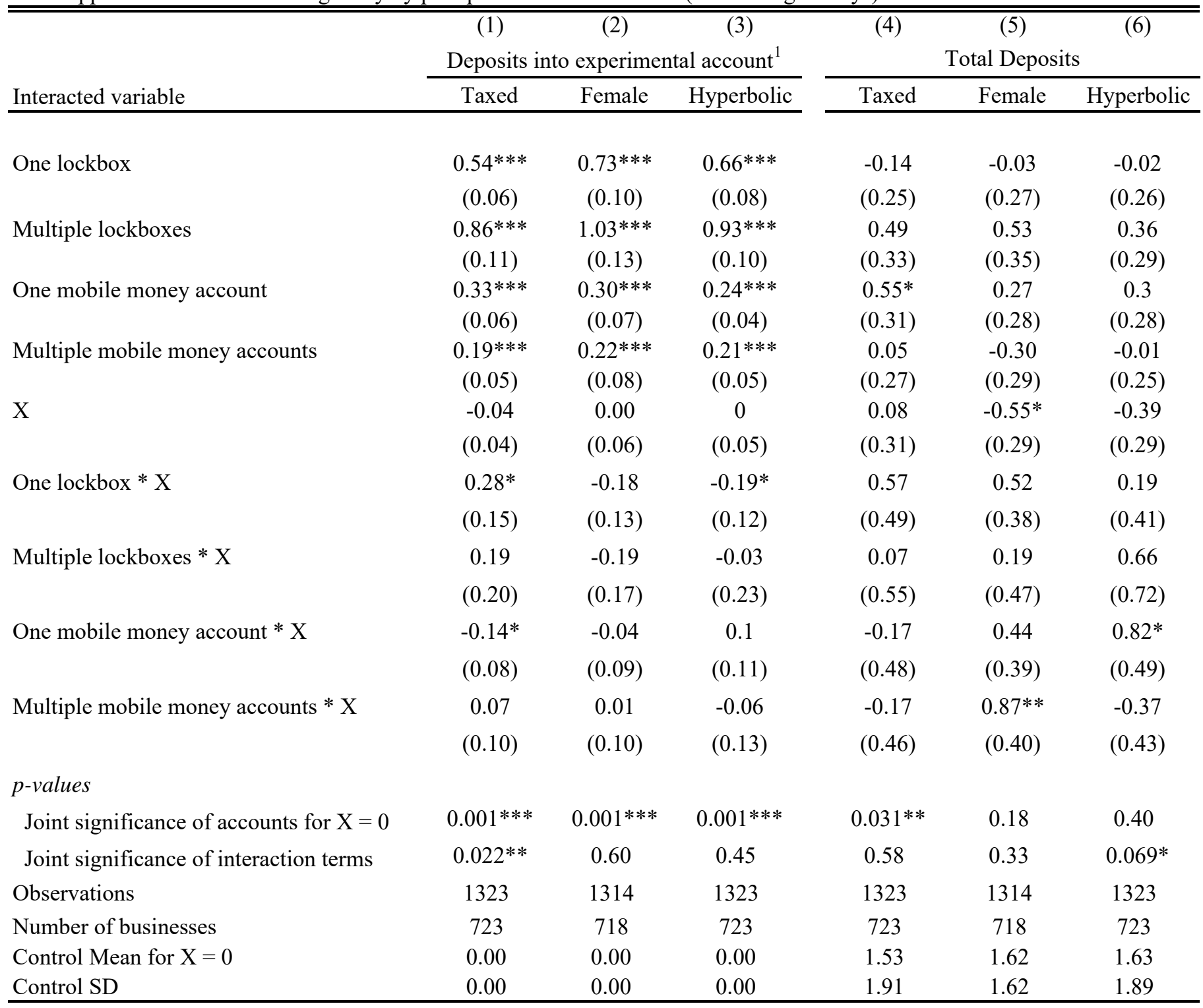

Notes: Each column is a separate regression of the outcome on the treatments, the given variable, and the interactions between the treatments and variable. The coefficient labeled as " $\mathrm{X}$ " is the variable, and the interactions "account * $\mathrm{X}$ " are the interactions. The variable "taxed" is equal to 1 if the respondent gave money at baseline but didn't receive. Deposits are measured over the past week and converted to daily values. All regressions control for strata, a measure of the dependent variable during the intake survey (where applicable), assignment to high frequency group and are probability weighted (see in the text for details). Survey date fixed effects are included.

Standard errors clustered at individual level in parentheses. *, **, and *** indicate significance at 10\%, 5\%, and $1 \%$ respectively.

${ }^{1}$ Experimental account is the mobile money or box, depending on the treatment group. 


\begin{tabular}{|c|c|c|c|c|c|c|c|c|c|}
\hline & (1) & (2) & (3) & (4) & (5) & (6) & (7) & (8) & (9) \\
\hline & \multicolumn{2}{|c|}{ Savings } & \multicolumn{4}{|c|}{ Labor supply } & \multicolumn{2}{|c|}{ Business outcomes } & \multirow{3}{*}{$\begin{array}{c}\text { Total } \\
\text { expenditures }\end{array}$} \\
\hline & \multirow{2}{*}{$\begin{array}{l}\text { Deposits into } \\
\text { experimental } \\
\text { account }^{1}\end{array}$} & \multirow{2}{*}{$\begin{array}{c}\text { Total } \\
\text { Deposits }\end{array}$} & \multicolumn{2}{|c|}{ Main business } & \multicolumn{2}{|c|}{ Farming } & \multirow[b]{2}{*}{ Profits } & \multirow[b]{2}{*}{ Revenues } & \\
\hline & & & $\begin{array}{c}=1 \text { if } \\
\text { worked }\end{array}$ & Hours & $\begin{array}{c}=1 \text { if } \\
\text { farmed }\end{array}$ & Hours & & & \\
\hline \multirow[t]{2}{*}{ Received a random payment last period } & - & -0.72 & 0.02 & 0.01 & 0.01 & 0.06 & 0.60 & $3.56^{* *}$ & -0.65 \\
\hline & - & $(0.74)$ & $(0.01)$ & $(0.15)$ & $(0.01)$ & $(0.08)$ & $(0.50)$ & (1.64) & $(0.64)$ \\
\hline \multirow[t]{2}{*}{1 Box * Received a random payment } & $-1.47 * *$ & 0.50 & 0.02 & $0.46^{*}$ & -0.03 & -0.11 & 1.10 & 3.28 & -0.01 \\
\hline & $(0.75)$ & $(1.50)$ & $(0.02)$ & $(0.24)$ & $(0.02)$ & $(0.10)$ & $(0.71)$ & $(2.49)$ & $(1.43)$ \\
\hline \multirow[t]{2}{*}{ Multiple Box * Received a random payment } & 0.18 & 2.15 & 0.05 & $0.54 *$ & -0.01 & 0.01 & 0.63 & 3.70 & 0.55 \\
\hline & $(0.68)$ & (1.39) & $(0.03)$ & $(0.29)$ & $(0.02)$ & $(0.12)$ & $(1.07)$ & $(3.70)$ & $(1.12)$ \\
\hline \multirow[t]{2}{*}{$1 \mathrm{MM} *$ Received a random payment } & 0.35 & 2.27 & -0.02 & $-0.48^{*}$ & 0.03 & $0.38 *$ & 1.00 & $4.70 *$ & -0.31 \\
\hline & $(0.40)$ & $(1.54)$ & $(0.03)$ & $(0.27)$ & $(0.03)$ & $(0.21)$ & $(0.68)$ & $(2.61)$ & $(1.13)$ \\
\hline \multirow[t]{2}{*}{ Multiple MM * Received a random payment } & -0.46 & 3.40 & $0.08 * *$ & $0.93 * *$ & 0.02 & 0.21 & 0.53 & 2.41 & -0.49 \\
\hline & $(0.54)$ & $(2.85)$ & $(0.03)$ & $(0.46)$ & $(0.02)$ & $(0.14)$ & $(0.87)$ & $(3.33)$ & $(1.33)$ \\
\hline \multicolumn{10}{|l|}{ p-values } \\
\hline Joint significance all account interactions & 0.18 & 0.22 & $0.039 * *$ & $0.011 * *$ & 0.22 & 0.20 & 0.42 & 0.25 & 0.97 \\
\hline Observations & 3808 & 3808 & 30460 & 30459 & 3806 & 3806 & 3854 & 3862 & 3808 \\
\hline Number of businesses & 384 & 384 & 392 & 392 & 383 & 383 & 385 & 385 & 384 \\
\hline Control Mean & 0.00 & 14.69 & 0.81 & 8.14 & 0.03 & 0.12 & 21.87 & 75.77 & 25.94 \\
\hline Control SD & 0.00 & 17.42 & 0.40 & 4.71 & 0.18 & 0.78 & 16.66 & 80.75 & 18.81 \\
\hline
\end{tabular}

Notes: Regressions include individual fixed effects. Deposits (columns 1-2), business earnings (columns 7-8) and total expenditures (column 9) are measured over the past week and converted to daily values. Labor supply in the main business (columns 3-4) is measured at the daily level in the past 7 days prior to the survey date. Farming is presented over a week since this is how it was measured in the surveys and it is the only way to present the extensive margin. All regressions control for individual fixed effects, strata, a measure of the dependent variable during the intake survey (where applicable), date fixed effects, assignment to high frequency group and are probability weighted (see in the text for details).

Standard errors clustered at individual level in parentheses. ${ }^{*}, * *$, and $* * *$ indicate significance at $10 \%, 5 \%$, and $1 \%$ respectively.

${ }^{1}$ Experimental account is the mobile money or box, depending on the treatment group. 